\title{
Friend Lens: Novel Web Content Sharing through Strategic Manipulation of Cached HTML
}

\author{
BY John W.
}

Gibbons

Submitted to the graduate degree program in Computer Engineering and the Graduate Faculty of the University of Kansas School of Engineering in partial fulfillment of the requirements for the degree of Master of Science.

Chairperson: Dr. Arvin Agah

Committee members

Dr. James Miller

Dr. Brian Potetz

Date defended: 
The Thesis Committee for John Gibbons certifies that this is the approved version of the following thesis:

Friend Lens: Novel Web Content Sharing through Strategic Manipulation of Cached HTML

Committee:

Chairperson: Dr. Arvin Agah

Dr. James Miller

Dr. Brian Potetz

Date approved: 


\section{Acknowledgements}

I would like to thank Dr. Arvin Agah. This thesis would not have been possible without his guidance, advice, example, and seemingly endless patience during this process. Because of Dr. Agah I can now look back on the last few years and know that I have greatly improved as a student, teacher, and researcher. 


\begin{abstract}
Content sharing has become a part our everyday lives. There are many forms for content sharing. Current methods of content sharing include blogs, Facebook, and Clip Marks. Content can be authored by users or taken from external sites. Blogs and Facebook allow for the quick and easy authoring of new content but do not support the complete extraction of external content. Clip Marks is a Firefox plug-in that does not allow for user to author original content, only allowing for the extraction of external content. This thesis details the construction and novel features of Friend Lens. Friend Lens is a web application that allows for user to author original content and for the extraction of complete copies of external sites using PHP. Friend Lens also implemented a novel means of collaboration with the ability to highlight posts and to make composite of multiple highlights. When viewing a composite of multiple highlights, a color scale is used to emphasize the content that received the most highlights. To evaluate Friend Lens, human subject evaluated Facebooks, Clip Marks, and Friend Lens in three general categories: community, posting content, and practicality of use. Friend Lens scored poorly in the community category since it does not have many features that allow for social networking. In the posting content category, Friend Lens ranked highest in the areas of extracting external content, showing other users the web sites one enjoys/visits most. In the practicality of use category, Friend Lens ranked highest is the areas of usability for peers to review one's work, and usability for one's profession.
\end{abstract}

Keywords: web based content sharing, blog, cached HTML, web collaboration 


\section{Table of Contents}

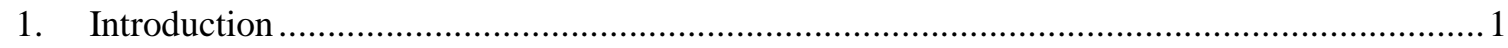

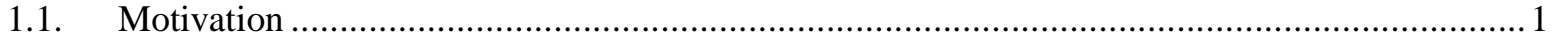

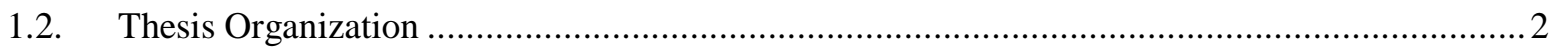

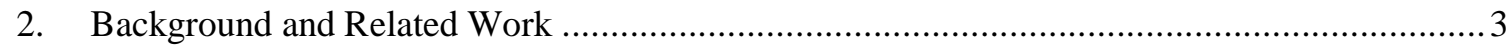

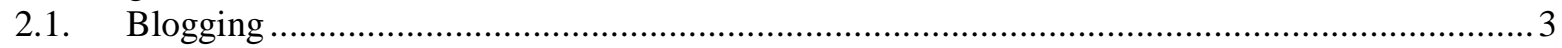

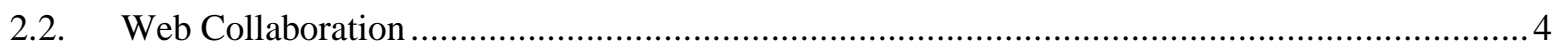

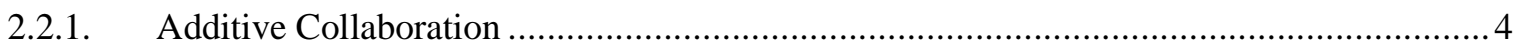

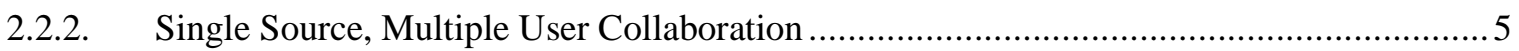

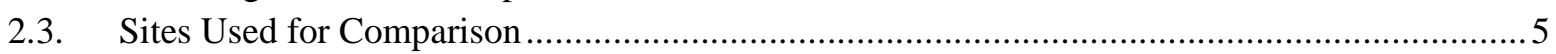

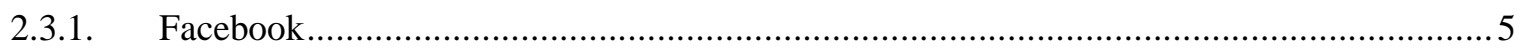

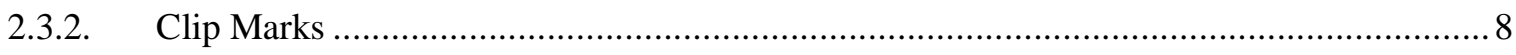

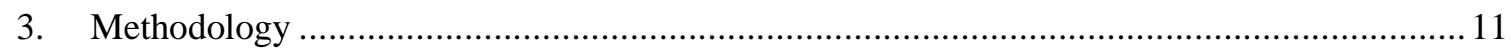

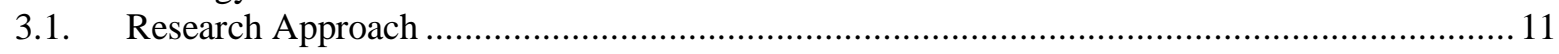

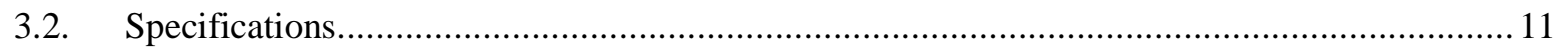

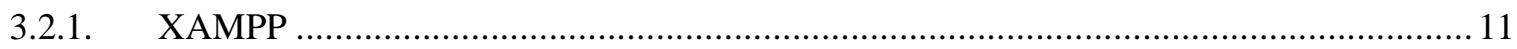

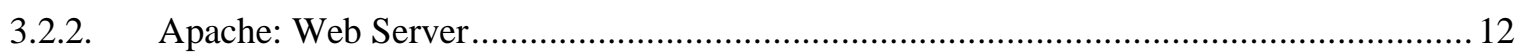

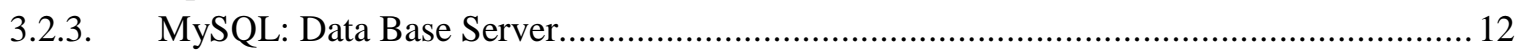

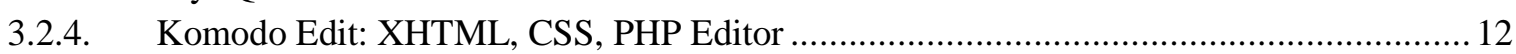

3.2.5. MySQL Query Browser: MySQL query browsing/validation ........................................ 13

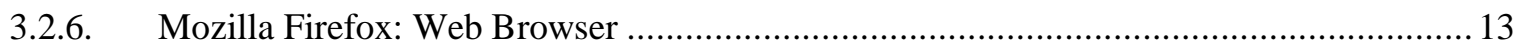

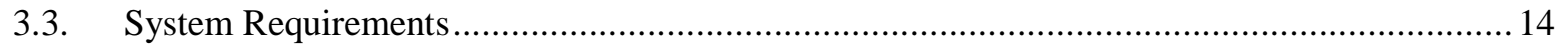

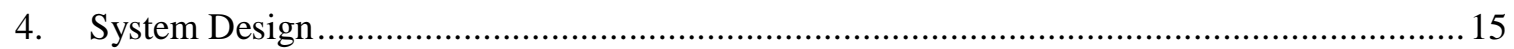

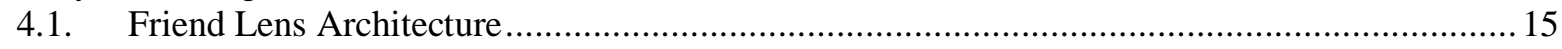

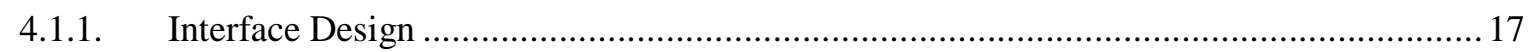

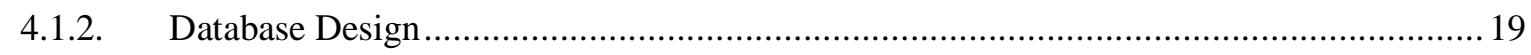

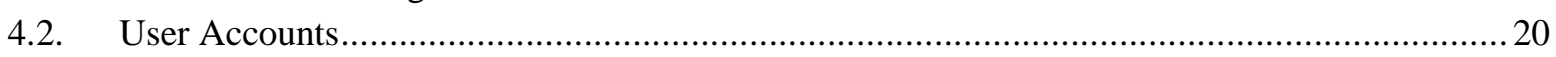

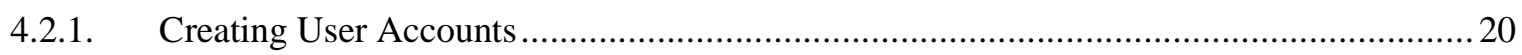

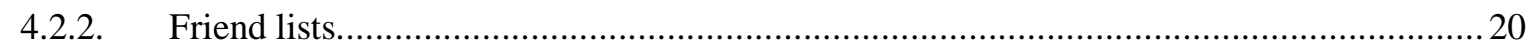

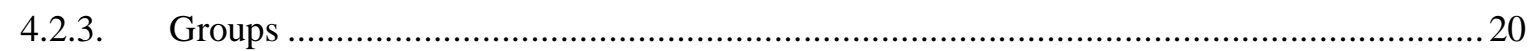

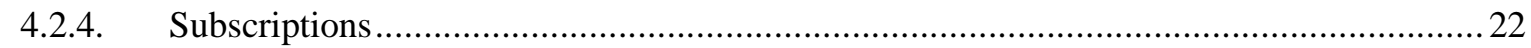

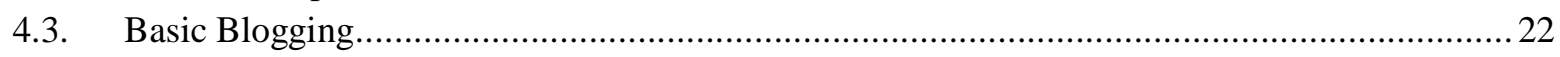

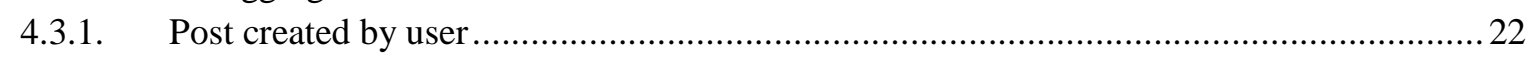

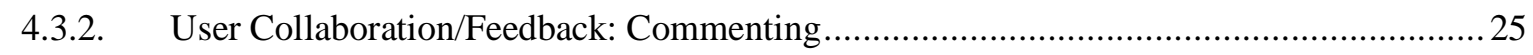

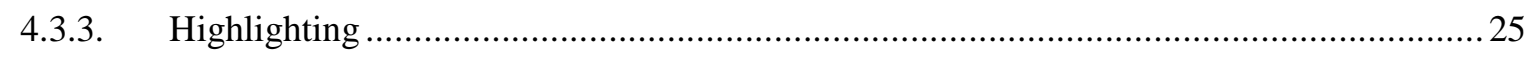

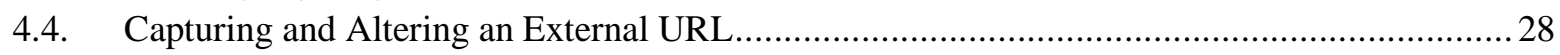

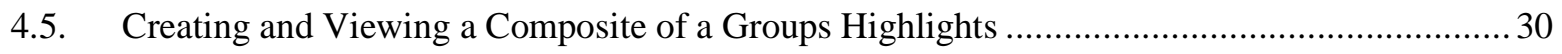

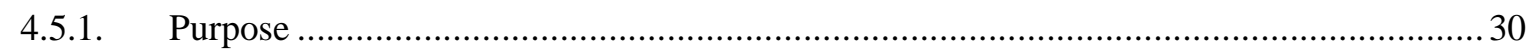

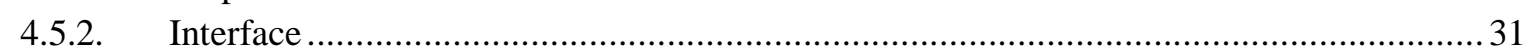

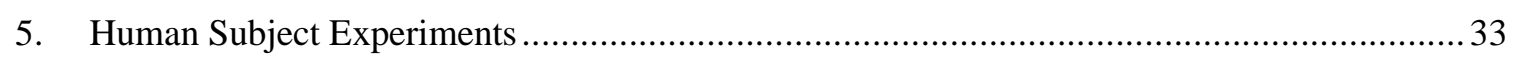

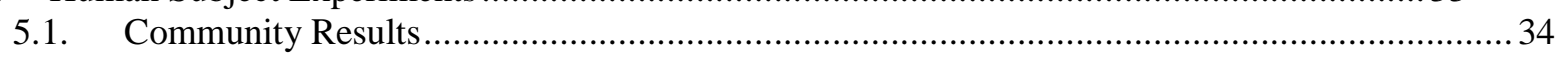

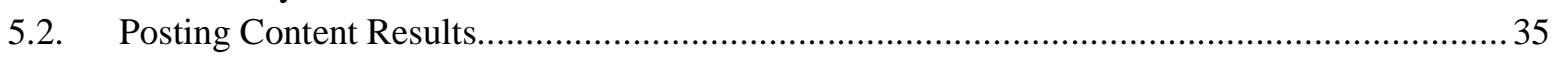

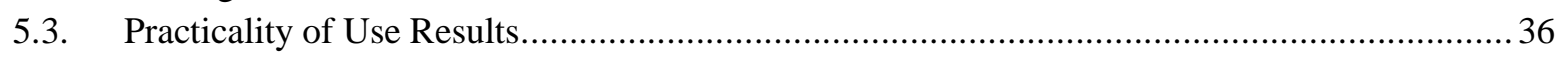




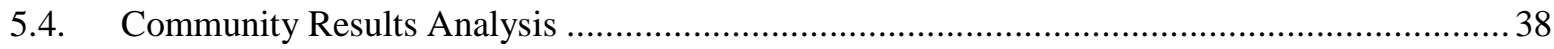

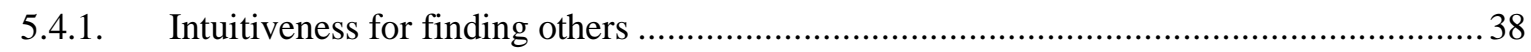

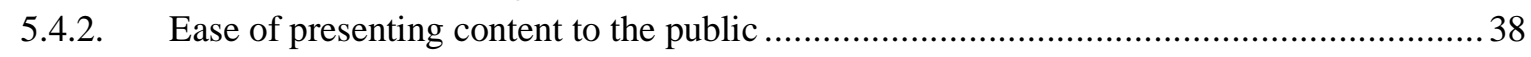

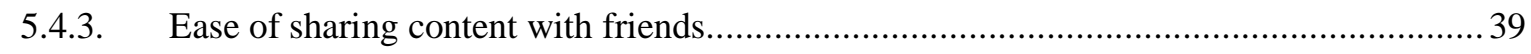

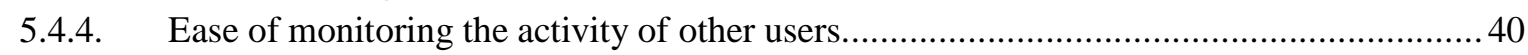

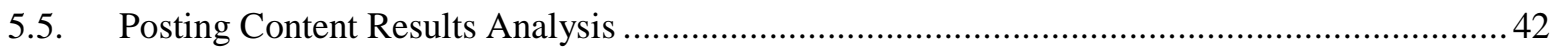

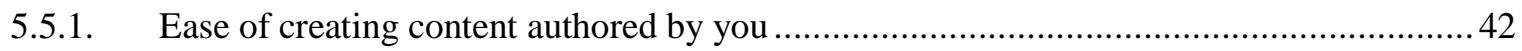

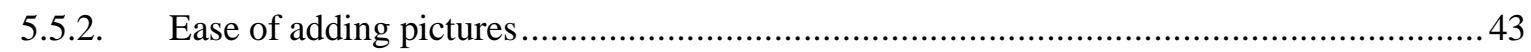

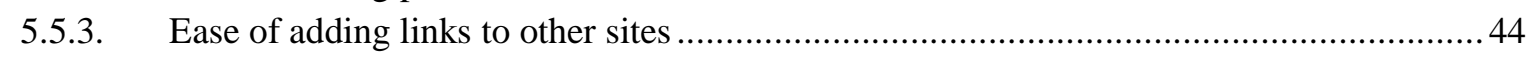

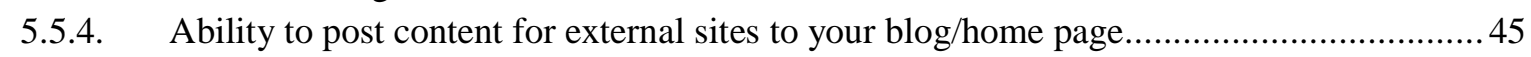

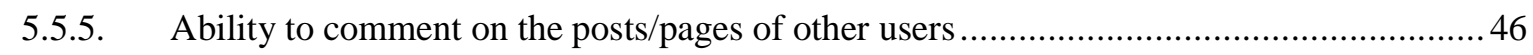

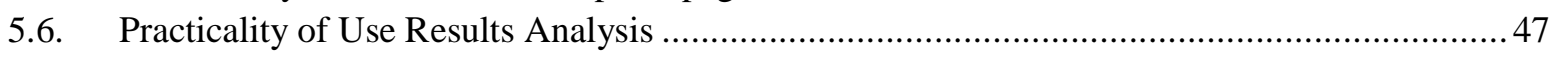

5.6.1. The ability of allowing others to edit/comment on material you authored .......................... 47

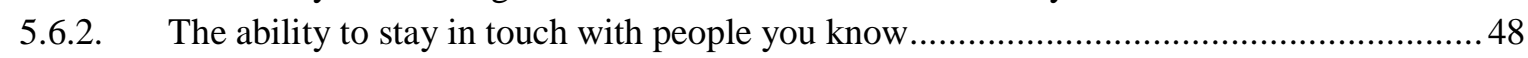

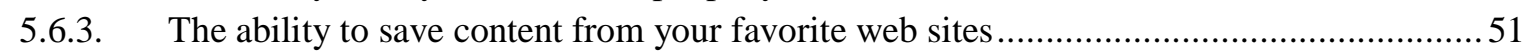

5.6.4. The ability to allow others to see the web sites you visit/enjoy most................................52

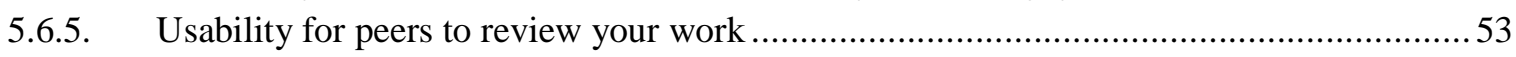

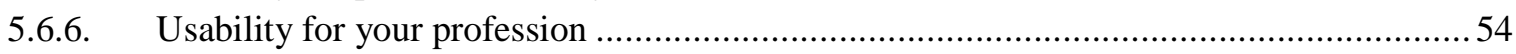

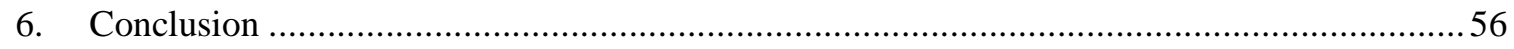

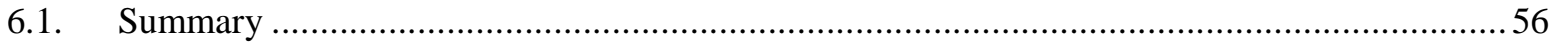

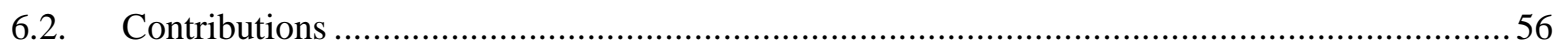

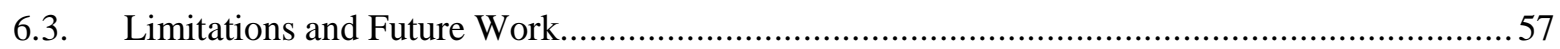

6.3.1. Expanding the functionality of highlighting various object in a web page........................58

6.3.2. Extract data from user activity in order to enhance their experience ..................................58

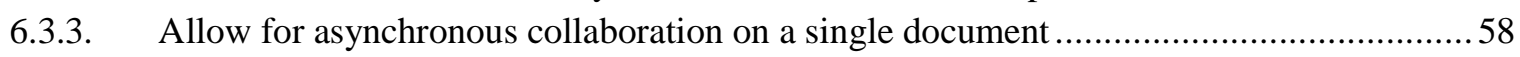

6.3.4. Web browsing from within Friend Lens for external page posting ................................. 59

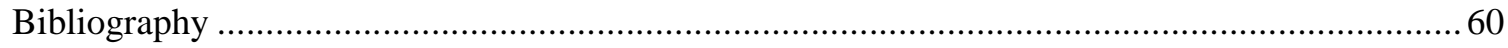

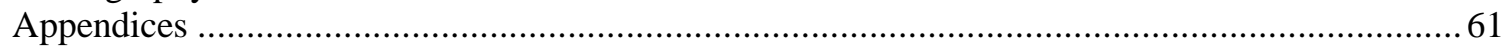

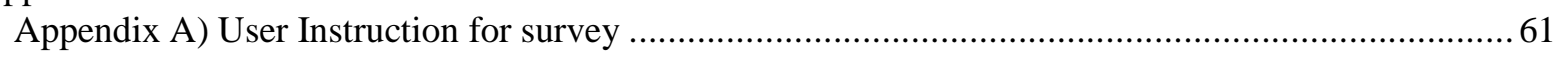

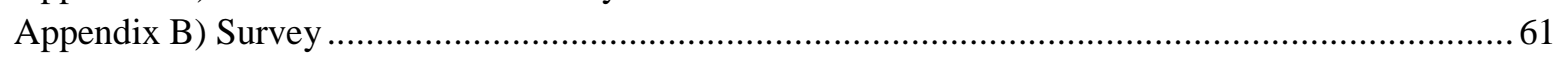

Appendix C) Responses made in the comment section by users ................................................... 71 


\section{List of Figures}

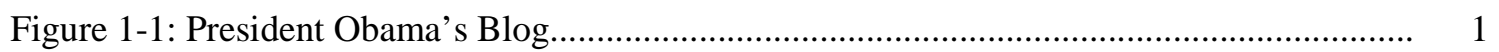

Figure 2-1: Blogs, Old and New.......................................................................................... 4

Figure 2-2: Choosing a URL (link) to post with Facebook........................................................... 7

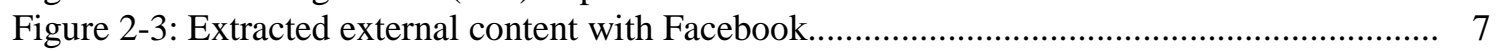

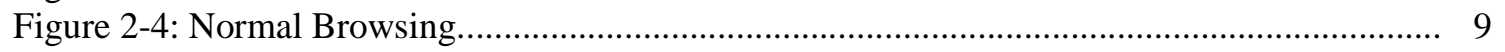

Figure 2-5: Selecting External Content from CNN.com......................................................... 9

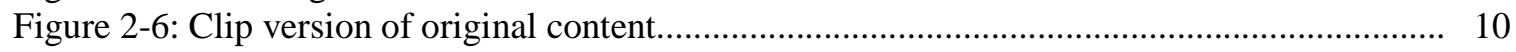

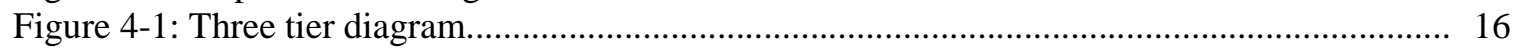

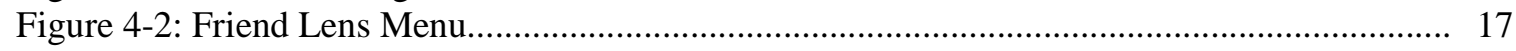

Figure 4-3: Friend Lens Menu Roles................................................................................. 17

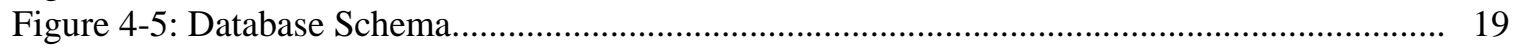

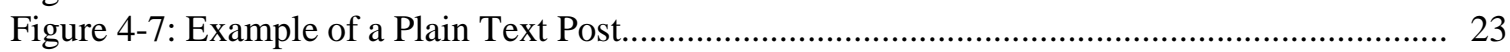

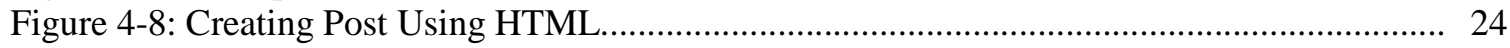

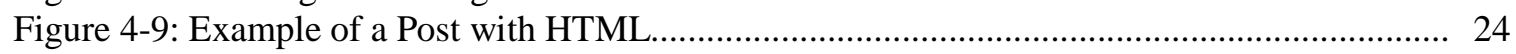

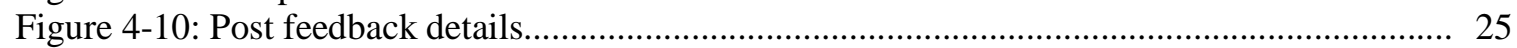

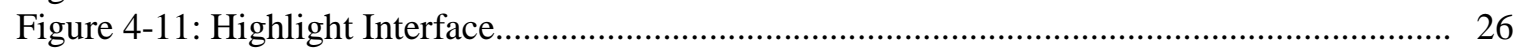

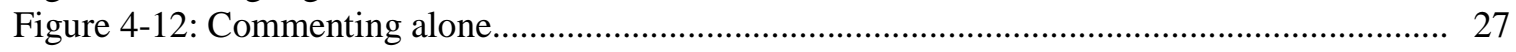

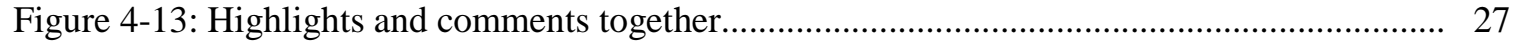

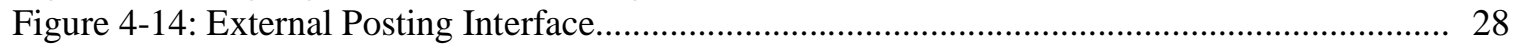

Figure 4-15: External Page Extraction................................................................................. 29

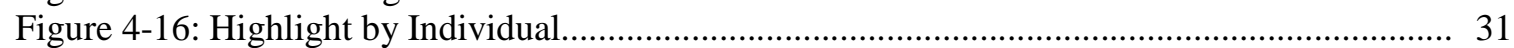

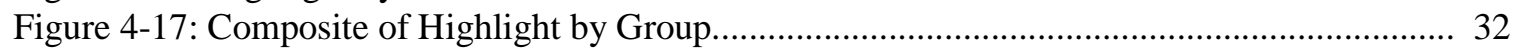

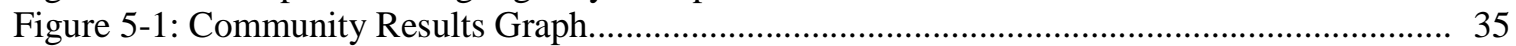

Figure 5-2: Posting Content Results Graph........................................................................... 36

Figure 5-3: Practicality of Use Result Graph.......................................................................... 37

Figure 5-4: Intuitiveness of finding other users..................................................................... 38

Figure 5-5: Ease of presenting content to the public................................................................. 39

Figure 5-6: Ease of sharing content with friends (users of the same site)..................................... 40

Figure 5-7: Ease of monitoring the activity of other users............................................................ 41

Figure 5-8: Ease of creating new content authored by you..................................................... 42

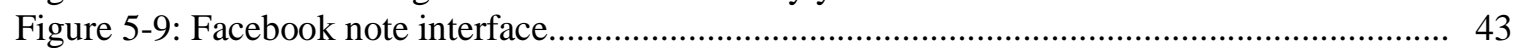

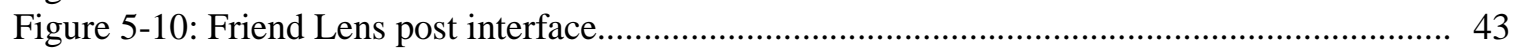

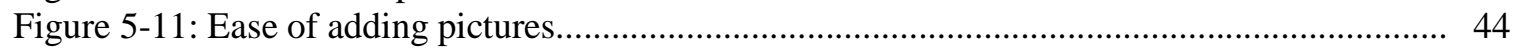

Figure 5-12: Ease of adding links to other sites....................................................................... 45

Figure 5-13: Ability to post content from external sites to your blog/home page............................. 46

Figure 5-14: Ability to comment on the posts/pages of other users........................................... 47

Figure 5-15: The ability of allowing other to edit/comment on material you authored................... 48

Figure 5-16: The ability to stay in touch with people you know................................................... 49

Figure 5-17: Ability to save content from your favorite sites........................................................ 51

Figure 5-18: The ability to allow others to see the web sites you visit/enjoy most.......................... 52

Figure 5-19: Usability for peers to review your work.................................................................. 53

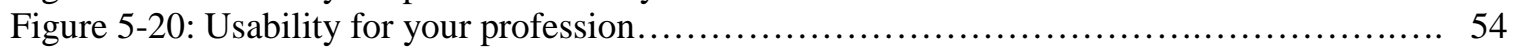




\section{List of Tables}

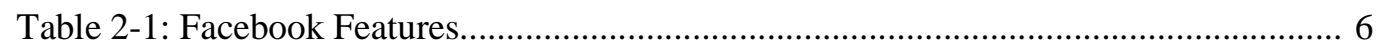

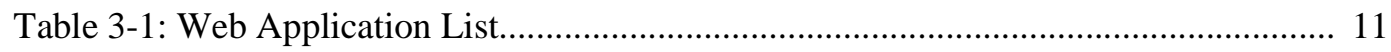

Table 3-2: Web Browser Usage for 2009...................................................................... 14

Table 3-3: Web Browser Usage for 2008.................................................................... 14

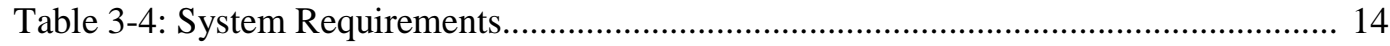

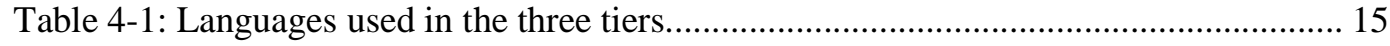

Table 4-2: Highlight Colors............................................................................................ 31

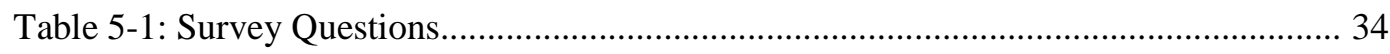

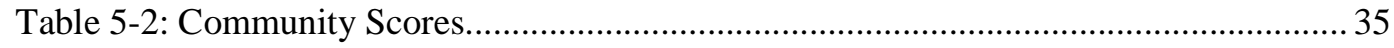

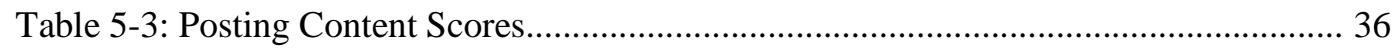

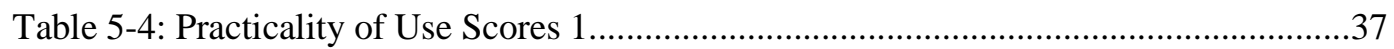

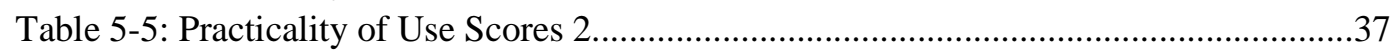

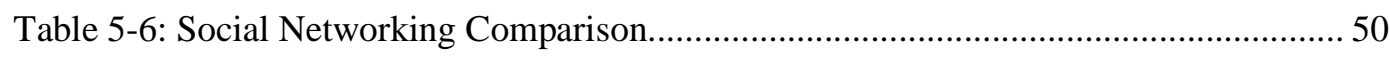

Table 5-7: Usability for Profession Scores........................................... 54 


\section{Introduction}

\subsection{Motivation}

There are over 2.35 billion results generated by a search on Google for the word "blog" [4]. The ability to create and share content has become a worldwide activity. From personal journals to professional sites, every day more and more people are using web site to share content and to read the content created by others. The blog has become a part of our everyday life; even the President of the United States has a blog [14], as shown in Figure 1-1.

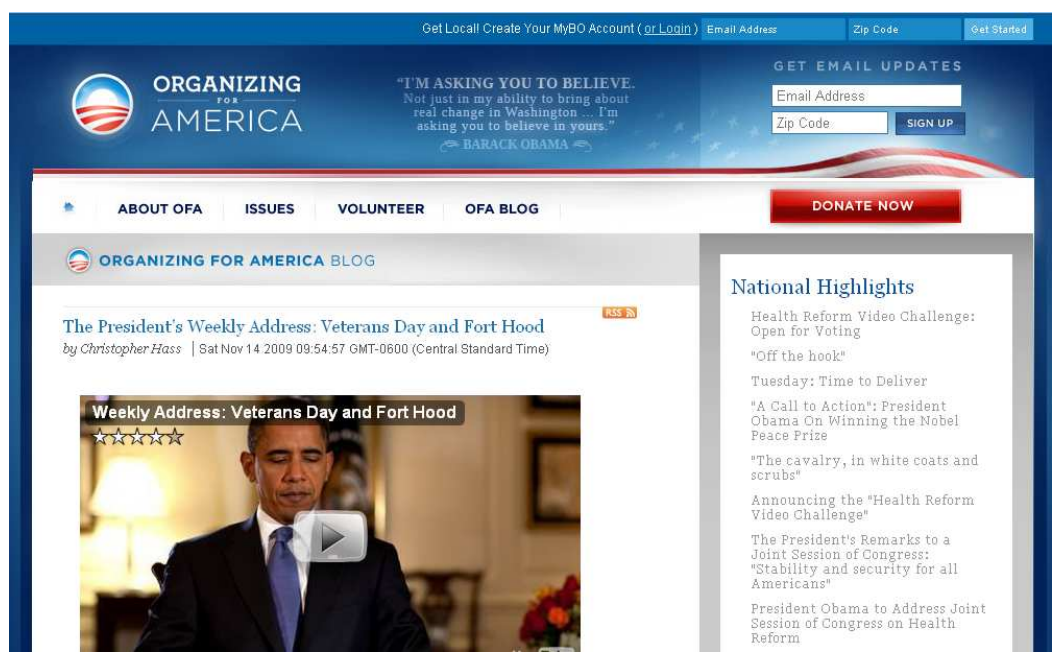

Figure 1-1: President Obama's Blog [14].

However, as more and more people begin sharing content on the internet, the more and more people do so in the same way.

Since the inception of the blog, very little has changed its features and purpose, but much has changed in browser capability, user needs, and the number of people sharing content. Friend Lens was designed and implemented to explore news ways for users to share content and to 
allow users more interaction with posted content. Current blogging applications lack the ability to:

- Bring focus to the desired parts of posted content

- Import entire web pages

- Compile user feedback

\subsection{Thesis Organization}

This thesis is organized as follows: chapter 2 provides the background and related work. Chapter 3 discusses the methodology and the tools needed by Friend Lens. Chapter 4 presents the Friend Lens design, including system architecture and interface design. Chapter 5 will then discuss the user survey used to evaluate Friend Lens. Finally, chapter 6 summarizes the thesis and presents future work. 


\section{Background and Related Work}

This chapter provides a description of current content sharing technology including blogs, Facebook, and Clip Marks. The basics of Web collaboration are also discussed in this chapter.

\subsection{Blogging}

A blog is a type of site, usually run by an individual, which is updated regularly with content sharing a common theme. The theme for the added content could be a specific topic (sports, politics, etc.), specific kind of media (images, videos, etc.), or just the personal entries of the author(s) of the blog. The word blog comes from a play on the words "web log." In 1999, Peter Merholz, took the words "web log" and came up with the phrase "we blog" [21]. Since then, the term blog is used worldwide. A blog's most basic element is the post. A post is similar to an article in magazine or newspaper. A post receives a title and contains information about a given topic. The content of a post can include text, images, links, or embedded videos.

The structure of a blog is setup to display posts in chronological order. The most recent post is displayed first. Most blogs offer some automated features to help users with organization:

- Automatic archives

- Labels for posts to aid in organization and for search engine purposes

- Built in searching of all post

Aside from some of the automated features that current blogging sites offer, the fundamental elements that make up a blog have not changed for over a decade. Figure 2-1 illustrates a side by side 
comparison a Web log post by Scripting News from 1997 and one of Google's blog post (hosted by Blogger) from 2009 [21,2].

\begin{tabular}{|c|c|c|}
\hline Web log from 1997 & Blog from 2009 & \\
\hline 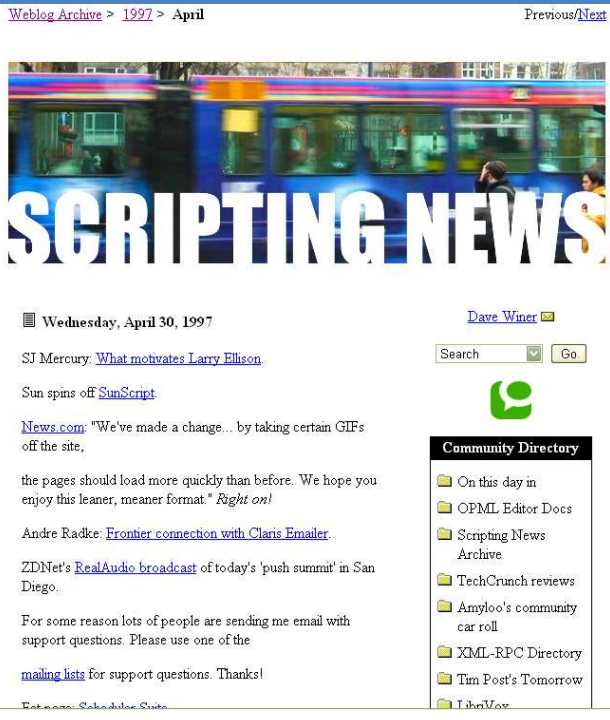 & 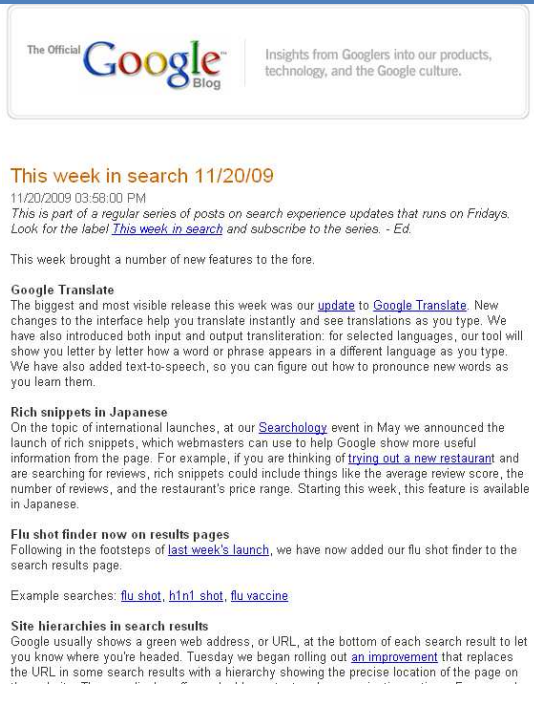 & 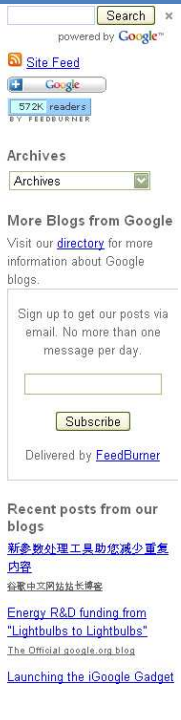 \\
\hline
\end{tabular}

Figure 2-1: Blogs, Old and New [21,2].

\subsection{Web Collaboration}

Web collaboration has many different forms, but they all share a central idea: have several contributors working on centralized data. There are many examples of Web collaboration already available.

\subsubsection{Additive Collaboration}

One of the oldest and most basic is the forum. In a forum, multiple users all contribute to a single thread. Each contribution is a piece of feed back to the original content. All contributions are additive, meaning that there is a single constantly growing collection of contributions. This 
paradigm is referred to as "commenting" in many other web applications. Blogs, Facebook, Clip Marks, Friend Lens and many other allow for users to leave comments on posted content [16].

\subsubsection{Single Source, Multiple User Collaboration}

Google Documents allows multiple users to edit a single document. All revisions are stored separately. The final result is a single document containing a compilation of all of the user's input. There are other web applications, such as online code repositories, that allow for similar behavior. Blogs, Clip Marks, and Facebook do not allow for a single source multiple user collaboration. In chapter 3, it will be discussed how Friend Lens incorporates multiple user collaboration into the blogging experience [10].

\subsection{Sites Used for Comparison}

\subsubsection{Facebook}

Facebook is a social networking site. Social networking web sites allow users to create profiles containing personal information and to share information with other users on the site. Currently, Facebook is the most popular, with over 250 million users, but there are literally hundreds of social networking sites, each with their own blend of features. Facebook, although is meant for social networking, it also incorporates many content sharing features that are found in most blogs. Table 2-1 includes a list of features Facebook offers by category. 


\begin{tabular}{|ll|}
\multicolumn{1}{|c}{ Social Networking } & \multicolumn{1}{c|}{ Content Sharing } \\
\hline User profiles with personal information & $\begin{array}{l}\text { User Created Posts (referred to as "Notes" on } \\
\text { Facebook, but referred to as "posts" from this } \\
\text { point on) }\end{array}$ \\
\hline $\begin{array}{l}\text { Friends, a mechanism to give users } \\
\text { privacy control. Which two users are } \\
\text { "friends" both users are notified and now } \\
\text { receive automatic updates regarding their } \\
\text { friends activity }\end{array}$ & $\begin{array}{l}\text { Link sharing, included a caption (usually the title } \\
\text { of the site) and a thumb nail of an image from the } \\
\text { page }\end{array}$ \\
\hline $\begin{array}{l}\text { Privacy settings to restricts public user } \\
\text { and friend access to various personal } \\
\text { information and shared content }\end{array}$ & $\begin{array}{l}\text { Image uploading and automatic gallery } \\
\text { generation }\end{array}$ \\
\hline $\begin{array}{l}\text { User messaging system, allowing for user } \\
\text { to user communication }\end{array}$ & Video embedding and uploading \\
\hline $\begin{array}{l}\text { Event creation system, featuring invitation } \\
\text { lists and automatic notification of } \\
\text { upcoming event }\end{array}$ & $\begin{array}{l}\text { Feeds, the automatic update to a user's home } \\
\text { page with recent friend activity including thumb } \\
\text { nailed version of uploaded/created content }\end{array}$ \\
\hline $\begin{array}{l}\text { Status, small posts that are intended to } \\
\text { share the user's current activity with all } \\
\text { friends }\end{array}$ & \\
\hline $\begin{array}{l}\text { Groups, an entity created by users but } \\
\text { separate than a user that revolves around } \\
\text { some user interests. Multiple users can } \\
\text { join a group each group can have its own } \\
\text { content }\end{array}$ & \\
\hline
\end{tabular}

Table 2-1: Facebook Features.

Figure 2-2 and Figure 2-3 are the interfaces for original content and posting of external content. In Figure 2-2, a user can copy and paste a valid URL into the text field. Figure 2-3 shows the content that is extracted from the external site. The extracted content is limited to a title, caption, link to the source, and an option image. 


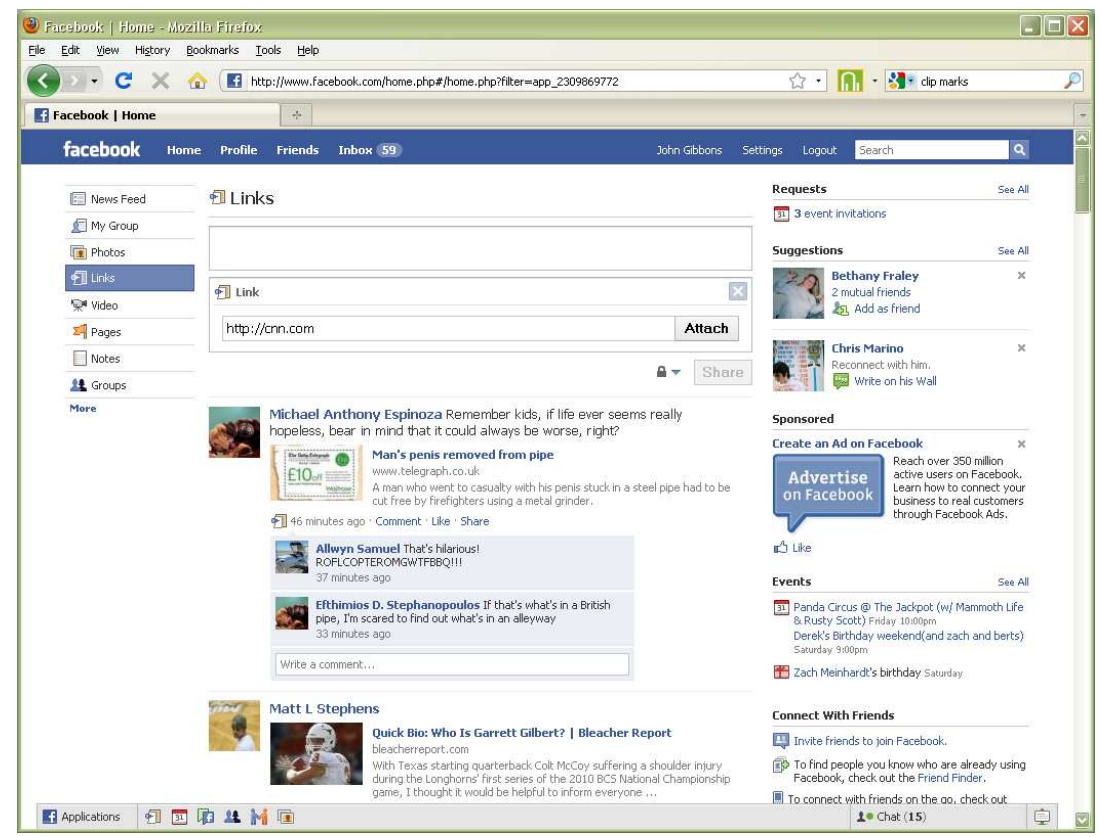

Figure 2-2: Choosing a URL (link) to post with Facebook.

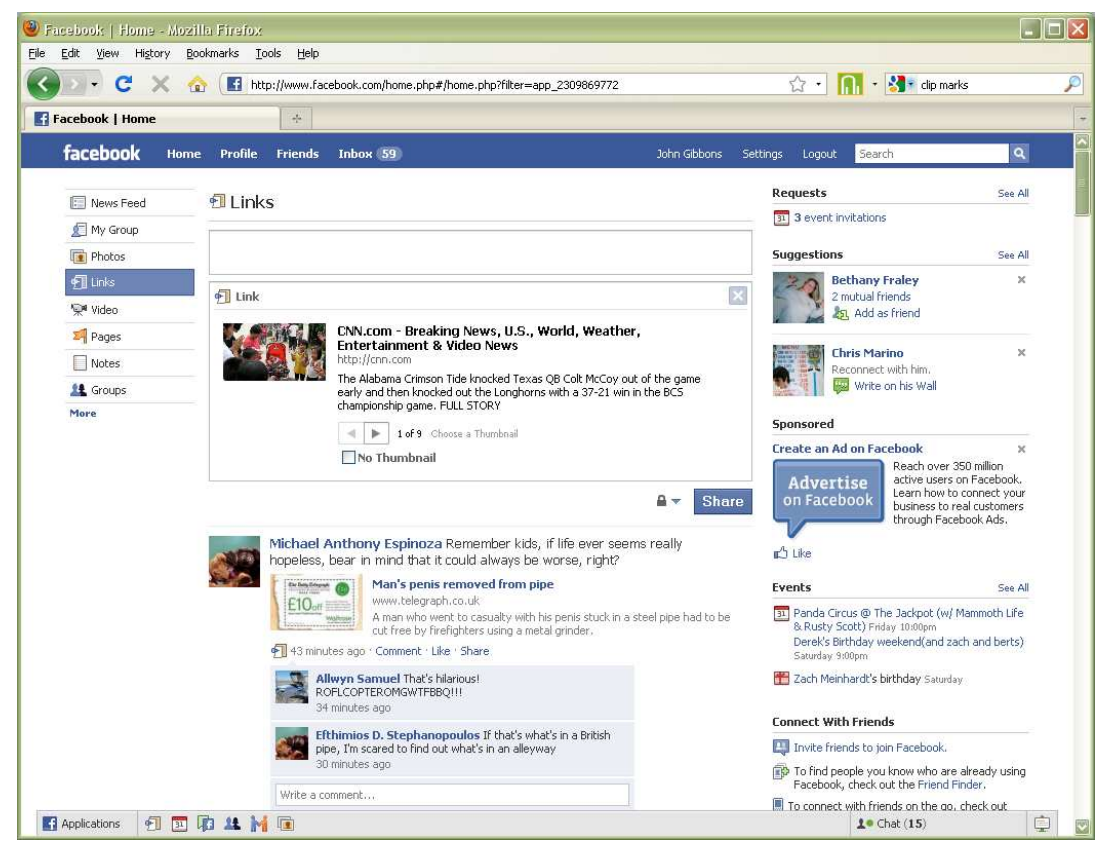

Figure 2-3: Extracted external content with Facebook. 
Facebook also has many third party "applications" which are extensions to the core site. They are created by third parties and have a wide spectrum of functions, from organizational utilities to games designed to utilize Facebook's framework. Since these applications are not created by or directly supported by Facebook they were not used during the research or experimentation phases of this thesis [9].

\subsubsection{Clip Marks}

Clip Marks is designed for content sharing. Contrary to Facebook, Clip Marks is not designed for social networking. Clip Marks focuses on extracting content from external sites and posting it as a "clip" on ClipMarks.com. To do so, users are required to install a plug-in for either Firefox or Internet Explorer. Users cannot author original posts; without the plug-in users have no means of posting content. A brief explanation of extracting external content using the Clip Marks plug-in is described [7].

First the user browses to a web site as normal. Figure 2-4 shows that the user has browsed to CNN.com. 


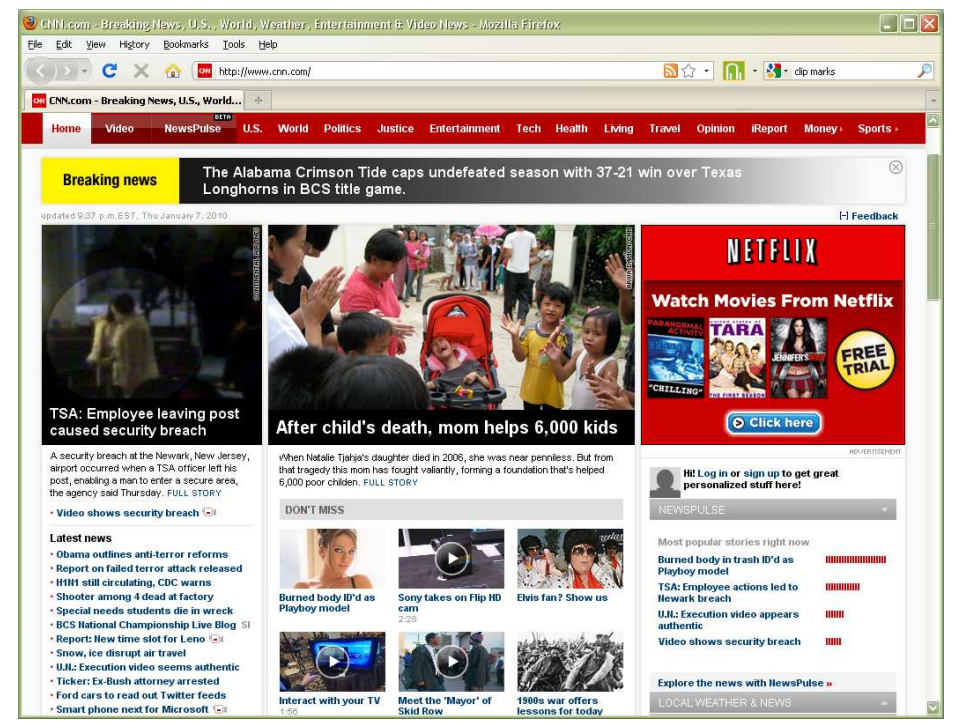

Figure 2-4: Normal Browsing.

When the user finds text, image, or a video to extract the user activates the plug-in and highlights the desired material, as shown in Figure 2-5.

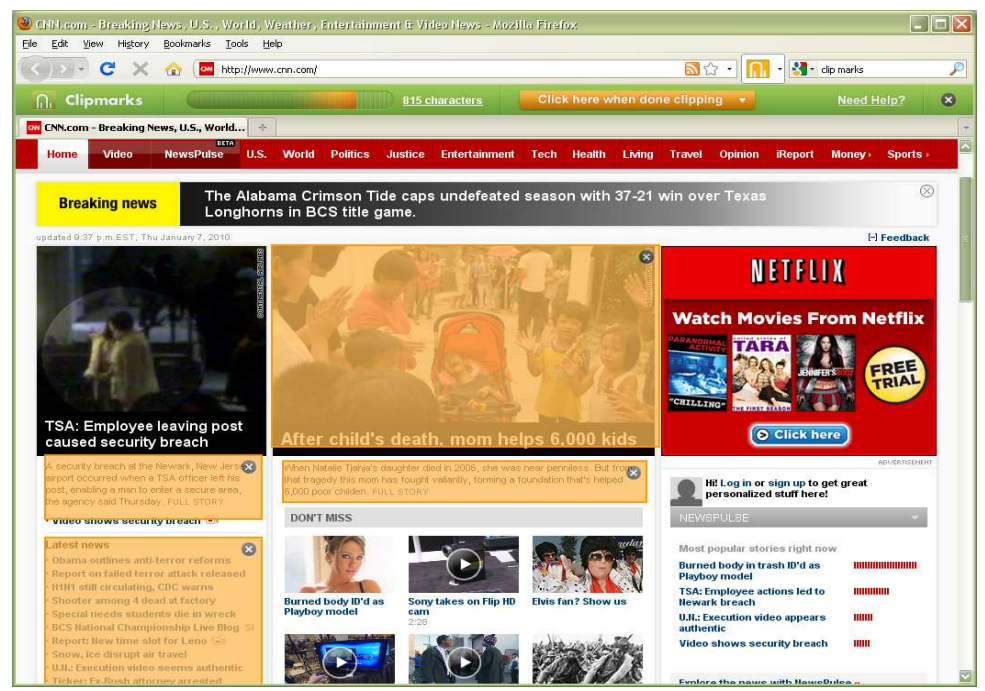

Figure 2-5: Selecting External Content from CNN.com.

After selecting the desired material the user can create a clip of the original. The clip does not preserve any styling attributes. This clip is then posted to the user's home page at ClipMarks.com where other users can view it and leave comments, as shown in Figure 2-6. 


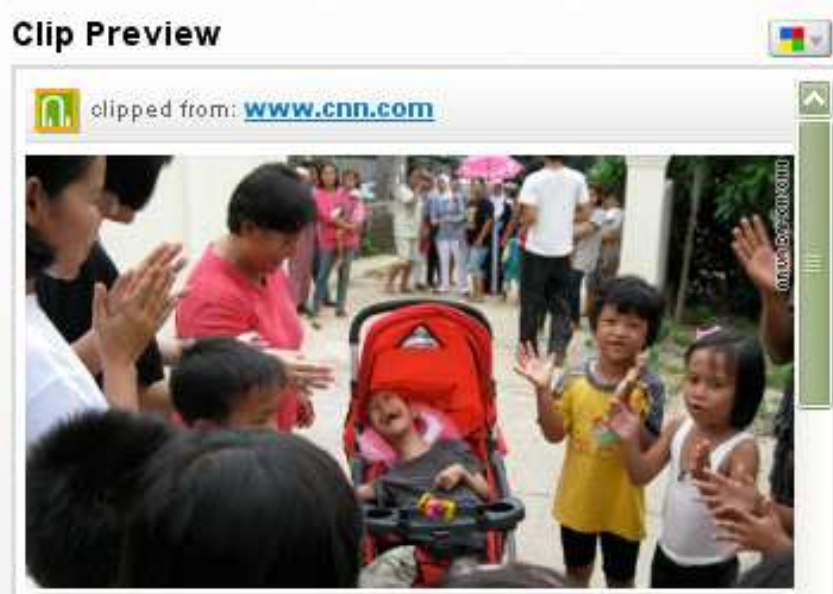

When Natalie Tjahja's daughter died in 2006, she was near penniless. But from that tragedy this mom has

fought valiantly, forming a foundation that's helped 6,000 poor childen. FULL STORY

Figure 2-6: Clip version of original content. 


\section{Methodology}

This chapter provides an overview of the research methodology. This chapter also details the tools and software used for developing Friend Lens as well as listing system requirements for the Friend Lens installation.

\subsection{Research Approach}

Web applications are constantly improving and changing. In order to discover areas for possible improvement, extensive use of current technology was performed. For over two years leading up to the conception of Friend Lens, the sites in Table 3-1 were used and source code examined:

\begin{tabular}{|c|c|}
\hline \multicolumn{1}{|c|}{ Site } & Functionality Examined \\
\hline Facebook & $\begin{array}{c}\text { Social Networking, Web Page Sharing, User } \\
\text { Interface }\end{array}$ \\
\hline Clip Marks & $\begin{array}{c}\text { External Content Posting, Firefox Plug-in } \\
\text { Capabilities }\end{array}$ \\
\hline Google Documents & Web Collaboration \\
\hline Youtube & Subscriptions, Ajax Updating \\
\hline
\end{tabular}

Table 3-1: Web Application List.

\subsection{Specifications}

Applications used to build Friend Lens are described in this section.

\subsubsection{XАMPP}


XAMPP is a free, cross platform, single install which includes all the needed software for creating a web server. It is a very convenient and quick way to install and automatically configure an Apache server and MySQL database. The installation of Apache and MySQL separately was an option, but the automatic configuration of all needed programs was ideal. XAMPP also offered free updates include all installed programs with the their latest versions. The web application used XAMPP full version 1.7.2 featuring PHP version 2.2.12 and MySQL version 5.1.37 (Community Server) with PBXT engine 1.0.08-rc [1].

\subsubsection{Apache: Web Server}

Apache is an HTTP server that listens for incoming requests and processes PHP. Apache allows for any computer that has it configured correctly (which XAMPP does automatically as part of the installation process) to answer incoming requests on the HTTP port, port 80 and allows for any files located in the public folder (htdocs by default) to be viewable by the public. All Friend Lens files were placed in the htdocs folder for online interaction [1].

\subsubsection{MySQL: Data Base Server}

MySQL stands for "My Structured Query Language" and provides simultaneous multi-user access to database(s). All user information, posts, comments, and highlights were stored using MySQL [1].

\subsubsection{Komodo Edit: XHTML, CSS, PHP Editor}

Kodomo Edit is a free, open source IDE for web applications. It supports PHP, (X)HTML, JavaScript, CSS, PHP, and many other languages. It was the only IDE used to complete Friend Lens. Its autocomplete and robust keyword lookup across all supported languages proved to be a 
great, time saving asset in throughout this project. Out of all IDE's available for web applications, the combination of open source and robustness made this the best choice. For Friend Lens version 5.1.4, build 3797 was used.

\subsubsection{MySQL Query Browser: MySQL query browsing/validation}

MySQL Query Browser is a program that can access a MySQL server and browse through all databases in the server. It can also (with the required access, such as root access) query the database. This browser was used as a quick way to browse the data base and validate that PHP was inserting data into the database correctly. It was also used it to test query syntax before implementing the same queries in PHP. For Friend Lens MySQL Query Browser version 1.2.15 was used.

\subsubsection{Mozilla Firefox: Web Browser}

Mozilla Firefox is a free, cross platform, open source web browser. Friend Lens can be viewed by all browsers, and the highlighting functionality is only available in Firefox. Of course a browser is needed to use Friend Lens, but we chose to have full support for Firefox for two main reasons: (1) Firefox has the ability to tracks a user's text selections that were needed for Friend Lens; (2) Firefox is the most popular cross platform web browser. Table 3-2 and Table 3-3 have the usages of all major web browsers from January 2008 (when the Friend Lens concept was first conceived) to October 2009 (when all programming was competed and user surveys began) [22, $20]$. 


\begin{tabular}{|c|c|c|c|c|c|c|c|}
\hline 2009 & IE8 & IE7 & IE6 & Firefox & Chrome & Safari & Opera \\
\hline October & $12.8 \%$ & $14.1 \%$ & $10.6 \%$ & $47.5 \%$ & $8.0 \%$ & $3.8 \%$ & $2.3 \%$ \\
\hline September & $12.2 \%$ & $15.3 \%$ & $12.1 \%$ & $46.6 \%$ & $7.1 \%$ & $3.6 \%$ & $2.2 \%$ \\
\hline August & $10.6 \%$ & $15.1 \%$ & $13.6 \%$ & $47.4 \%$ & $7.0 \%$ & $3.3 \%$ & $2.1 \%$ \\
\hline July & $9.1 \%$ & $15.9 \%$ & $14.4 \%$ & $47.9 \%$ & $6.5 \%$ & $3.3 \%$ & $2.1 \%$ \\
\hline June & $7.1 \%$ & $18.7 \%$ & $14.9 \%$ & $47.3 \%$ & $6.0 \%$ & $3.1 \%$ & $2.1 \%$ \\
\hline May & $5.2 \%$ & $21.3 \%$ & $14.5 \%$ & $47.7 \%$ & $5.5 \%$ & $3.0 \%$ & $2.2 \%$ \\
\hline April & $3.5 \%$ & $23.2 \%$ & $15.4 \%$ & $47.1 \%$ & $4.9 \%$ & $3.0 \%$ & $2.2 \%$ \\
\hline March & $1.4 \%$ & $24.9 \%$ & $17.0 \%$ & $46.5 \%$ & $4.2 \%$ & $3.1 \%$ & $2.3 \%$ \\
\hline February & $0.8 \%$ & $25.4 \%$ & $17.4 \%$ & $46.4 \%$ & $4.0 \%$ & $3.0 \%$ & $2.2 \%$ \\
\hline January & $0.6 \%$ & $25.7 \%$ & $18.5 \%$ & $45.5 \%$ & $3.9 \%$ & $3.0 \%$ & $2.3 \%$ \\
\hline
\end{tabular}

Table 3-2: Web Browser Usage for 2009.

\begin{tabular}{lccccc|c|c|c|}
\hline \multicolumn{1}{c}{20008} & IE7 & IE6 & IE5 & Firefox & Chrome & Safari & Opera \\
\hline December & $26.1 \%$ & $19.6 \%$ & & $44.4 \%$ & $3.6 \%$ & $2.7 \%$ & $2.4 \%$ \\
November & $26.6 \%$ & $20.0 \%$ & & $44.2 \%$ & $3.1 \%$ & $2.7 \%$ & $2.3 \%$ \\
October & $26.9 \%$ & $20.2 \%$ & & $44.0 \%$ & $3.0 \%$ & $2.8 \%$ & $2.2 \%$ \\
September & $26.3 \%$ & $22.3 \%$ & & $42.6 \%$ & $3.1 \%$ & $2.7 \%$ & $2.0 \%$ \\
August & $26.0 \%$ & $24.5 \%$ & & $43.7 \%$ & & $2.6 \%$ & $2.1 \%$ \\
July & $26.4 \%$ & $25.3 \%$ & & $42.6 \%$ & & $2.5 \%$ & $1.9 \%$ \\
June & $27.0 \%$ & $26.5 \%$ & $0.5 \%$ & $41.0 \%$ & & $2.6 \%$ & $1.7 \%$ \\
May & $26.5 \%$ & $27.3 \%$ & $0.7 \%$ & $39.8 \%$ & & $2.4 \%$ & $1.5 \%$ \\
April & $24.9 \%$ & $28.9 \%$ & $1.0 \%$ & $39.1 \%$ & & $2.2 \%$ & $1.4 \%$ \\
March & $23.3 \%$ & $29.5 \%$ & $1.1 \%$ & $37.0 \%$ & & $2.1 \%$ & $1.4 \%$ \\
February & $22.7 \%$ & $30.7 \%$ & $1.3 \%$ & $36.5 \%$ & & $2.0 \%$ & $1.4 \%$ \\
January & $21.2 \%$ & $32.0 \%$ & $1.5 \%$ & $36.4 \%$ & & $1.9 \%$ & $1.4 \%$ \\
\hline
\end{tabular}

Table 3-3: Web Browser Usage for 2008.

\subsection{System Requirements}

The system requirements are listed in Table 3-4.

\begin{tabular}{|c|cc|}
\hline Memory & CPU & Hard Drive Space \\
\hline $256 \mathrm{MB}$ & $233 \mathrm{MHz}$ or greater & $300 \mathrm{MB}$ \\
\hline
\end{tabular}

Table 3-4: System Requirements. 


\section{System Design}

This chapter details the architecture, interface, and features of Friend Lens. The purpose of each of the languages used in Friend Lens is also detailed.

\subsection{Friend Lens Architecture}

Friend Lens has a "Three Tier" architecture: Presentation tier, Logic tier, and Data tier. The presentation tier handles page layout, styling, and user interface. The Logic tier handles events and user interaction to make logical decisions and to handles query creation to send to the data tier. The data tier stores and handles retrieving of data. The tiers are listed in Table 4-1.

\begin{tabular}{llll}
\hline & Presentation Tier & Logic Tier & Data Tier \\
\hline Languages Used & HTML 4.01, CSS & JavaScript, PHP & MySQL \\
\hline
\end{tabular}

Table 4-1: Languages used in the three tiers. 


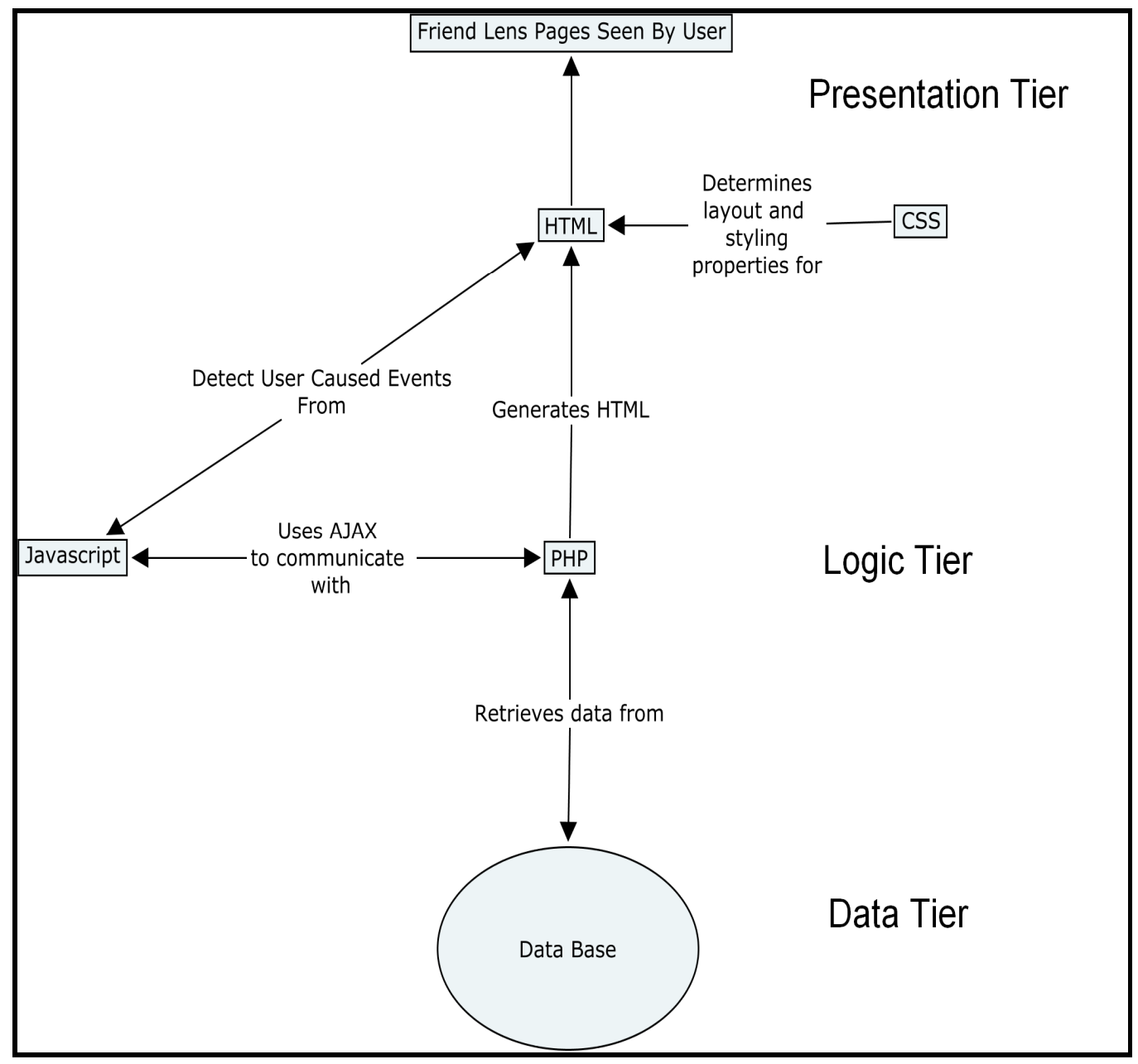

Figure 4-1: Three tier diagram.

Figure 4-1 illustrates where the various languages used in Friend Lens are in the Three Tier Architecture. The presentation tier will be seen by the user and consists of HTML and CSS. JavaScript is embedded inside of HTML code, however it does produce any elements seen by user; JavaScript only manipulates CSS code which then styles the HTML. JavaScript detects and handles user input (mouse click, dragging the mouse, pressing enter, etc.). The logical tier handles user input and HTML generation. PHP is used to generate the correct HTML based on user navigation. JavaScript and PHP can update the content of a page without requiring the browser to refresh using AJAX. AJAX allows for data to be shared between JavaScript and PHP and can be used as a cue for JavaScript to update the content 
of various HTML tags. PHP also retrieves data (user information, post content, etc.) from the data base using the built in MySQL tools.

\subsubsection{Interface Design}

Friend Lens has a single menu that serves as a launch point to all possible activity. Figure 4-2 shows the menu location and submenu labels.

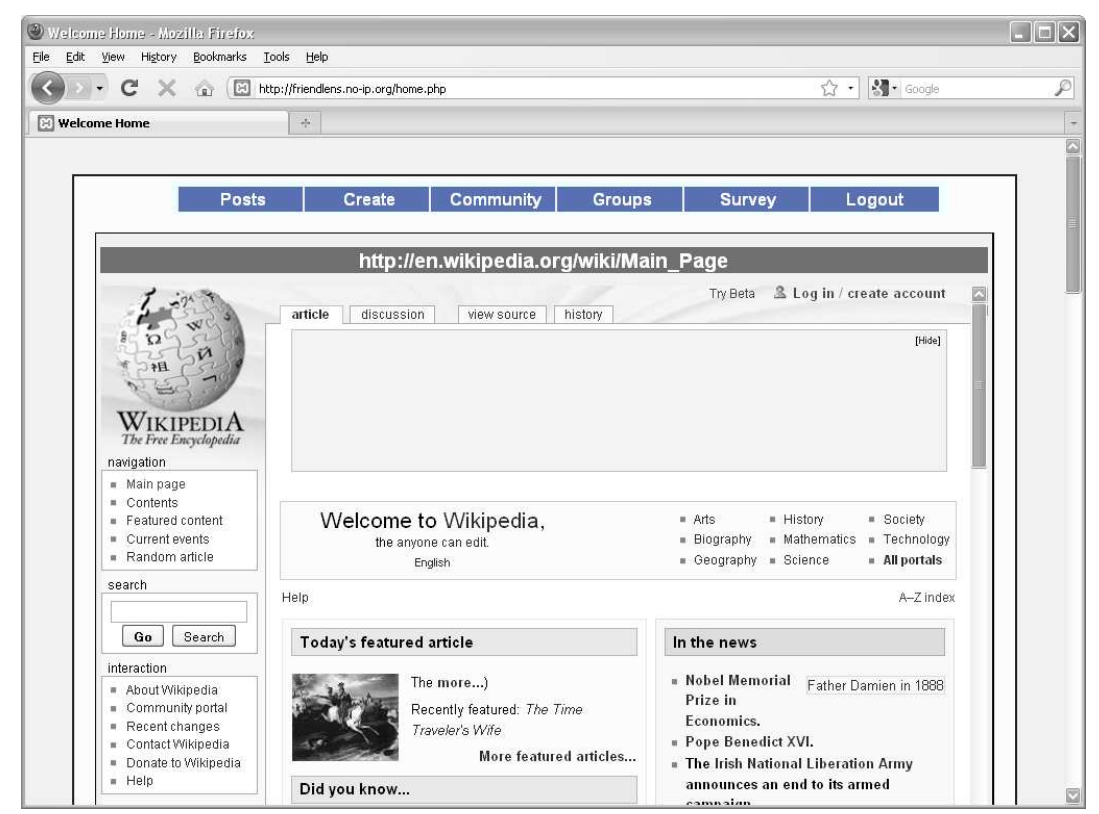

Figure 4-2: Friend Lens Menu.

Figure 4-3 is an illustration of the activities a user can access from the menu. There are six submenus: Posts, Create, Community, Groups, Survey, Logout.
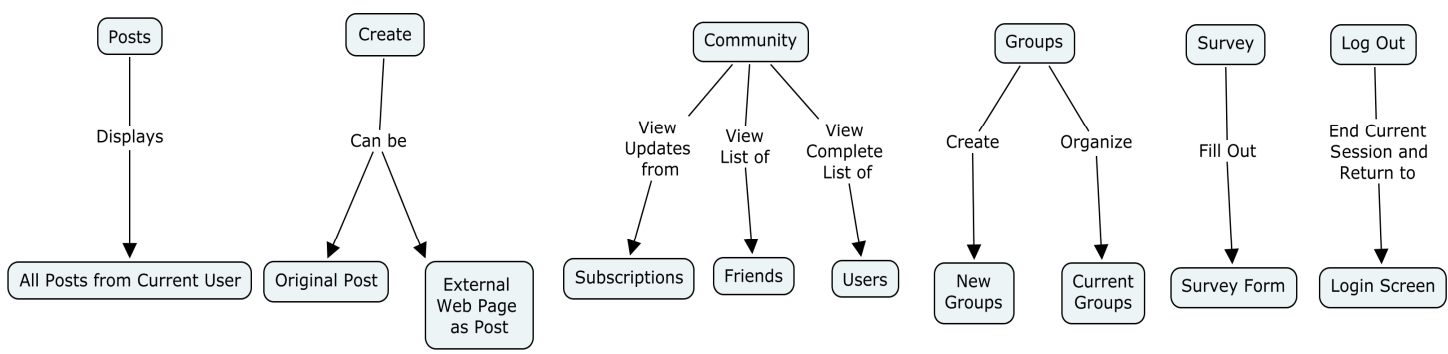

Figure 4-3: Friend Lens Menu Roles. 
This menu was designed to grant quick, intuitive access to all parts of the Friend Lens architecture. The Post submenu displays all posts the user has created. The Create submenu is a launching point for the user to create an original post or to capture an external Web page as a post. Posts are discussed in detail in sections 4.3 and 4.4. The Community submenu allows users to create subscriptions, detailed in section 4.2.4, friends detailed in section 4.2.2, and to see a list of all users, as shown in Figure 4-4. The menu was based off of similar menus found in the applications listed in Table 3-1.

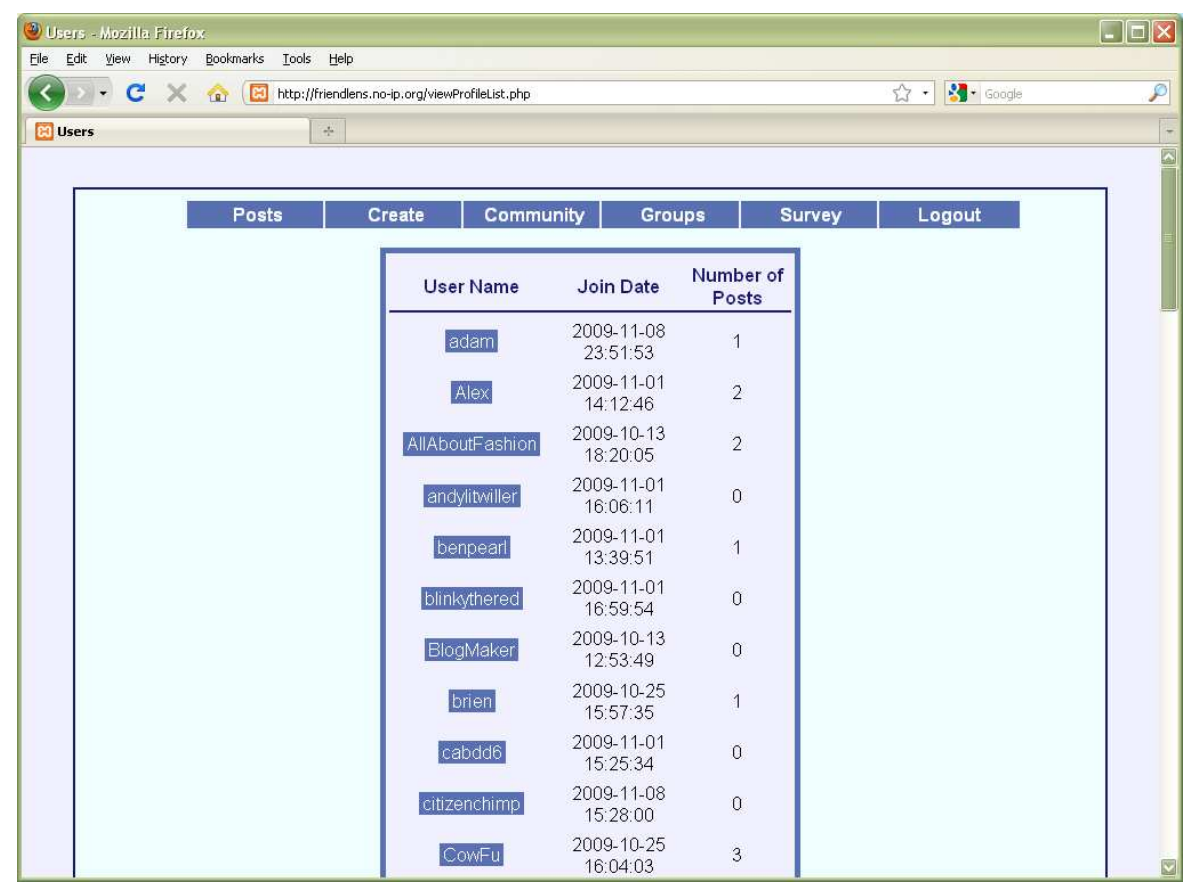

Figure 4-4: User List. 


\subsubsection{Database Design}

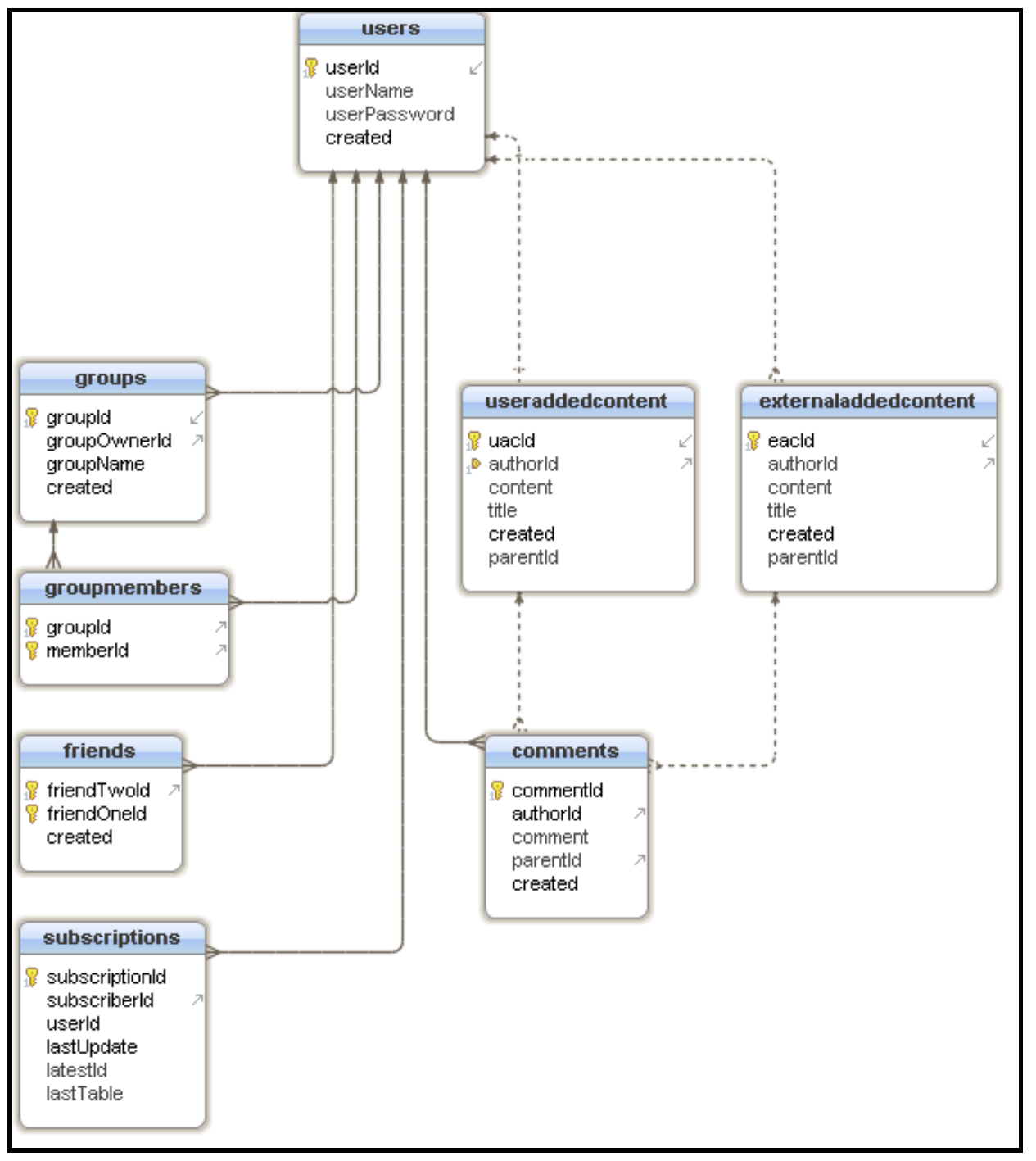

Figure 4-5: Database Schema.

Figure 4-5 is an illustration of the database schema used in Friend Lens. All data stored in Friend Lens is attached to the user who created them. All posts, groups, subscriptions, friends, comments, and users have a user ID as either a primary or a foreign key. In the case of posts and comments, they also have to have the id of the parent post stored. All database interaction is through PHP using the MySQL functions that are part of the PHP 4.0 or greater standard. 


\subsection{User Accounts}

A user account grants access to Friend Lens and to all content on the site. Friend Lens is a completely open site with no privacy limitations or restricted access to any of the content. This was done to promote as much activity as possible. Every user has the exact privileges as every other user and all that are content either created or added by a user can be viewed and interacted with by all users.

\subsubsection{Creating User Accounts}

Only information needed from user is a user name and a password. No personal information, such as real name or email address, is required. The only restriction is that every user name must be unique, so once a user name is taken no other user can sign up with that user name.

\subsubsection{Friend lists}

Friends, initially, do not change the user experience in anyway. If user A adds user B as a friend the only immediate change for user A is the link to user B's profile in user A's friend list. Friendship, contrary to the common definition, is entirely one way within friend lens. For example, if user A makes user B a friend, user B is given no notification and there is absolutely zero change for user B (not even the link user A receives is added for user B). Although they have very little impact, making friends becomes extremely important when the concept of groups is added.

\subsubsection{Groups}


Groups allows for a user to organize the comments and highlights of others. Every user is given a default group called "Other." The interface allows users to view the highlights and comments of an individual user or all of comments and highlights of a group of users. A user can make any number of groups and a friend can be placed into multiple groups. The purpose of groups is to help users organize the feedback from other users in a way that is most beneficial to them. For example, a user can make a group for all family members, another for coworkers, and a third for classmates. Figure 4-6 is example of how the post interface can benefit from using groups. The user created a group called "Family." All groups the user creates, along with the default group "Other," are listed on the left side of the post. All users in this group that have either commented or highlighted the post being viewed are listed. In this example, two members of the family group have left highlights on the current post. The user can toggle the highlights and comments of individual users or entire groups. The viewing of an entire group's highlights is discussed in section 4.5 . 


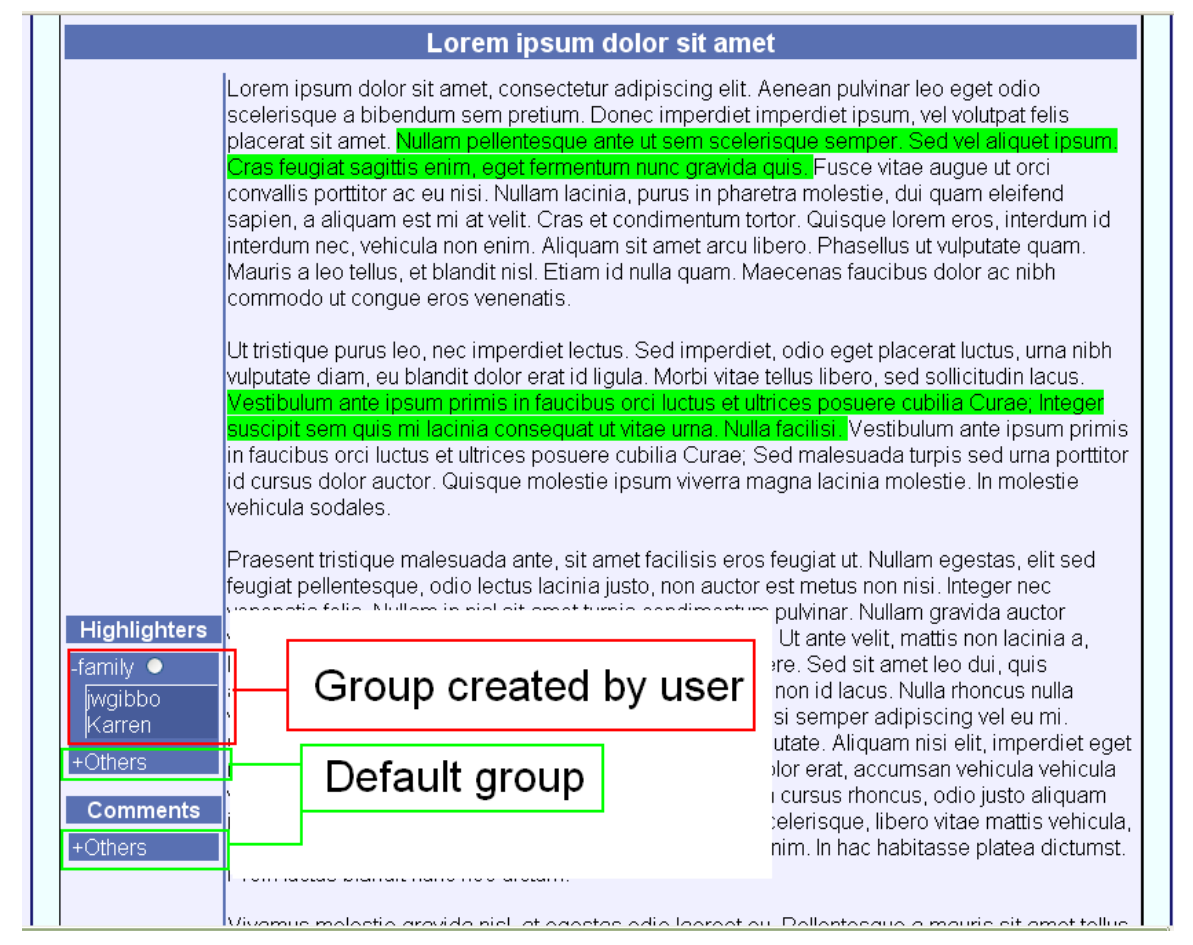

Figure 4-6: Viewing a post after creating a group.

\subsubsection{Subscriptions}

Subscriptions are a convenience utility. User A can subscribe to user B and from then on when user B makes a new post, user A will see a notification of this new post in his/her subscriptions list. Subscriptions are also entirely one way, meaning if user A subscribes to user B, user B will experience zero change in experience. The purpose of a subscription is to allow users to stay upto-date on the most recent blog posts of the authors they follow most.

\subsection{Basic Blogging}

\subsubsection{Post created by user}

Users can create a blog post using text and any standard HTML. Friend Lens does not support the uploading of files. However, any images, videos, or embedded objects that have an absolute 
URL can be put into a post using the appropriate HTML tag. Upon creation of a post, that post appears first on the user's home page, as shown in Figure 4-7.

\section{Lorem ipsum dolor sit amet}

Lorem ipsum dolor sit amet, consectetur adipiscing elit. Aenean pukinar leo eget odio scelerisque a bibendum sem pretium. Donec imperdiet imperdiet ipsum, vel volutpat felis placerat sit amet. Nullam pellentesque ante ut sem scelerisque semper. Sed vel aliquet ipsum. Cras feugiat sagitils enim, eget fermentum nunc gravida quis. Fusce vitae augue eros interdum id interdum nec, vehicula non enim. Aliquam sit amet arcu libero. Phasellus ut vulputate quam. Mauris a leo tellus, et blandit nisl. Etiam id nulla quam. Maecenas faucibus dolor ac nibh commodo ut congue eros venenatis.

Ut tristique purus leo, nec imperdiet lectus. Sed imperdiet, odio eget placerat luctus, urna nibh vulputate diam, eu blandit dolor erat id ligula. Morbi vitae tellus libero, sed sollicitudin lacus. Vestibulum ante ipsum primis in faucibus orci luctus et utrices posuere cublia Curae, Integer suscipit sem quis mi lacinia consequat ut vitae unna. Nulla facilis Vestibulum ante ipsum primis in taucibus orciluctus cetulices posuere cubilia curae, sed malesuada turpis sed uma porttitor id cursus dolor auctor. Quisque molestie ipsum

Praesent tristique malesuada ante, sit amet facilisis eros feugiat ut. Nullam egestas, elit sed feugiat pellentesque, odio lectus lacinia justo, non auctor est metus non nisi. Integer lacinia a, lacinia eu ante. Aliquam bibendum mattis magna in posuere. Sed sit amet leo dui, quis accumsan mi. Mauris nec massa vel tortor cursus lobortis non id lacus. Nulla rhoncus nulla vestibulum mauris vulputate pulvinar. Donec et augue at nisi semper adipiscing vel eu mi. Curabitur gravida nibh quils nisı porta ut suscipit diam vulputate. Aliquarn nisi elit, imperdet eget honcus non, rutrum eget nulla. Suspendisse potent. Ut dolor erat, accumsan vehicula vehicula viae, molestie sit amet nunc. Maecenas blandit, magna in

Vivamus molestie gravida nisl, at egestas odio laoreet eu. Pellentesque a mauris sit amet tellus aliquam aliquet id ut dolor. Curabitur consectetur egestas mattis. Suspendisse turpis massa, feugiat sit amet scelerisque sed, porttitor eu leo. Aenean sit amet velit id felis tincidunt hendrerit quis ut leo. In facilisis arcu vitae sapien molestie blandit faucibus ante euismod. Aenean ac arcu rhoncus lectus suscipit consequat non vel magna. Sed a lorem eu quam tempus sollicitudin. Duis fringilla, ligula non volutpat tincidunt, turps massa dapibus velit, sed aliquet enim mauris et augue. Vestibulum eros est, blandit at pharetra quis, pulvinar cursus libero. Aliquam erat volutpat. Vivamus augue nisl, consectetur vel sodales vel, placerat st amet eros. Qusque in neque injusto semper egotas sed a justo. Nuntreus

Suspendisse suscipit ligula at arcu consectetur laoreet. Donec a pretium nunc. Sed ac suscipit mauris. In et augue volutpat arcu dapibus interdum a dapibus tortor. Praesent arcu sapien, rutrum non condimentum a, malesuada in tortor. Ut viverra nulla at tellus venenatis eget pulvinar lorem lacinia. Vivamus laculis pellentesque nunc vitae pretium. Suspendisse eros orci, sollicitudin sit amet laculis porta, ornare eu urna. Morbi sem velit, tristique sed feugiat rutrum, tempus sit amet enim. Integer quis nulla mi, eu pulvinar risus. Nullam sit amet vulputate lorem. Vivamus at auctor ellit.

\begin{tabular}{c} 
Created on: 2009-10-13 20:14:35 \\
Make Highilights and Comments \\
There are 3 comment(s) and 7 highlight(s) \\
Delete Post \\
\hline
\end{tabular}

Figure 4-7: Example of a Plain Text Post. 
Figure 4-8 shows the post creation process when using HTML. Any HTML that is part of the 4.01 standard is completely compatible with Friend Lens posts.

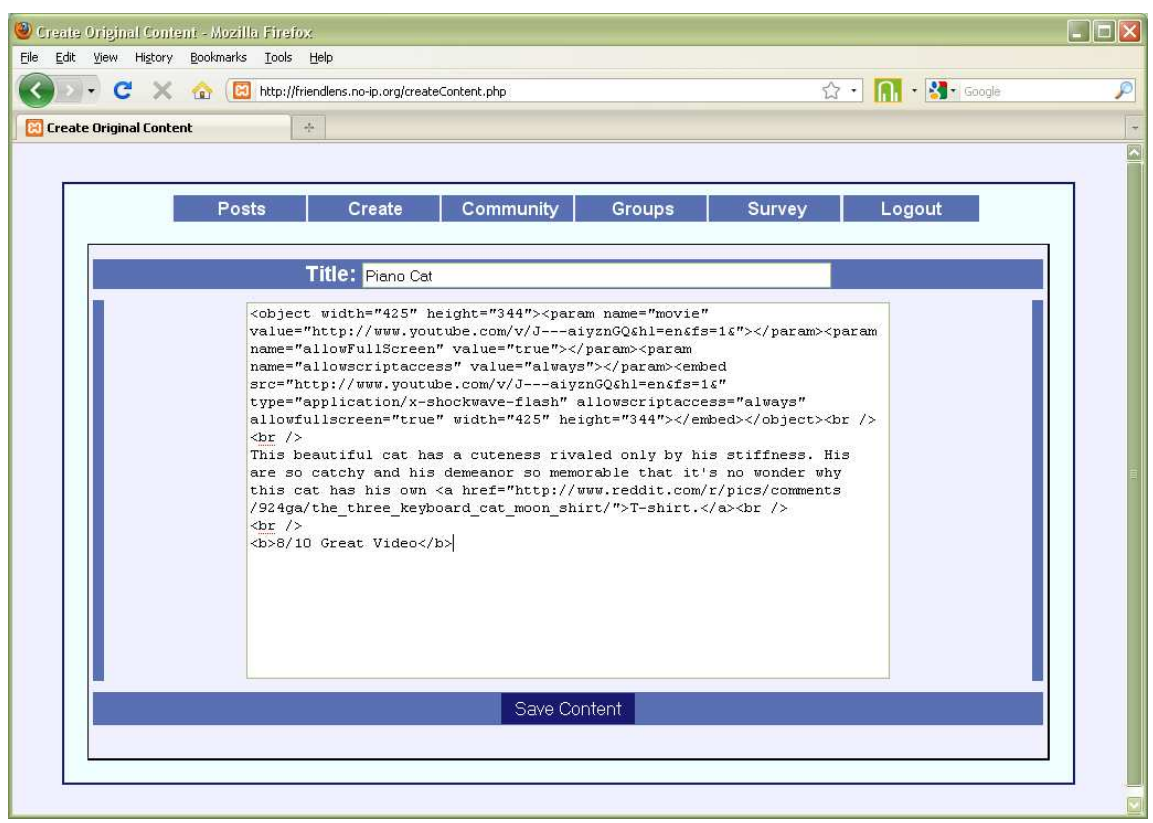

Figure 4-8: Creating Post Using HTML.

Figure 4-9 is the final result of a user created post that used HTML from the Figure 4-8 source code.

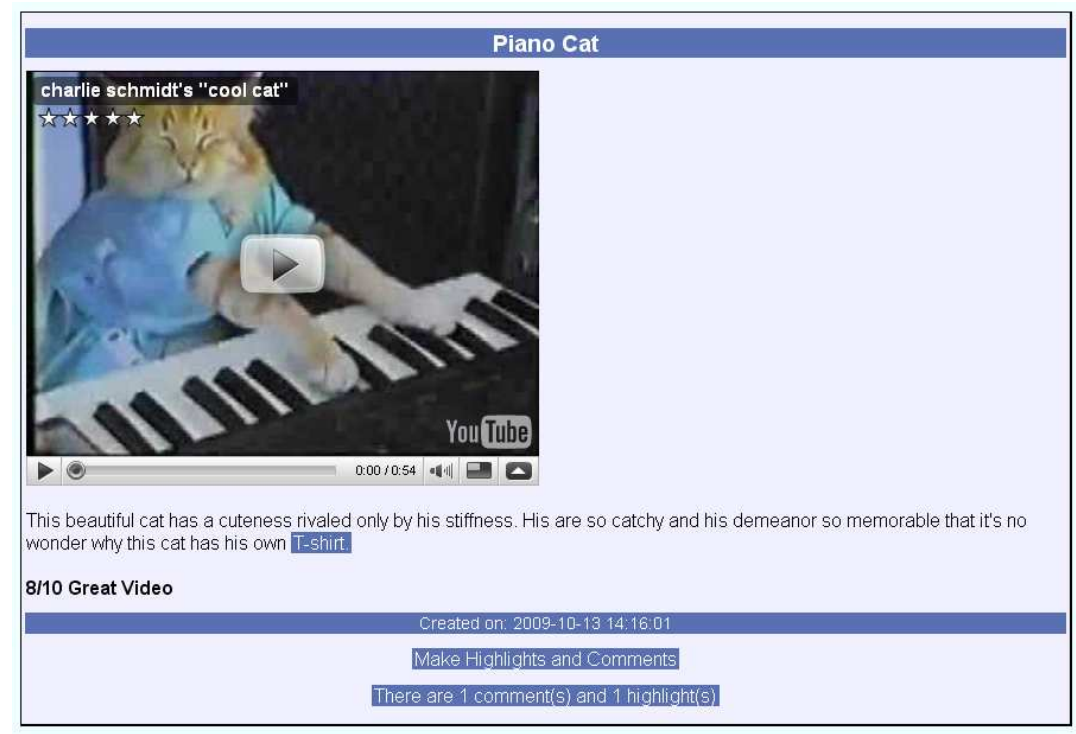

Figure 4-9: Example of a Post with HTML. 


\subsubsection{User Collaboration/Feedback: Commenting}

Any post that the user makes, original or external, can be commented and highlighted. The numbers of comments and highlights are automatically updated and displayed below the post, as shown in Figure 4-10.

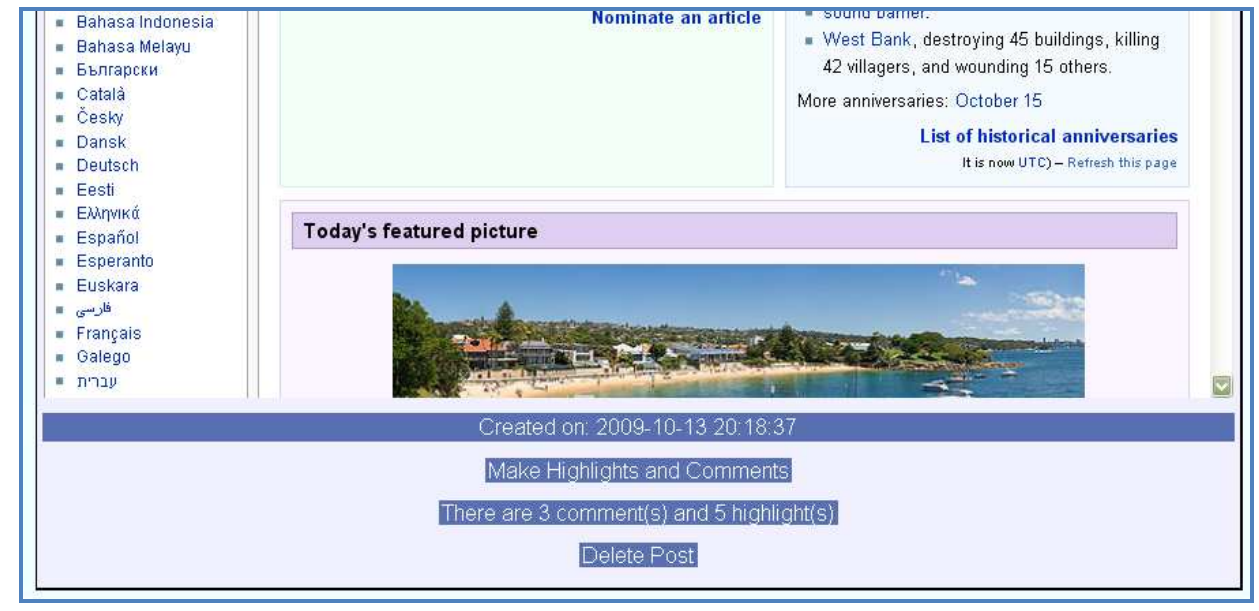

Figure 4-10: Post feedback details.

Commenting is used as a means of feedback to any post. Comments are different from posts in only one regard: they require a parent post. This means that a comment can contain any text or HTML that a post can; images, videos, or any other embeddable objects.

\subsubsection{Highlighting}

A novel tool unique to Friend Lens is the ability to highlight posts. Highlights have many uses:

- Emphasizing parts of posts that are important to that user

- Peer reviewing

- Clearly showing to which part of the post a corresponding comments is referring to 
In order to highlight, users go into the highlight and comment interface. From there the post looks exactly the same as it does on the home page with the addition of highlight buttons, but this is actually a copy of the original post. To highlight text or links, user selects the desired text and presses the highlight button. This act, dynamically updates the source code with the needed styling code, which is why a copy is needed. The original post is preserved and the post with highlights is stored separately. The highlight interface is shown in Figure 4-11.

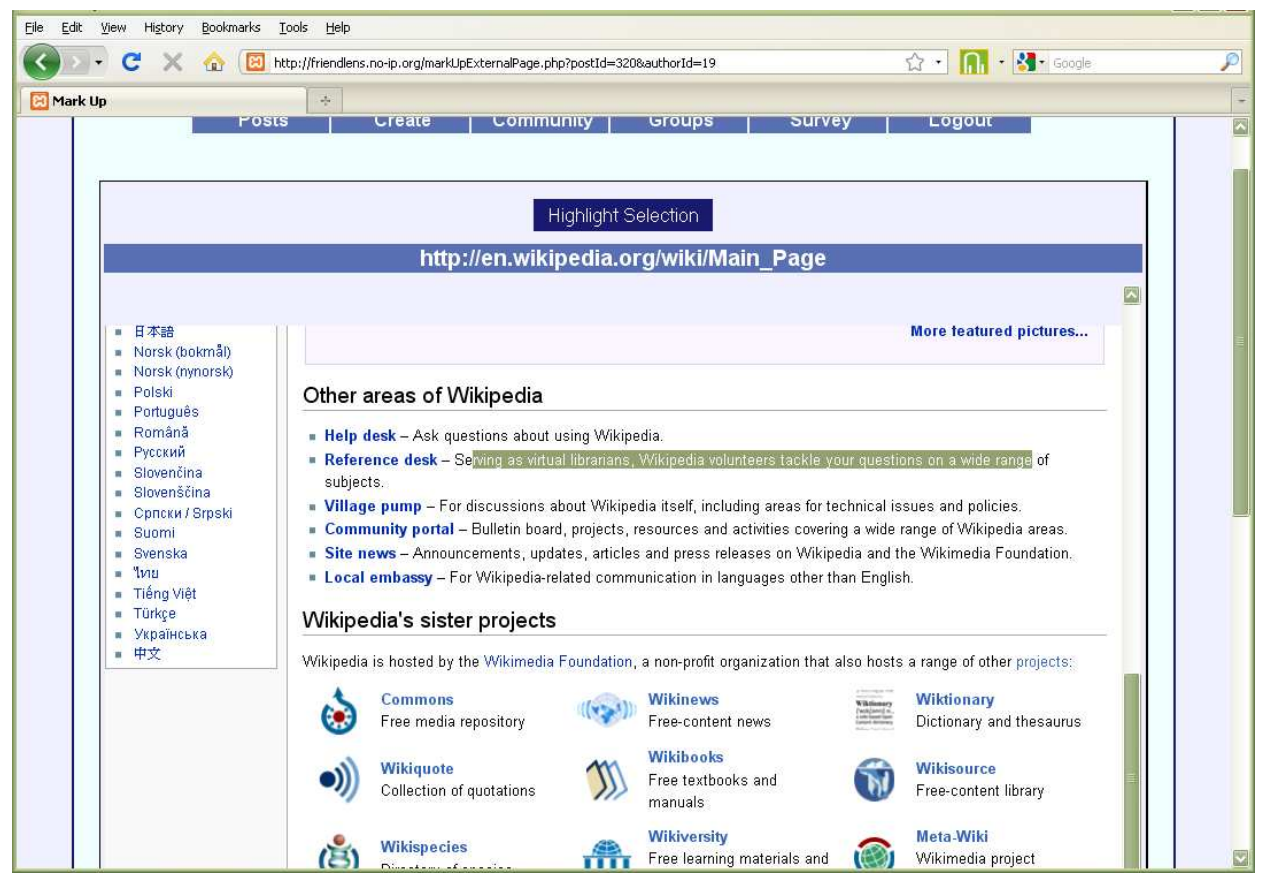

Figure 4-11: Highlight Interface.

Figure 4-12 and Figure 4-13 are examples of how highlighting can be used to improve feedback, help in collaboration, and be used in peer revision. Figure 4-12 is a comment to a post discussing a possible spelling error. However, the comment is vague because it does not indicate where the spelling error in the original post may be. 


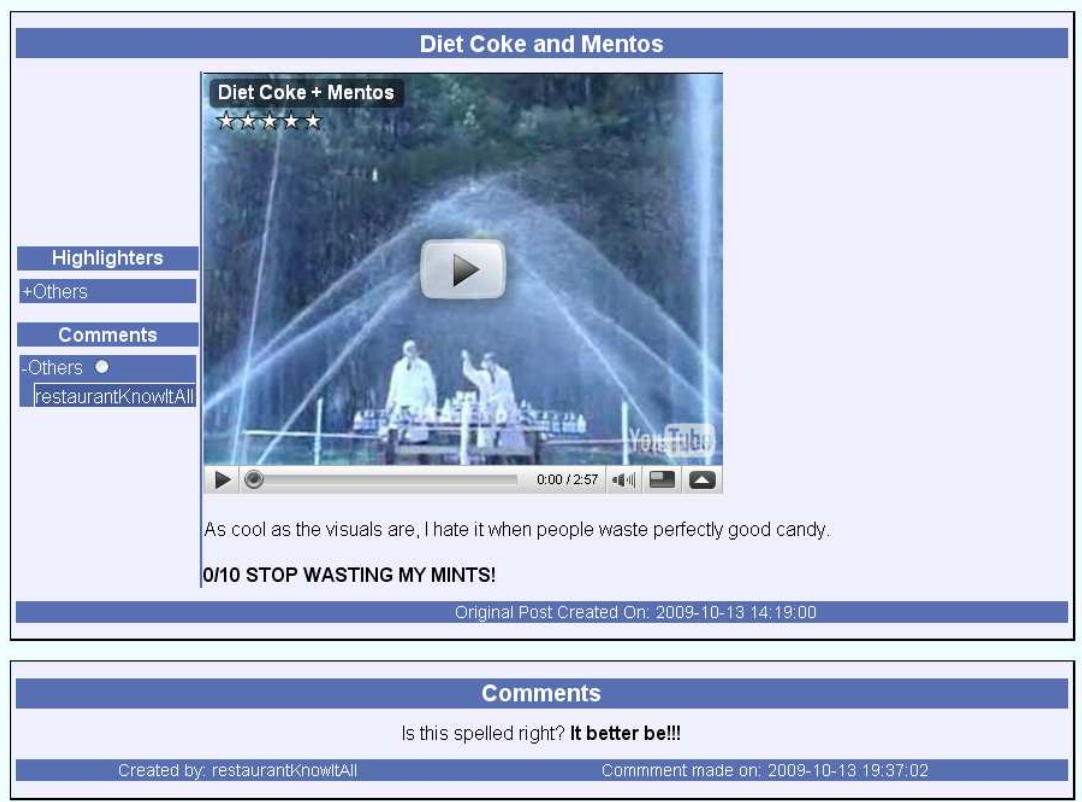

Figure 4-12: Commenting alone.

In Figure 4-13, the comment is discussing a possible spelling issue. The comment alone is not helpful. When the comment and the highlight are viewed at the same time, the feedback is much more clear and useful.

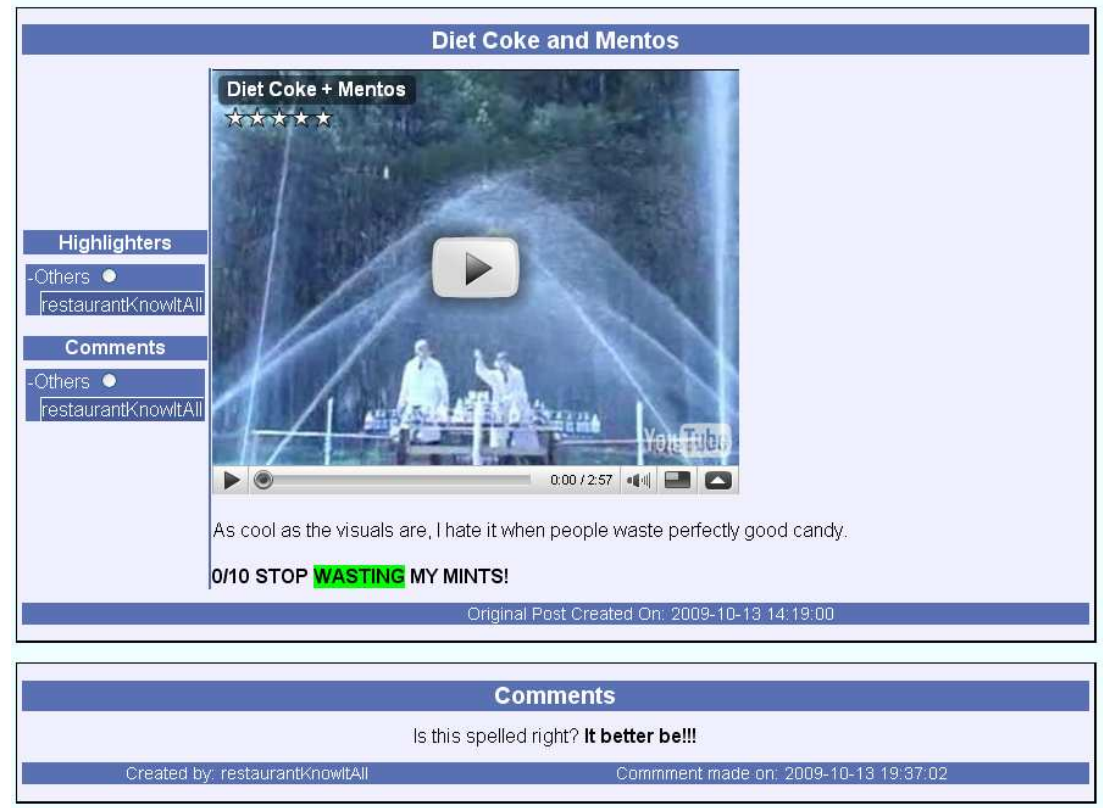

Figure 4-13: Highlights and comments together. 


\subsection{Capturing and Altering an External URL}

A novel feature of Friend Lens is the ability for users to post entire web pages as blog posts. This feature allows users that have found a web page of interest to post that page, in its entirety to their home page. The user interface is shown in Figure 4-14.

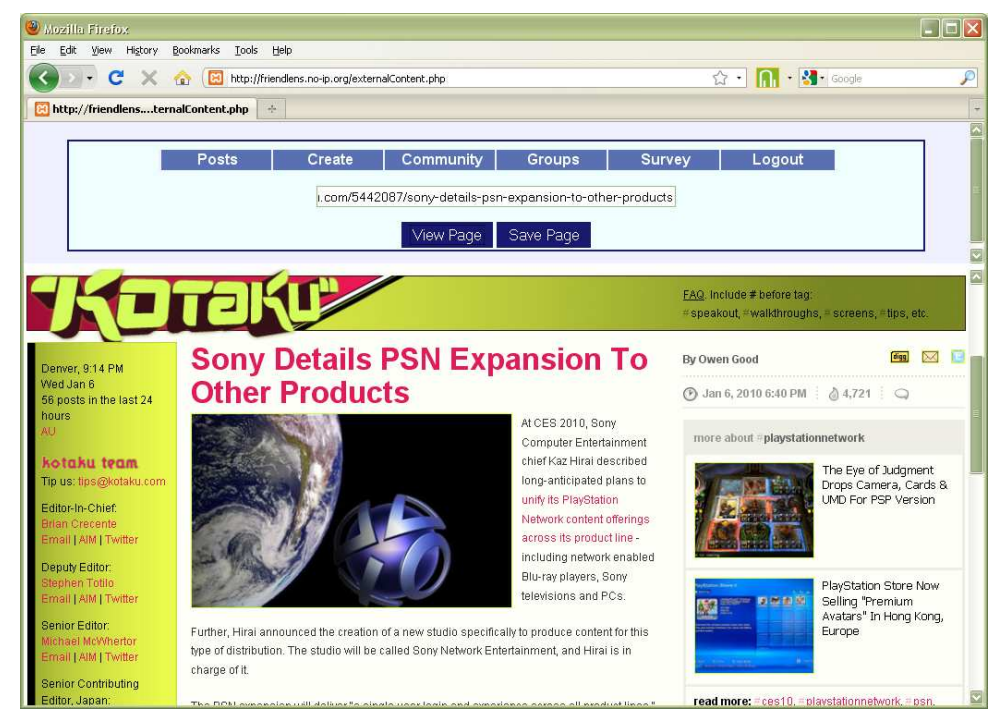

Figure 4-14: External Posting Interface.

The user interface is a set of two frames, meaning that the page is split into two independent web pages. The top frame is the Friend Lens menu. The bottom frame contains a cached copy of the desired web page. Capturing an external URL has the following steps:

1. Paste a valid URL into the text field

2. View the page: The cached copy of the original URL is created and displayed in the bottom frame

3. Save the page: The entire page is now posted to the user's home page 


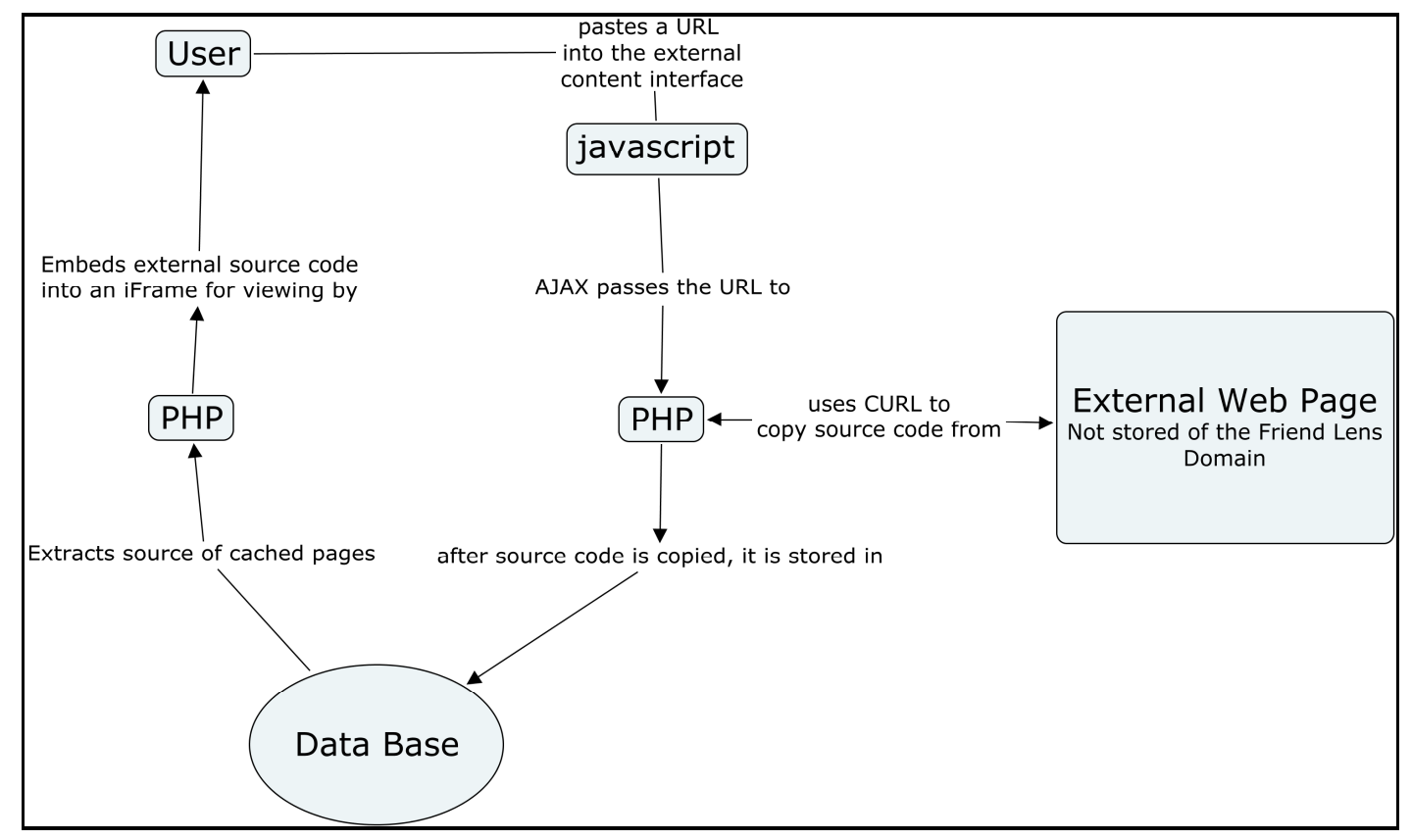

Figure 4-15: External Page Extraction.

The details of creating a copy of an external Web page and saving the copy as a post are detailed in Figure 4-15. After a user pastes a URL into the text field of the top frame, as shown in Figure 4-14, JavaScript sends the URL to PHP via AJAX and PHP then uses a mechanism known as "curling" to copy the source code. The mechanism for capturing the external source code is part of the PHP 4.0.2 or greater standard. The copy is then stored in the data where it can be retrieved by PHP.

A difficult challenge was in preserving the original source code of an external URL. To minimize file transfers and to enable all of the Friend Lens features, the pages needed to be cached as single HTML document, but when the source code for a web page moves from one domain to another, the behavior of the page is not guaranteed to be preserved. It is common for the original source code to have relative paths for images, links, or script files. For example, a typical image tag could have the following components: 
<img src="myImageFolder/pic1.jpg" />

The problem here is that the folder "myImageFolder" is a directory that does not exist on the Friend Lens server. That directory only exists on the original domain. If this code is viewed anywhere else other than the original domain, then the image will not be displayed. To correct this, Friend Lens will search the cached copy of the source code, before displaying it to the user, and will auto correct any images tags with this problem. The result from auto correction would be the following absolute path:

<img src="http://OriginalDomain/myImageFolder/pic1.jpg" />

Image tags are just one tag that can suffer from this very common problem. Other tags that Friend Lens auto corrects are:

- Link tags that link CSS

- Script tags

- Anchor tags (hyper link tags)

\subsection{Creating and Viewing a Composite of a Groups Highlights}

\subsubsection{Purpose}

When a post has highlights from multiple users, Friend Lens can make a composite of all highlights. This allows the author to get a quick summary of what are the most commonly highlighted text (image composite not available).

The highlight composite takes all highlights for a post and searches for any highlights that are subsets of any other highlights. A preset, three color scale is used in the composite. The text that has the most highlights is used to scale the color for all other highlights, as shown in Table 4-2. 


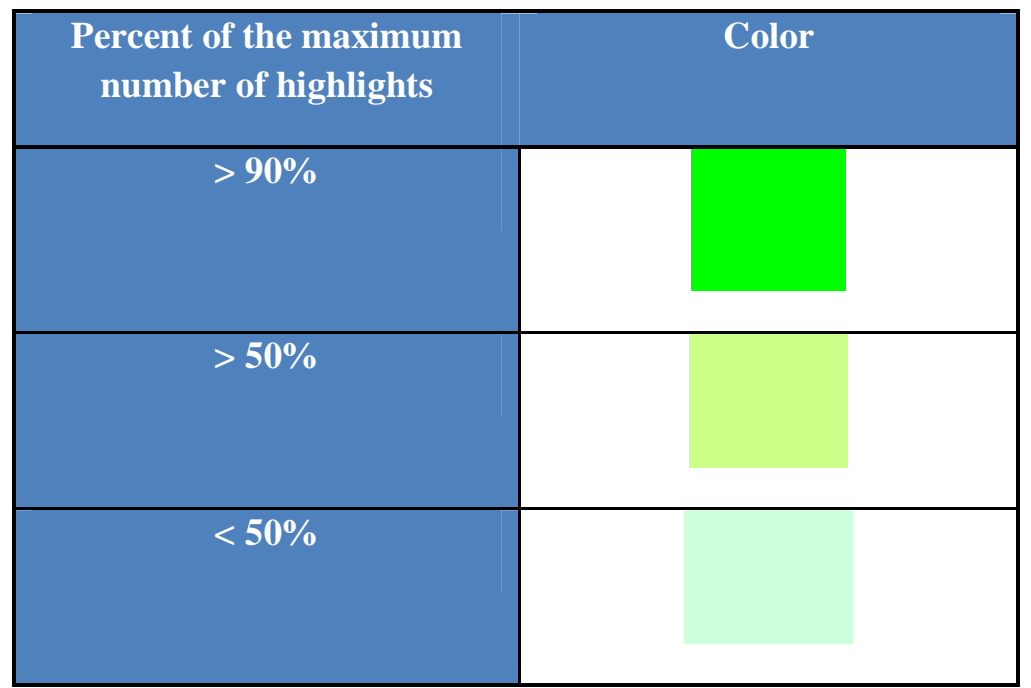

Table 4-2: Highlight Colors.

\subsubsection{Interface}

The highlight composite is the driving force behind groups. Each group receives its own highlight composite. Making different groups allows for organization of highlights and for quick overview of what each group highlights most. An example of individual highlights is shown in Figure 4-16.

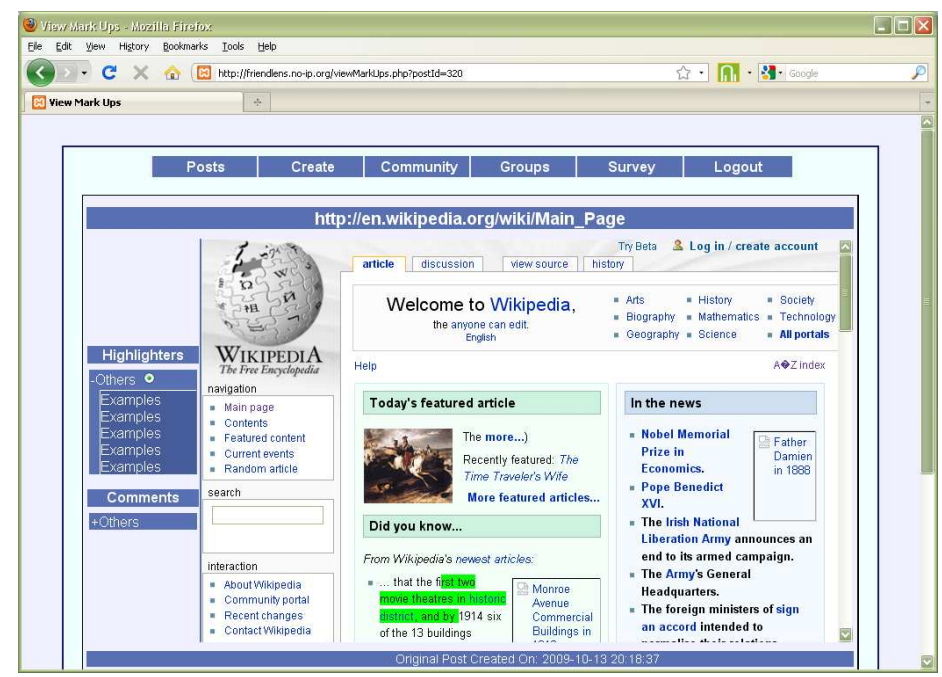

Figure 4-16: Highlight by Individual.

An example of composite highlights is illustrated in Figure 4-17. 


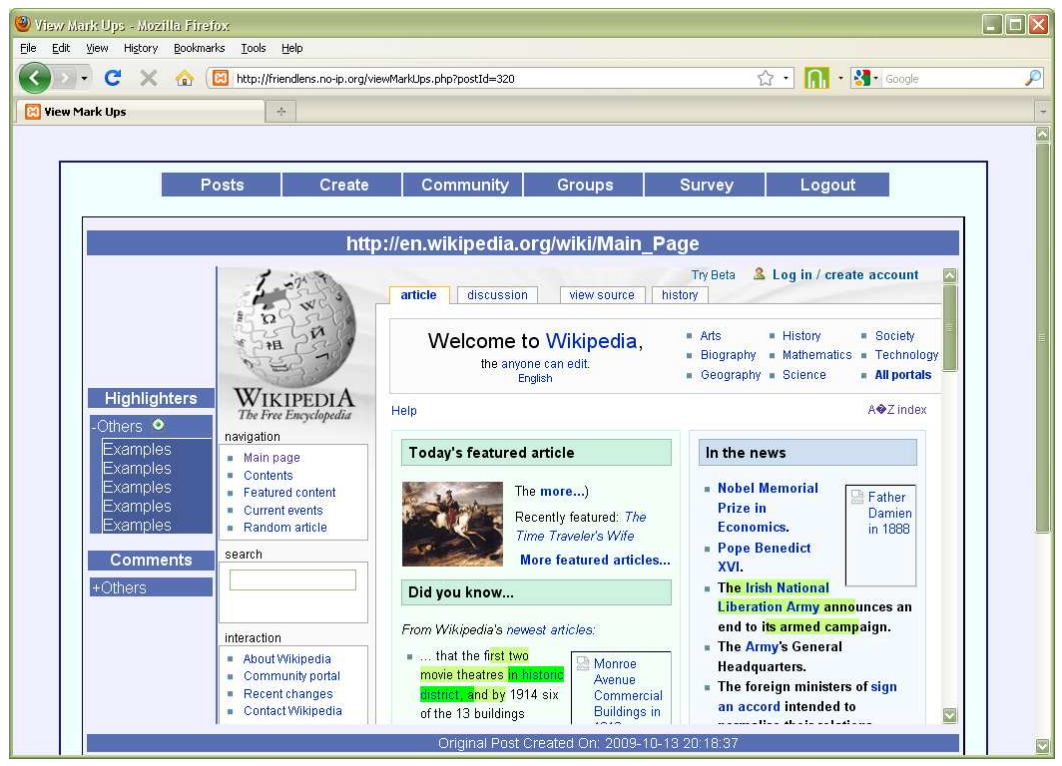

Figure 4-17: Composite of Highlight by Group. 


\section{Human Subject Experiments}

In order to evaluate the usefulness and to discover if Friend Lens improves user experience beyond currently available applications, human subject experiments conducted. Three web applications were compared: Facebook, Clip Marks, and Friend Lens. Facebook was chosen for its large user base, social networking capabilities, and to compare its content sharing capabilities to Friend Lens. Clip Marks was chosen for its extreme similarity in functionality for posting external content. The survey had users evaluate the following areas:

- Community

- Posting Content

- Practicality of Use

The 31 subjects were men and women ranging from 20 to 30 years old. All subjects were in college or had graduated from college. The majority of the subjects had a background in engineering. None of the subjects had used Friend Lens prior to participating in the experiment.

The questions were designed after each system was used and were designed such that some question had an expected winner. The reason for this was to ensure that responses were honest and that the users actually took the time to become familiar with each system. The survey questions are listed in Table 5-1. The instructions the user received are shown in Appendix A. Appendix B contains a copy of the original questions. Human subjects were allowed to leave comment, and these comments are shown in Appendix C. 
The questions were on a scale of 0 to 5, with 0 indicating "None" or "Not Available/Applicable" and 5 being the highest ranking. The scale was integer based so the subject had to enter a 0 , $1,2,3,4$, or 5; decimal values were not allowed. The results across all surveys were averaged and are analyzed in this chapter.

\begin{tabular}{|l|l|l|}
\hline Question & $\begin{array}{l}\text { Expected } \\
\text { Winner }\end{array}$ & Actual Winner \\
\hline Intuitiveness of finding other users. & Facebook & Facebook \\
\hline Ease of presenting content to the public. & Facebook & Tie (Facebook and Clip Marks) \\
\hline Ease of sharing content with friends (users on the same site). & Facebook & Facebook \\
\hline Ease of monitoring the activity of other users. & Facebook & Facebook \\
\hline Ease of creating new content authored by you. & Unknown & Facebook \\
\hline Ease of adding pictures & Facebook & Facebook \\
\hline Ease of adding links to other sites & Facebook & Tie (Facebook and Clip Marks) \\
\hline $\begin{array}{l}\text { Ability to post content for external sites to your blog/home } \\
\text { page. }\end{array}$ & Friend Lens & Friend Lens \\
\hline Ability to comment on the posts/pages of other users. & Unknown & Facebook \\
\hline $\begin{array}{l}\text { The ability of allowing others to edit/comment on material } \\
\text { you authored }\end{array}$ & Unknown & Facebook \\
\hline The ability to stay in touch with people you know & Facebook & Facebook \\
\hline The ability to save content from your favorite web sites & Friend Lens & Friend Lens \\
\hline $\begin{array}{l}\text { The ability to allow others to see the web sites you visit/enjoy } \\
\text { most }\end{array}$ & Unknown & Friend Lens \\
\hline Usability for peers to review your work. & Unknown & Friend Lens \\
\hline Usability for your profession & Unknown & Friend Lens \\
\hline
\end{tabular}

Table 5-1: Survey Questions.

\subsection{Community Results}

The first category of questions evaluated each site's ability to build a community for the users. Figure 5-1 is a graph of the averages for each question in the community category. Table 5-2 contains the numeric values for the averages for each question in the community category. Section 5.4 contains an in depth analysis of the result for this category. 


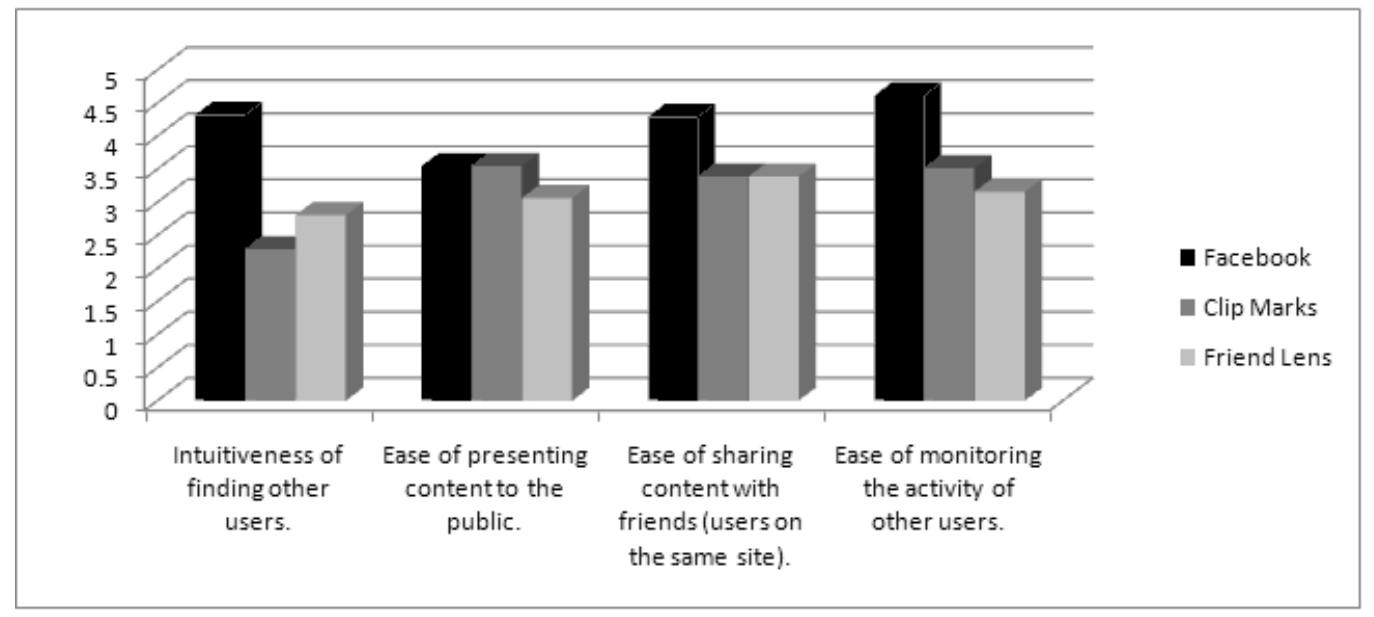

Figure 5-1: Community Results Graph.

\begin{tabular}{|c|c|c|c|c|}
\hline & $\begin{array}{l}\text { Intuitiveness of } \\
\text { finding other } \\
\text { users. }\end{array}$ & $\begin{array}{c}\text { Ease of presenting } \\
\text { content to the } \\
\text { public. }\end{array}$ & $\begin{array}{l}\text { Ease of sharing } \\
\text { content with } \\
\text { friends (users on } \\
\text { the same site). }\end{array}$ & $\begin{array}{l}\text { Ease of } \\
\text { monitoring } \\
\text { the activity } \\
\text { of other } \\
\text { users. }\end{array}$ \\
\hline Facebook & 4.3226 & 3.5484 & 4.2903 & 4.6129 \\
\hline Clip Marks & 2.2903 & 3.5484 & 3.3871 & 3.5161 \\
\hline Friend Lens & 2.8065 & 3.0645 & 3.3871 & 3.1613 \\
\hline
\end{tabular}

Table 5-2: Community Scores.

\subsection{Posting Content Results}

The second category of questions evaluated each site's content posting features. Figure 5-2 is a graph of the averages for each question in the posting content category. Table 5-3 contains the numeric values for the averages for each question in the community category. Section 5.5 contains an in depth analysis of the result for this category. 


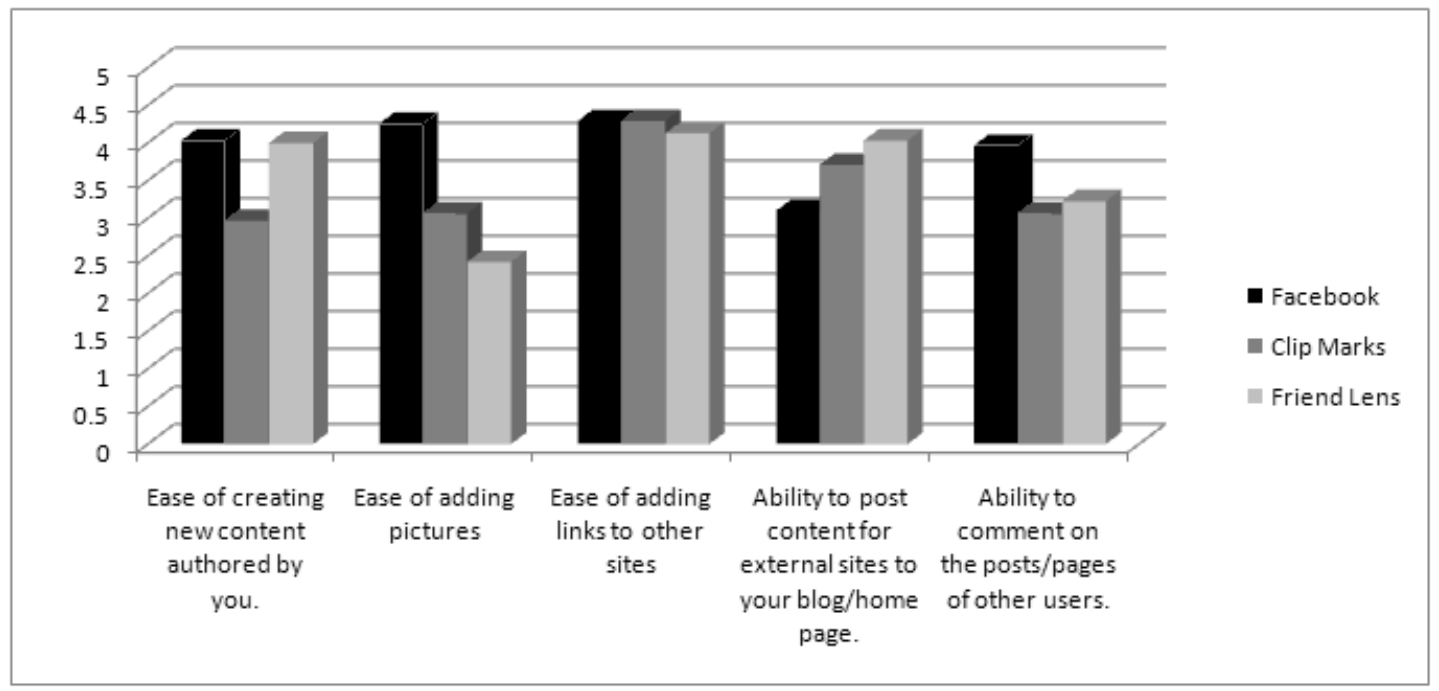

Figure 5-2: Posting Content Results Graph.

\begin{tabular}{|c|c|c|c|c|c|}
\hline & $\begin{array}{l}\text { Ease of } \\
\text { creating new } \\
\text { content } \\
\text { authored by } \\
\text { you. }\end{array}$ & $\begin{array}{l}\text { Ease of } \\
\text { adding } \\
\text { pictures }\end{array}$ & $\begin{array}{l}\text { Ease of } \\
\text { adding links } \\
\text { to other sites }\end{array}$ & $\begin{array}{l}\text { Ability to } \\
\text { post content } \\
\text { from external } \\
\text { sites to your } \\
\text { blog/home } \\
\text { page. }\end{array}$ & $\begin{array}{l}\text { Ability to } \\
\text { comment } \\
\text { on the } \\
\text { posts/pages } \\
\text { of other } \\
\text { users. }\end{array}$ \\
\hline Facebook & 4.0323 & 4.2581 & 4.2903 & 3.0968 & 3.9677 \\
\hline Clip Marks & 2.9677 & 3.0645 & 4.2903 & 3.7097 & 3.0645 \\
\hline Friend Lens & 4.0000 & 2.4194 & 4.1290 & 4.0323 & 3.2258 \\
\hline
\end{tabular}

Table 5-3: Posting Content Scores.

\subsection{Practicality of Use Results}

The third category of questions evaluated each site's practicality of use. The goal of these questions was to evaluate each site's potential useful in the user's everyday life. Figure 5-3 is a graph of the averages for each question in the posting content category. 


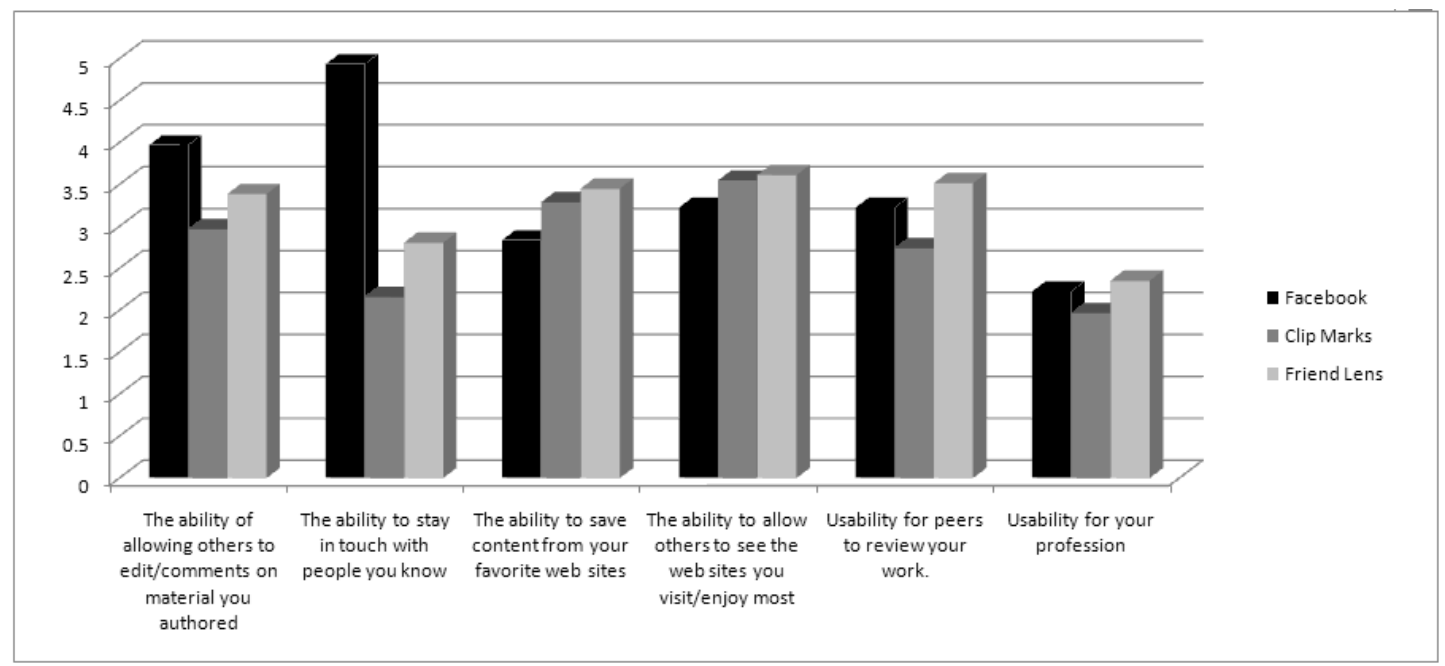

Figure 5-3: Practicality of Use Result Graph.

Table 5-4 and Table 5-5 contain the numeric values for the averages for each question in the community category. Section 5.5 contains an in depth analysis of the result for this category.

\begin{tabular}{|c|c|c|c|}
\hline & $\begin{array}{c}\text { The ability of allowing } \\
\text { others to edit/comments } \\
\text { on material you } \\
\text { authored }\end{array}$ & $\begin{array}{l}\text { The ability to stay in } \\
\text { touch with people you } \\
\text { know }\end{array}$ & $\begin{array}{l}\text { The ability to save } \\
\text { content from your } \\
\text { favorite web sites }\end{array}$ \\
\hline Facebook & 3.9677 & 4.9355 & 2.8387 \\
\hline Clip Marks & 2.9677 & 2.1613 & 3.2903 \\
\hline Friend Lens & 3.3871 & 2.8065 & 3.4516 \\
\hline
\end{tabular}

Table 5-4: Practicality of Use Scores 1.

\begin{tabular}{|c|c|c|c|}
\hline & $\begin{array}{c}\text { The ability to allow } \\
\text { others to see the web } \\
\text { sites you visit/enjoy } \\
\text { most }\end{array}$ & $\begin{array}{l}\text { Usability for peers to } \\
\text { review your work. }\end{array}$ & $\begin{array}{l}\text { Usability for your } \\
\text { profession }\end{array}$ \\
\hline Facebook & 3.2258 & 3.2258 & 2.2258 \\
\hline Clip Marks & 3.5484 & 2.7419 & 1.9677 \\
\hline Friend Lens & 3.6129 & 3.5161 & 2.3548 \\
\hline
\end{tabular}

Table 5-5: Practicality of Use Scores 2. 


\subsection{Community Results Analysis}

\subsubsection{Intuitiveness for finding others}

Figure 5-4 contains the averaged rankings for "intuitiveness of finding other users" from the human subject experiments.

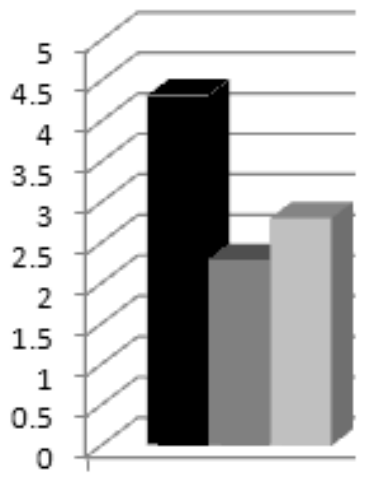

$$
\begin{aligned}
& \text { - Facebook } \\
& \text { Clip Marks } \\
& \text { Friend Lens }
\end{aligned}
$$

Figure 5-4: Intuitiveness of finding other users.

Facebook is the clear winner. This result was expected due to Facebook's very robust user search system that features suggestion based upon location, schools, and even tracking friends of friends.

Friend Lens had only one mechanism, a single list of all users as seen in Figure 4-4, to use for finding others. Although this lone feature was not very robust, or even searchable, it was enough to score higher than Clip Marks which lacks any direct link to user list or user search.

\subsubsection{Ease of presenting content to the public}

Figure 5-5 contains the averaged rankings for "ease of presenting content to the public" from the human subject experiments. 


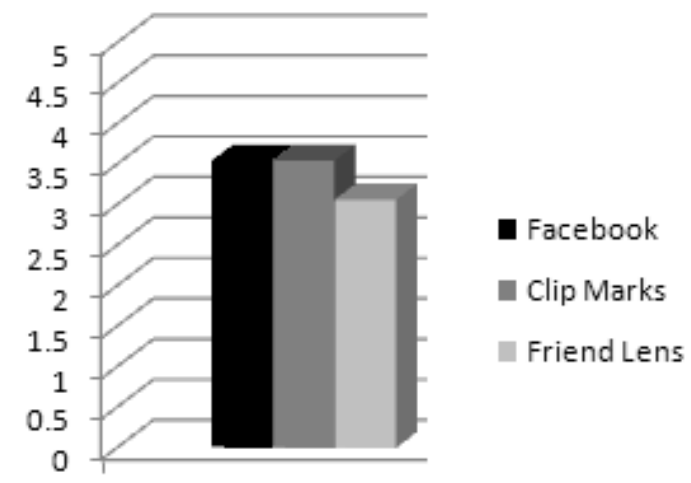

Figure 5-5: Ease of presenting content to the public.

In this category, Facebook and Clip Marks are very close. The original hypothesis was that Facebook would score the highest, Clip Marks second highest, and Friend Lens would score lowest. This result is particularly surprising because most user comments describe a frustration with Clip Marks because one must install a plug-in before any content can be presented to the public.

Friend Lens' low score is due to its interface issues. It had the least robust interface out of all three. However, it still scored very closely with the other two, which seems to support the suspicion that an overly simplified interface can help users understand exactly what to do without confusion.

\subsubsection{Ease of sharing content with friends}

Figure 5-6 contains the averaged rankings for "ease of sharing content with friends" from the human subject experiments. 


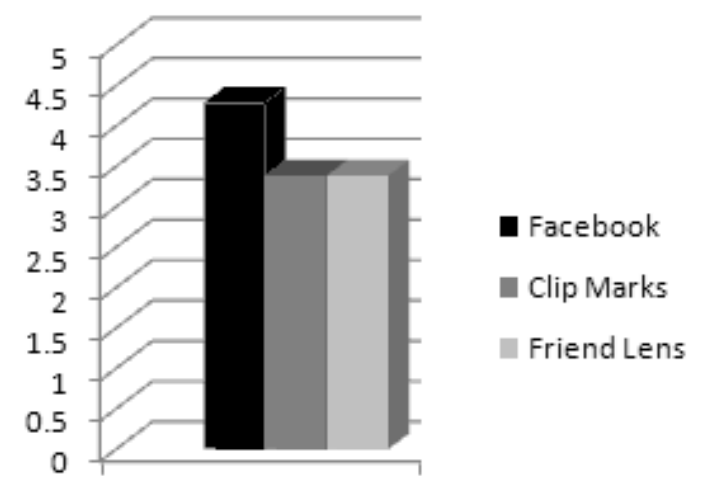

Figure 5-6: Ease of sharing content with friends (users of the same site).

The most important part of this question is the concept of sharing with "friends." Facebook was the expected and actual winner for this reason. In social networking it is rare to want to share information with the general public; instead, users want specific people, which use the same web site, to view the content they have created. Facebook features live feed updates that automatically shows all friends any new content a user creates from his/her home pages.

Clip Marks and Friends both rely solely on a subscription paradigm which is very similar to a "friend" but only one direction. This means that a subscriber's activity does not affect and is not seen by the user to whom they have subscribed. Facebook's notion of "friend" is two-way, where both parties interaction, communicate, and automatically share content with each other.

\subsubsection{Ease of monitoring the activity of other users}

Figure 5-7 contains the averaged rankings for "ease of presenting content to the public" from the human subject experiments. 


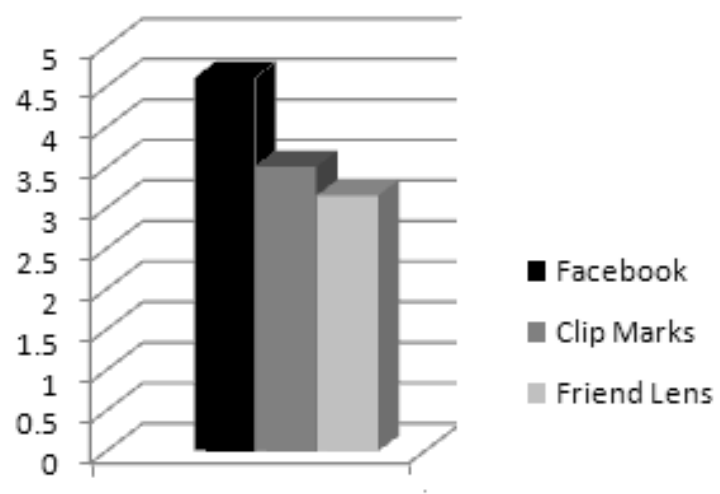

Figure 5-7: Ease of monitoring the activity of other users.

Much like the results for sharing content, Facebook dominated the "monitoring activity of other users" category. Facebook will show the user the activity of all of the user's friends automatically as soon as the users log on to the site. However, for both Clip Marks and Friend Lens, the user must search through his/her subscriptions (in Clip Marks it is called "Guides") in order to monitor user activity.

More importantly, the question asked about activity, not merely postings. Friend Lens and Clip Mark only allow users to monitor content postings. Facebook allows users to see a much larger spectrum of user activity such as:

- New Friendships

- Picture Uploads

- Games (Applications) being played

- Relationship Status

- Events Creation, Invitation, Attendance

- Current Status (frequent, miniature, text only posts made by users) 


\subsection{Posting Content Results Analysis}

\subsubsection{Ease of creating content authored by you}

Figure 5-8 contains the averaged rankings for "ease creating content authored by you" from the human subject experiments.

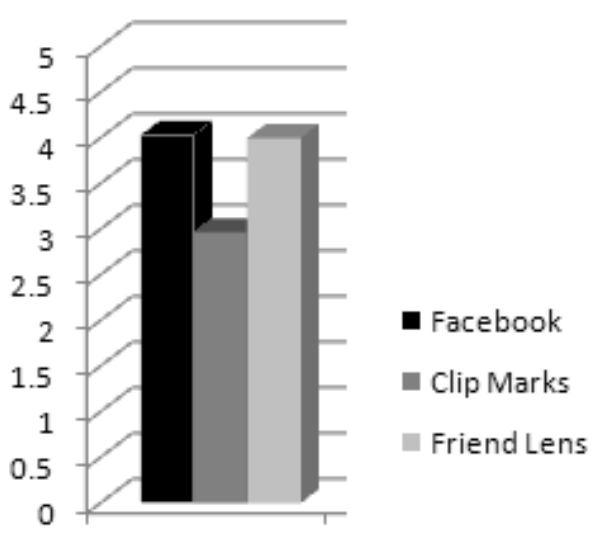

Figure 5-8: Ease of creating new content authored by you.

Facebook scored slightly higher than Friend Lens and higher than Clip Marks. Clip Marks was expected to score lowest when the question was designed because Clip Marks does not allow for content creation, only content extraction from other sites. The similar, high scores of both Facebook and Friend Lens is due to their extremely similar interfaces; Figure 5-9 shows the Facebook interface and Figure 5-10 shows the Friend Lens interface for creating content. 


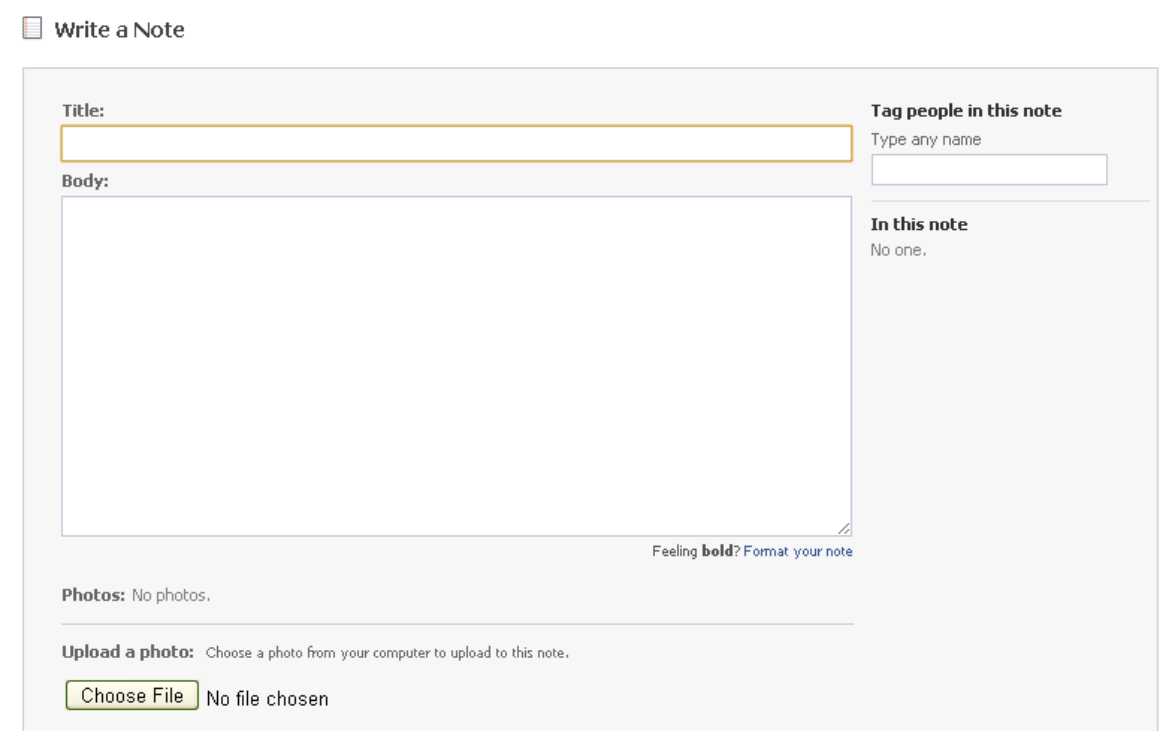

Figure 5-9: Facebook note interface.

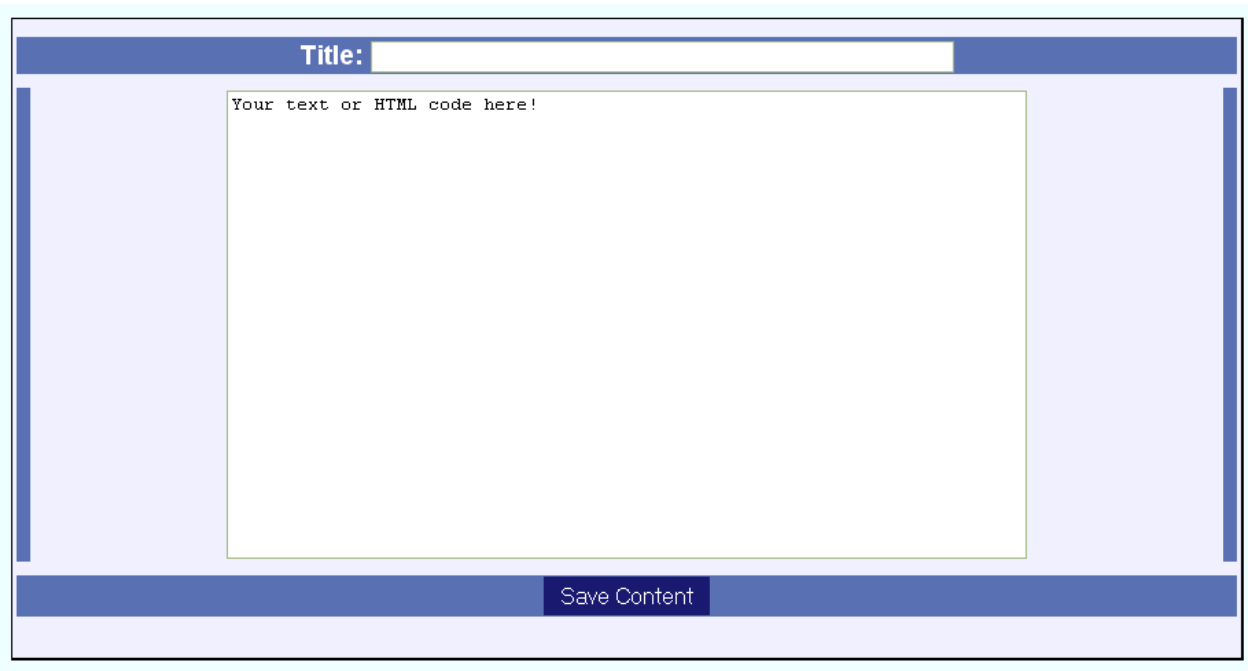

Figure 5-10: Friend Lens post interface.

Facebook has a more robust interface, with options for adding photos, adjusting privacy, and tagging friend, but the interface for creating the content are identical. This interface is a very general interface used by nearly all major blogs and forums.

\subsubsection{Ease of adding pictures}


Figure 5-11 contains the averaged rankings for "ease of adding pictures" from the human subject experiments.

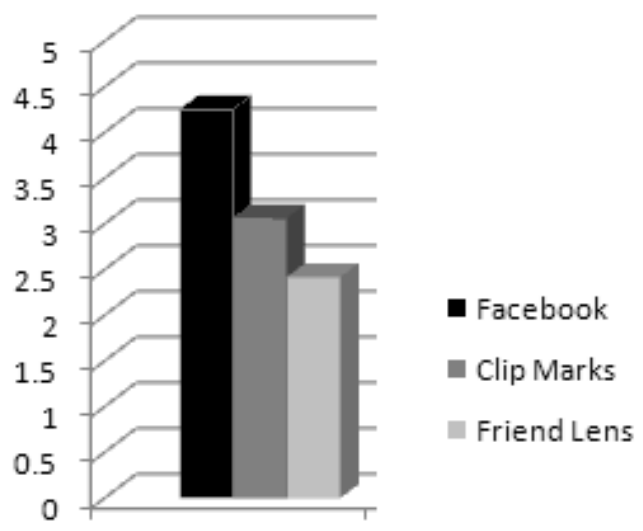

Figure 5-11: Ease of adding pictures.

Facebook is extremely well adept at adding pictures. It has a Java utility that allows users to upload pictures in bulk, making it the only one of these three applications able to do so. Clip Marks and Friend Lens cannot upload images from disk; images must be added from an existing image URL. Clip Marks can add images much easier than Friend Lens since the only method of adding images to Friend Lens is to know the required HTML in order to embed the image in a user created post. In theory, the user could use Friend Lens' external page caches, but that would bring along any images contained in the page without any means to filter out the unwanted images.

\subsubsection{Ease of adding links to other sites}

Figure 5-12 contains the averaged rankings for "ease of adding links to other sites" from the human subject experiments. 


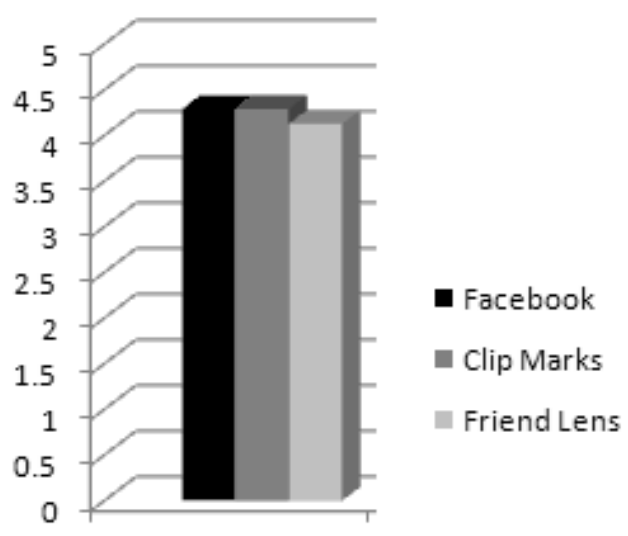

Figure 5-12: Ease of adding links to other sites.

Clip Mark and Facebook both provide automatic link creation if the user can copy and paste a URL. Friend Lens automatically generates links for all external posts but for users to have links embedded in a post authored by them, they have to know the required HTML for generating a hyperlink.

\subsubsection{Ability to post content for external sites to your blog/home page}

Figure 5-13 contains the averaged rankings for "ability to post content for external sites to your blog/home page" from the human subject experiments. 


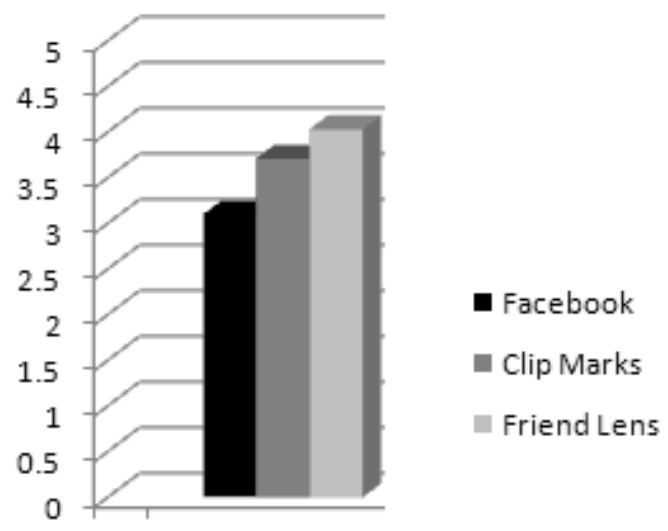

Figure 5-13: Ability to post content from external sites to your blog/home page.

The only expected result for this question was for Facebook to score lowest. Facebook only imports a caption and generates a link for external content (Facebook can currently handle embedded video). Clip Marks and Friend Lens are unique in the sense that they allow for the extraction of external content. The difference in scores between Clip Marks and Friend Lens is explained by how the external content is extracted. The lower score indicates that hand picking individual items for extraction is more difficult for users than extracting the entire page. This is not unexpected though, since the Friend Lens interface was designed to be as simple as possible; users only have to be able to copy and paste a URL in order to post external content.

\subsubsection{Ability to comment on the posts/pages of other users}

Figure 5-14 contains the averaged rankings for "ability to comment on the posts/pages of other users" from the human subject experiments. 


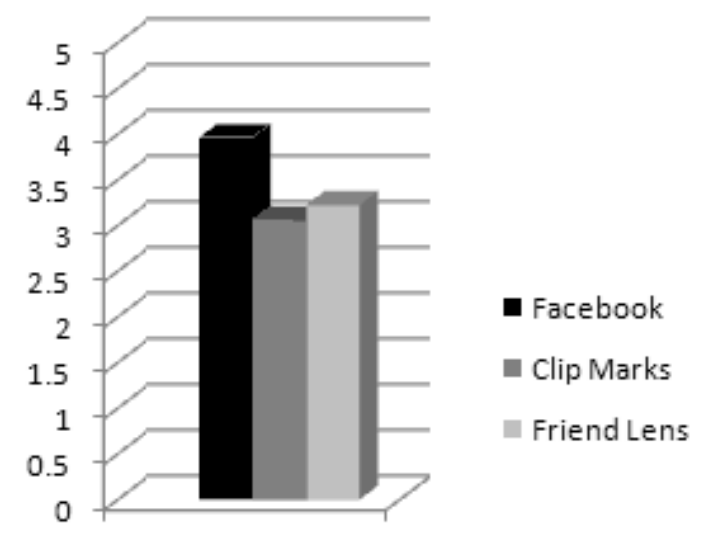

Figure 5-14: Ability to comment on the posts/pages of other users.

Facebook incorporates feedback into all possible user activity and does so very intuitively. When a user is looking at a post (known as a note on Facebook), picture, or status a comment button is always attached. Clip Marks and Friend Lens, although having fewer things to comment, allow for commenting in the same way. The main advantage is that clicking the link uses AJAX to generate a box for leaving comments as oppose to taking them to another page. The most important conclusion from this question is that users gave lower scores to any interface that interrupts their interaction with a page transfer.

\subsection{Practicality of Use Results Analysis}

\subsubsection{The ability of allowing others to edit/comment on material you authored}

Figure 5-15 contains the averaged rankings for "the ability of allowing others to edit/comment on material you authored" from the human subject experiments. 


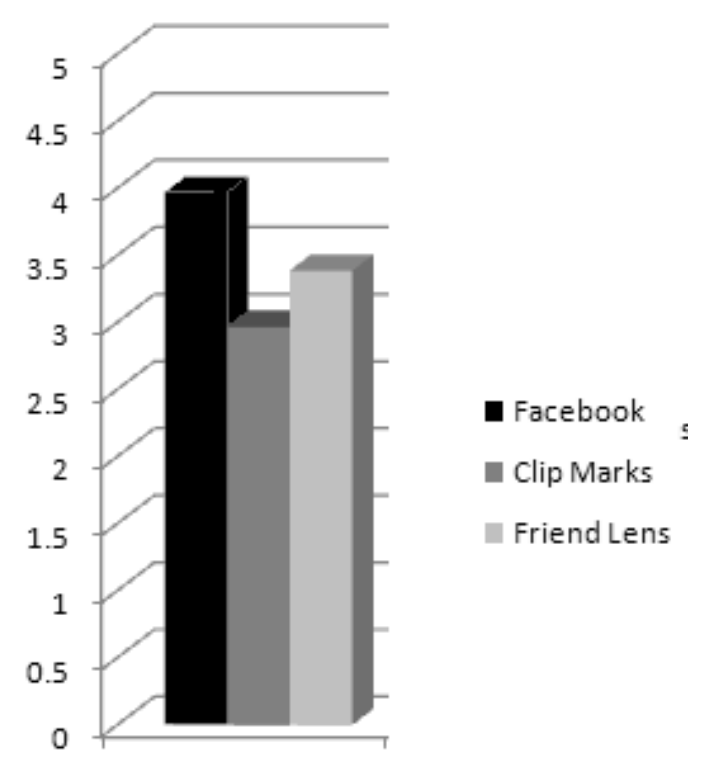

Figure 5-15: The ability of allowing other to edit/comment on material you authored.

This question deals with the author's control over the editing/commenting by others. Facebook is the only candidate that allows for user controlled restrictions on these. In Facebook, privacy settings can be adjusted to allow only certain users to see content posted and thus, restrict the users that are allowed to edit/comment to a subset of all friends. Clip Marks and Friend Lens both follow a "public by default" approach. The only restriction on commenting is that a commenter must be a member of the same site.

\subsubsection{The ability to stay in touch with people you know}

Figure 5-16 contains the averaged rankings for "the ability to stay in touch with people you know" from the human subject experiments. 


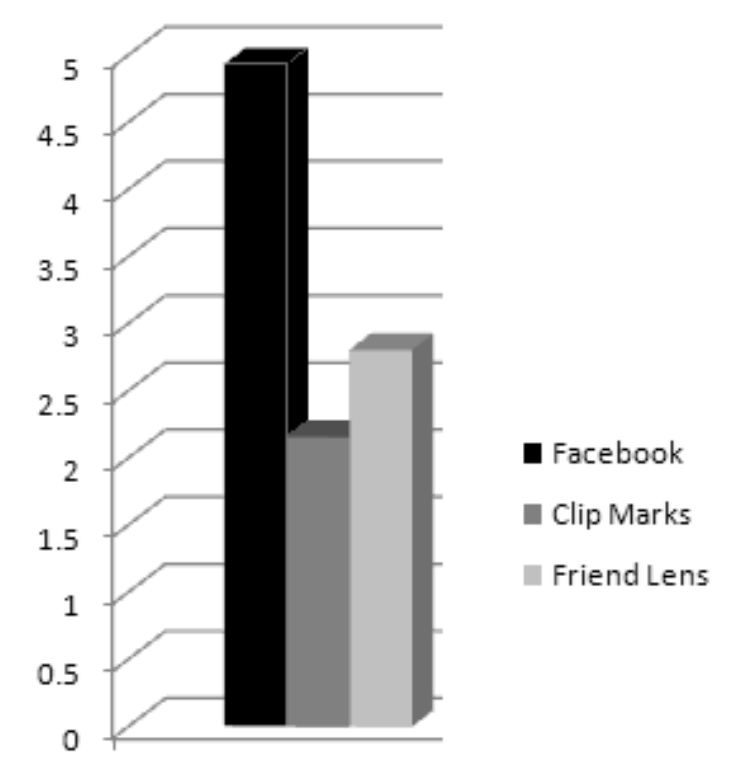

Figure 5-16: The ability to stay in touch with people you know.

Facebook is the clear winner, as expected, in this category. Staying in touch with people is the purpose of Facebook, where as the purpose of Clip Marks and Friend Lens is content presentation. These scores can be explained by a simple comparison of tools that each site offers for social networking, as shown in Table 5-6.

\begin{tabular}{|l|}
\hline \multicolumn{1}{|c|}{ Social Networking } \\
$\begin{array}{l}\text { User profiles with } \\
\text { personal information }\end{array}$ \\
\hline $\begin{array}{l}\text { Friends, a mechanism } \\
\text { to give users privacy } \\
\text { control. When two } \\
\text { users are "friends" both } \\
\text { users are notified and } \\
\text { now receive automatic } \\
\text { updates regarding their } \\
\text { friends activity }\end{array}$ \\
\hline
\end{tabular}




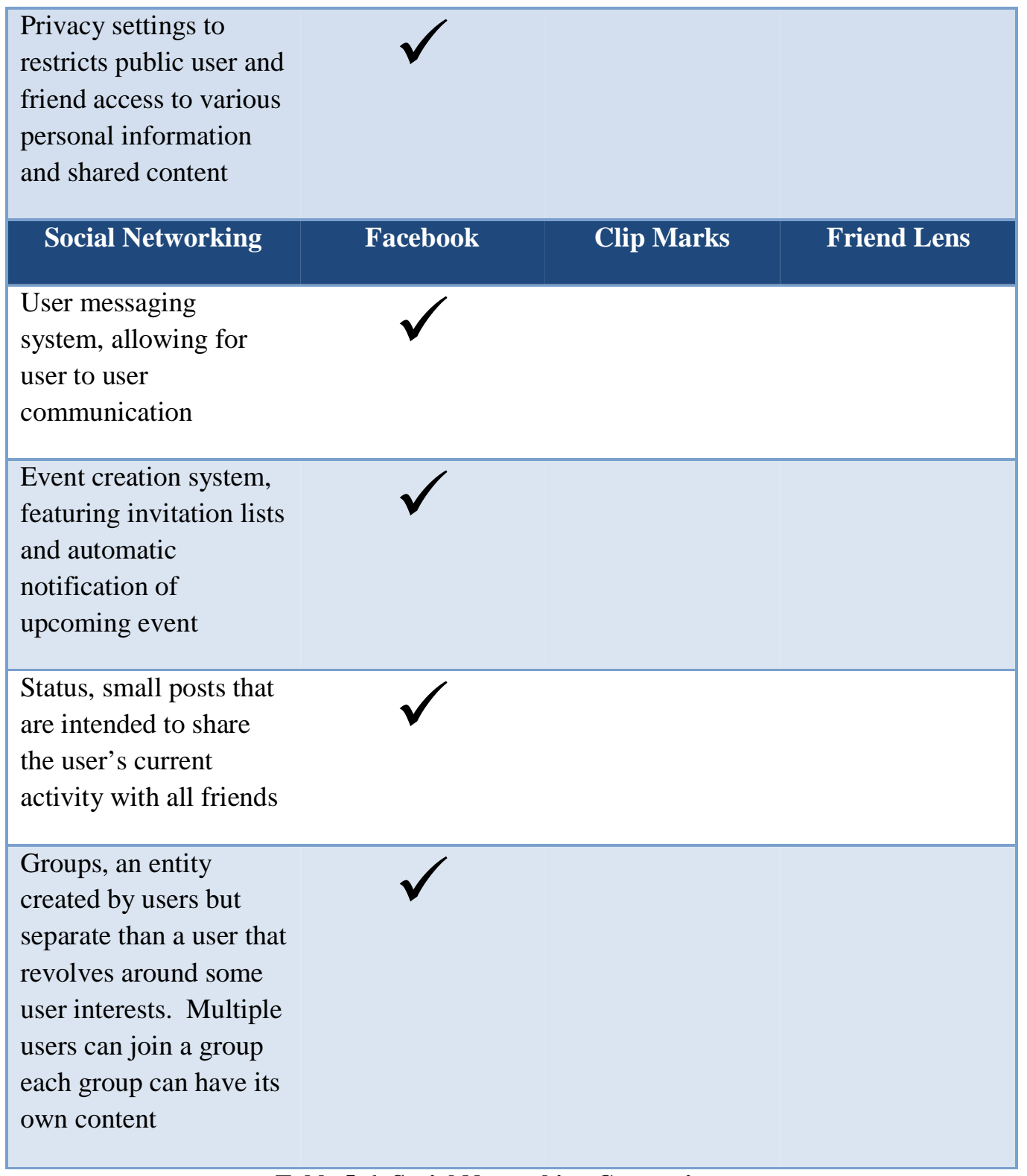

Table 5-6: Social Networking Comparison.

It should be noted that although Friend Lens has an entity known as a "group," it is not a group that can users can join and use for socializing. A group in Friend Lens is used only for highlight organization.

Table 5-6 illustrates why Facebook was the clear winner, but does not explain why Friend Lens, with no social networking capabilities, would score higher than Clip Marks. One explanation 
could be that a user being able to author original content, something impossible in Clip Marks, is considered as a mean of staying in touch. Another possible explanation is that the feedback system in Friend Lens is a better means for users to communicate than the feedback system in Clip Marks. This will be further discussed in the future work section.

\subsubsection{The ability to save content from your favorite web sites}

Figure 5-17 contains the averaged rankings for "the ability to stay in touch with people you know" from the human subject experiments.

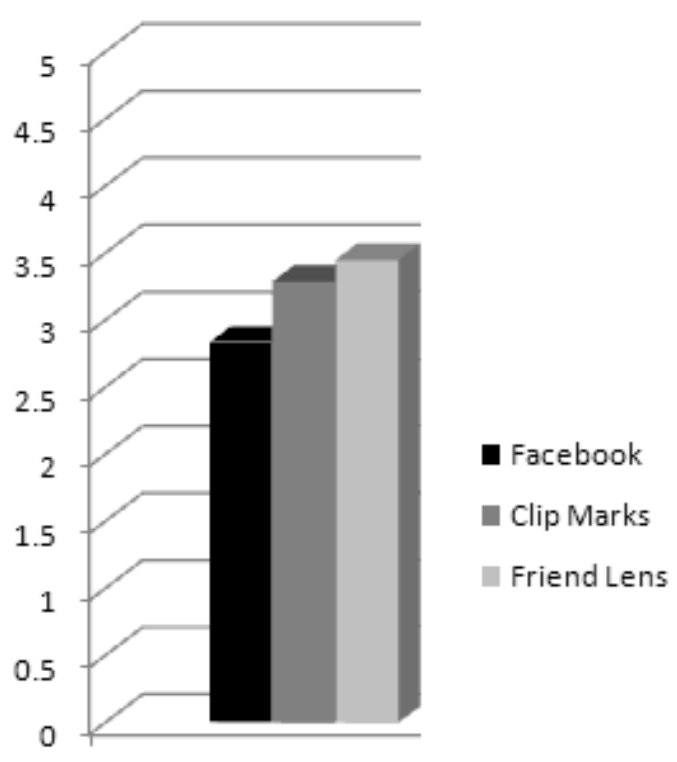

Figure 5-17: Ability to save content from your favorite sites.

This is the area that Friend Lens was designed to improve upon and results indicate success. Friend Lens was designed to allow users to save copies of entire web pages without the installation of a plug-in. Before testing began there was suspicion that Clip Mark required plugin installation would lead to lower scores. However, Facebook does not require the installation of 
a plug-in for external content extraction, but still scored the lowest. This indicates that users prefer completeness of external content extraction. Since Friend Lens is the only application that can capture an external web page's entire source, it is logical to deduce that is why it scored the highest.

\subsubsection{The ability to allow others to see the web sites you visit/enjoy most}

Figure 5-18 contains the averaged rankings for "the ability to allow other to see the web sites you visit/enjoy most" from the human subject experiments.

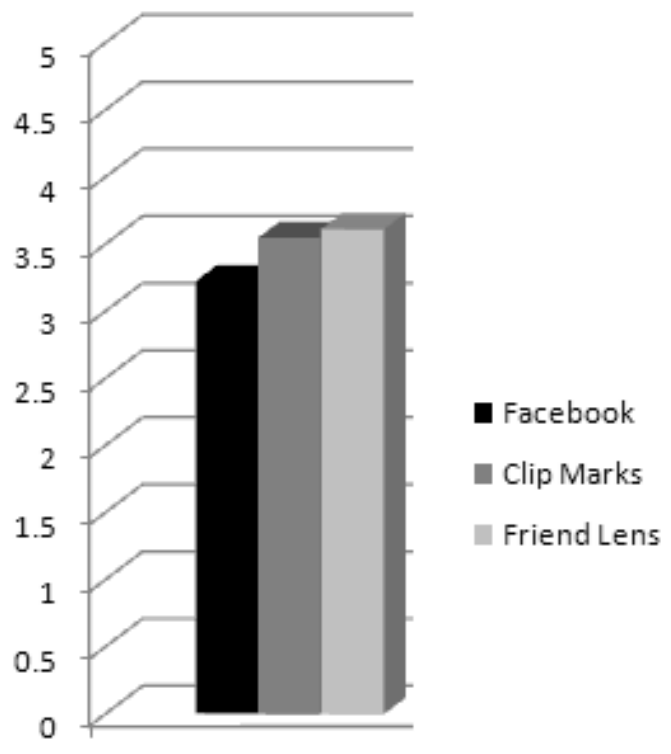

Figure 5-18: The ability to allow others to see the web sites you visit/enjoy most.

It is not unexpected that the sites that are best at saving and posting external content would also score the highest in this category. This category was designed to see if the extraction of external content could be used to detect trends in user activity. Seeing as Facebook extracts the least from any external page, only images, links, video, and captions, it is now obvious that the methods 
implemented by Clip Marks and Friend Lens are better for showing what other sites a user visits/enjoys most.

\subsubsection{Usability for peers to review your work}

Figure 5-19 contains the averaged rankings for "usability for peers to review your work" from the human subject experiments.

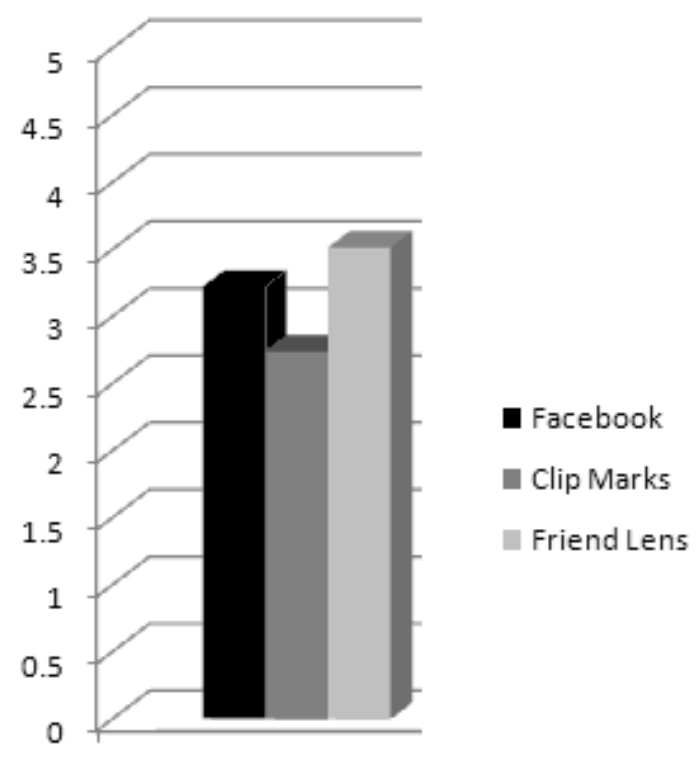

Figure 5-19: Usability for peers to review your work.

This question was used to gain insight into the usefulness of the combination commenting and highlighting that Friend Lens offers. Although all of these sites allows for work to be shown to other users and for feedback to be given, Friend Lens is the only site that allows for direction interaction with the original post. Friend Lens allowing the combination of highlighting text or an image, then creating a comment corresponding with those highlights gives the user more tools for peer revision. Possible extensions to the highlighting and commenting features will be discussed in the future work. 


\subsubsection{Usability for your profession}

Figure 5-20 contains the averaged rankings for "usability for your profession" from the human subject experiments.

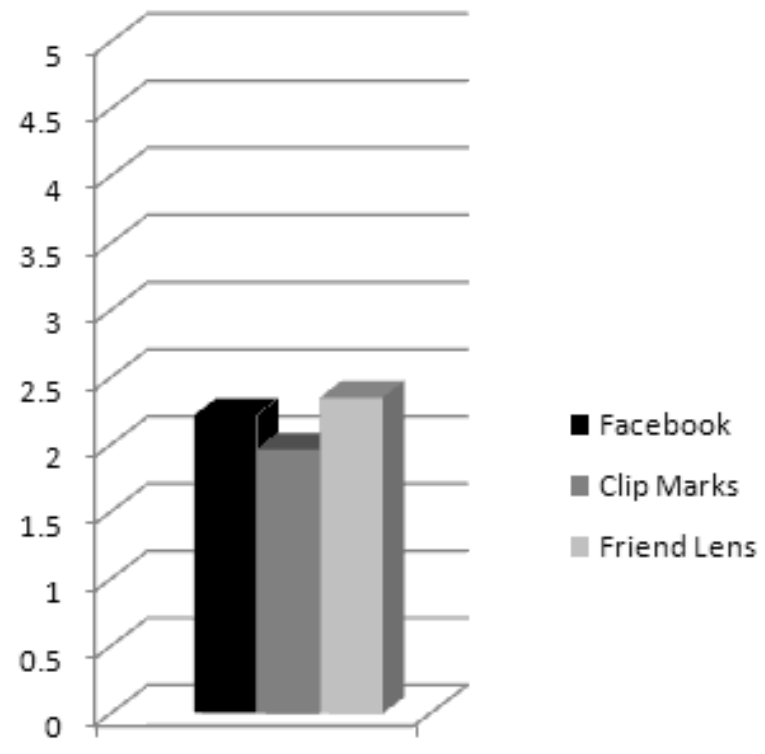

Figure 5-20: Usability for your profession

With these results, it is less important to declare a winner, but to rather note how poorly all sites scored, as listed in Table 5-7:

\begin{tabular}{|c|c|}
\hline & $\begin{array}{l}\text { Usability for your } \\
\text { profession }\end{array}$ \\
\hline Facebook & 2.2258 \\
\hline Clip Marks & 1.9677 \\
\hline Friend Lens & 2.3548 \\
\hline
\end{tabular}

Table 5-7: Usability for Profession Scores 
Even though Friend Lens has the highest score, no site scored above a 2.5 which indicates users would not likely use any for professional use. For explanation, there are two areas to be examined:

1) The tools each site offers for professionals.

2) Appeal of each site to professionals.

All sites allow users to communicate with other users either through direct messaging or through feedback left in comments. All sites allow for the creation and sharing of original content. The question remains, "what do professionals want to use a site for?" Possible answers and expansions to Friend Lens will be discussed in section 6 . 


\section{Conclusion}

\subsection{Summary}

Web applications are now a part of our everyday lives and more and more people are sharing content online. The way people share content has not changed significantly over the last decades and new methods for content sharing and online collaboration are needed. Blogs and social networks are need of improvement and the incorporation of external content and improving feedback are areas that needs more exploration.

\subsection{Contributions}

Friend Lens introduced many novel approaches to the blogging, user feedback, and collaboration. Friend Lens introduced the ability to extract entire web pages as user posts. From there, a user can use comments and the novel approach of highlights as feedback. Friend Lens introduced highlight composites allowing users to quickly summarize and analyze the feedback from others. The addition of groups allows for the organization of user feedback to further improve the quality of user feedback. All of these contributions were implemented using existing, open source technology.

In order to evaluate the usefulness of Friend Lens' new features a user survey was conducted with 31 anonymous users to evaluate Facebook, Clip Marks, and Friend Lens. The results were presented and evaluated thoroughly.

The results of the human subject experiments showed that Friend Lens improved upon both Facebook and Clip Marks in the following areas: 
- The ability to post content from external sites to one's blog/home page

- The ability to allow others to see the web sites one visits/enjoys most

- Usability for peers to review one's work

- Usability for one's profession

The results of the human subject experiments showed that Friend Lens Improved upon Clip Marks in the following areas:

- Intuitiveness of finding other users

- Creating new content authored by users

- The ability to comment on posts/pages of other users

- The ability of allowing others to edit/comment on material authored by users

- The ability to stay in touch with people a user knows

The results of the human subject experiments showed that Friend Lens did the poorest in the following areas:

- Ease of presenting content to the public

- Ease of sharing content with friends

- Ease of monitoring the activity of other users

- Ease of adding pictures

- Ease of adding links to other sites

\subsection{Limitations and Future Work}

Friend Lens does not support all valid URLs. All possible forms of generating links, incorporating styling, and embedded objects that depend upon local files may cause viewing problems. 


\subsubsection{Expanding the functionality of highlighting various object in a web page}

The highlight interface is currently very limited. There are many features that could help improve the user experience when highlighting or viewing highlights:

- Highlight color selection

- Embedded object highlights

- Composite of image highlights

\subsubsection{Extract data from user activity in order to enhance their experience}

One of the motivations of Friend Lens was to show users, quickly and easily, what parts of their post fellow Friend Lens users cared about most. With this in mind, it would beneficial to add in automated interest tracking. There are many different sources of data that can be used to gain information regarding user interest:

- Sources of a users external posts

- Common titles or phrases in posts

- Text that user commonly highlights

- Areas of interest to which users subscribe

\subsubsection{Allow for asynchronous collaboration on a single document}

The next step beyond merely highlighting a post is for collaborative highlight, commenting, and even editing of a post. Since Friend Lens already preserves a copy of all edits to a post, this could be implemented without harming any current functionality and would be easily incorporated into the current architecture. As shown from the results, Friend Lens scored the highest in the areas of "review for work" and "use for profession." 


\subsubsection{Web browsing from within Friend Lens for external page posting}

Friend Lens currently has the capability to view external pages, but if a user begins browsing that external page (clicking links, loading videos, etc.) there is not a guarantee that all links will work. If a link is dynamically generated using a scripting language, such as JavaScript, the language is able to detect that the code is not being hosted on the expected and can behave in unpredictable ways. To address this, Friend Lens forces links within cached pages to open in a new window. A desirable behavior would be for the cached version of the external page to behave exactly as the original copy. 


\section{Bibliography}

1. “Apache Friend - XAMPP" http://www.apachefriends.org/en/xampp.html Retrieved 2007-08.

2. "After 10 Years of Blogs, the Future's Brighter Than Ever". Retrieved 2009-10-06.

3. "Ajax Tutorial". http://www.w3schools.com/Ajax/Default.Asp Retrieved 2008-10.

4. "Blog - Google Search". http://google.com Retrieved 2009-11-27.

5. "Browser Statistics". http://www.w3schools.com/browsers/browsers_stats.asp Retrieved 2008-12, 2009-10-06.

6. "Bulletin Community Forum - FAQ: What is a bulletin board?". vBulletin.com. Retrieved 2009-1127.

7. “Clip Marks" http://clipmarks.com/ Retrieved 2008-10.

8. "Design Patterns" http://msdn.microsoft.com/en-us/library/ms998478. aspx Retrieved 2009-10-06.

9. "Facebook - Now connecting 250 million people". http://blog.facebook.com/blog.php?post=106860717130 Retrieved 2009-11-27.

10. "Google Docs Tour". http://www.google.com/google-d-s/tour1.html Retrieved 2008-11.

11. "It's the links, stupid". The Economist. 2006-04-20. Retrieved 2009-10-06.

12. Kottke, Jason (2003-08-26). "kottke.org". Retrieved 2009-10-06.

13. Merholz, Peter (1999). "Peterme.com". The Internet Archive. Archived from the original on 1999-1013. Retrieved 2009-10-06.

14. "Organizing for America | BarackObama.com | OFA Blog". http://my.barackobama.com/page/content/hqblog Retrieved 2009-11-15.

15. "Origins of "Blog" and "Blogger", American Dialect Society Mailing List (Apr. 20, 2008).

16. "PHP: PHP Manual - Manual" http://www.php.net/manual/en/index.php Retrieved 2008-10.

17. "phpBB History". http://www.phpbb.com/about/history Retrieved 2009-11.22.

18. "The Architecture of Web Applications" http://www.ibm.com/developerworks/ibm/library/itbooch_web/ Retrieved 2009-11-02.

19. "The Development of Social Network Analysis Vancouver". Linton C. Freeman. Vancouver, CA: Empirical Press, 2004.

20. "W3Schools Online Web Tutorials". http://www.w3schools.com

21. "Weblogs: A History And Perspective, Rebecca Blood, September 7, 2000.

22. "Web Developer: Add-ons for Firefox". https://addons.mozilla.org/en-US/firefox/addon/60 Retrieved 2008-11. 


\section{Appendices}

\section{Appendix A) User Instruction for survey}

\section{Instructions}

\section{Hello User,}

Thank you participating in this user survey of the following web applications:

Facebook

Clip Marks

Friend Lens

To participate in this survey you must meet the following minimum requirements:

1. If not already installed, install Firefox 3.0 or greater. (Internet Explorer and Chrome will not benefit our survey. We also request that all participants use the same web browser in the hopes to removing interface inconsistencies)

2. Create an account at each site

3. If any of the web applications require a firefox plug-in please follow the instructions on the respective site in order to do so. (Note: Installation of Facebook "Apps" are not required for this survey)

The survey that you will take can be found at http://friendlens.no-ip.org (it is a large link in the top menu after login)

Part of the survey is to evaluate the ease and intuitiveness of using a particular site, so you will not be given instructions here. In other words, it up the each web application to teach you how to use it. Feel free to look over the survey before you begin to ensure that you can confidently reply to all questions.

Important notes:

1. If any web site is unreachable or down, please notify the survey coordinator, John Gibbons atjwgibbo@gmail.com, immediately

2. Remember to be as unbiased in your responses as possible. Do not allow prior familiarity with any of the web applications or knowledge of the origins of a web application to influence your responses.

3. This is an open survey. You can forward this email to anyone you wish as long as they will follow all of the instructions.

4. All survey submissions are anonymous. You do not have to submit or post personal information if you do not want to.

Web Site URLs

Facebook: http://facebook.com

Clip Marks: http://clipmarks.com

Friend Lens: http://friendlens.no-ip.org

Thank you very much for your time. It is greatly appreciated.

\section{Appendix B) Survey}


NOTE: You must have first used Friend Lens (http://Friend Lens.no-ip.org), Facebook (http://facebook.com), and Clip Marks (http://clipmarks.com) long enough to answer the questions found in this survey. You CANNOT SAVE, so please look over all questions and be prepared to complete the entire survey.

This survey is not a ranking of the applications used. Rank each web application independently (i.e. different applications can receive the same score in the same category).

Evaluate the following for the respective web applications.

* Required

\section{Community}

Intuitiveness of finding other users. *Facebook

\begin{tabular}{lllllll}
0 & 1 & 2 & 3 & 4 & 5 \\
\hline
\end{tabular}

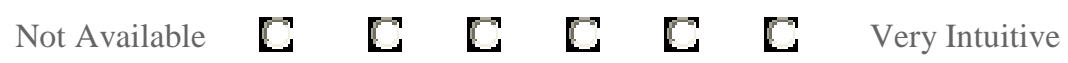

Intuitiveness of finding other users. *Clip Marks

$\begin{array}{llllll}0 & 1 & 2 & 3 & 4 & 5\end{array}$

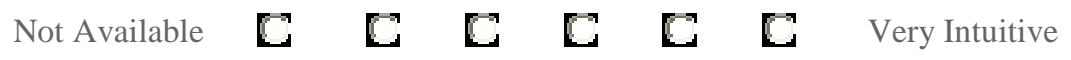

Intuitiveness of finding other users. *Friend Lens

$\begin{array}{llllll}0 & 1 & 2 & 3 & 4 & 5\end{array}$

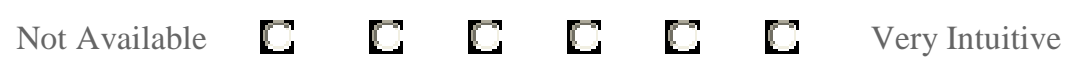

Ease of presenting content to the public. *Facebook

$\begin{array}{llllll}0 & 1 & 2 & 3 & 4 & 5\end{array}$




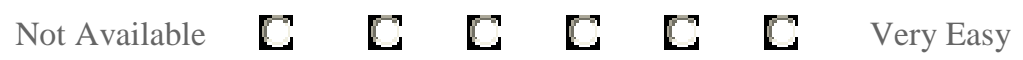

Ease of presenting content to the public. *Clip Marks

$\begin{array}{llllll}0 & 1 & 2 & 3 & 4 & 5\end{array}$

$\begin{array}{llllllll}\text { Not Available } & \mathbf{C} & \mathbf{C} & \mathbf{C} & \mathbf{C} & \mathbf{C} & \mathbf{C} & \text { Very Easy }\end{array}$

Ease of presenting content to the public. *Friend Lens

$\begin{array}{llllll}0 & 1 & 2 & 3 & 4 & 5\end{array}$

$\begin{array}{llllllll}\text { Not Available } & \mathbf{C} & \mathbf{C} & \mathbf{C} & \mathbf{C} & \mathbf{C} & \mathbf{C} & \text { Very Easy }\end{array}$

Ease of sharing content with friends (users on the same site). *Facebook

$\begin{array}{llllllll} & 0 & 1 & 2 & 3 & 4 & 5 & \\ \text { Not Available } & \mathbb{C} & \mathbb{C} & \mathbb{C} & \mathbb{C} & \mathbb{C} & \mathbb{C} & \text { Very Easy }\end{array}$

Ease of sharing content with friends (users on the same site). ${ }^{*}$ Clip Marks

$\begin{array}{llllllll} & 0 & 1 & 2 & 3 & 4 & 5 & \\ \text { Not Available } & \boldsymbol{C} & \boldsymbol{C} & \boldsymbol{C} & \boldsymbol{C} & \mathbb{C} & \boldsymbol{C} & \text { Very Easy }\end{array}$

Ease of sharing content with friends (users on the same site). *Friend Lens

$\begin{array}{llllll}0 & 1 & 2 & 3 & 4 & 5\end{array}$

$\begin{array}{llllllll}\text { Not Available } & \mathbf{C} & \mathbf{C} & \mathbf{C} & \mathbf{C} & \mathbf{C} & \mathbf{C} & \text { Very Easy }\end{array}$ 
Ease of monitoring the activity of other users. *Facebook

$\begin{array}{lllllllll} & 0 & 1 & 2 & 3 & 4 & 5 & \\ \text { Not Available } & \boldsymbol{C} & \boldsymbol{C} & \boldsymbol{C} & \boldsymbol{C} & \boldsymbol{C} & \boldsymbol{C} & \text { Very Easy }\end{array}$

Ease of monitoring the activity of other users. *Clip Marks

$\begin{array}{llllll}0 & 1 & 2 & 3 & 4 & 5\end{array}$

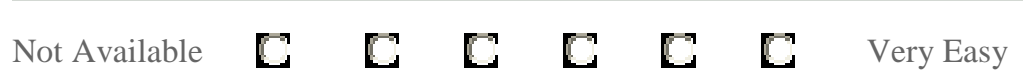

Ease of monitoring the activity of other users. *Friend Lens

$\begin{array}{llllll}0 & 1 & 2 & 3 & 4 & 5\end{array}$

$\begin{array}{llllllll}\text { Not Available } & \mathbf{C} & \mathbf{C} & \mathbf{C} & \mathbf{C} & \mathbf{C} & \mathbf{C} & \text { Very Easy }\end{array}$

\section{Posting Content}

Ease of creating new content authored by you. *Facebook

\begin{tabular}{llllllll}
0 & 1 & 2 & 3 & 4 & 5 \\
\hline
\end{tabular}

$\begin{array}{llllllll}\text { Not Available } & \mathbf{C} & \mathbf{C} & \mathbf{C} & \mathbf{C} & \mathbf{C} & \mathbf{C} & \text { Very Easy }\end{array}$

Ease of creating new content authored by you. *Clip Marks

\begin{tabular}{llllllll}
0 & 1 & 2 & 3 & 4 & 5 \\
\hline
\end{tabular}

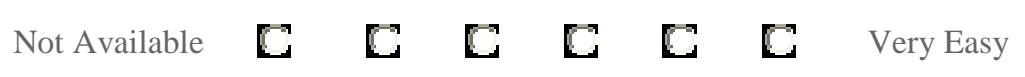

Ease of creating new content authored by you. *Friend Lens 


$\begin{array}{llllllll} & 0 & 1 & 2 & 3 & 4 & 5 & \\ \text { Not Available } & \mathbb{C} & \mathbb{C} & \mathbb{C} & \mathbb{C} & \mathbb{C} & \mathbb{C} & \text { Very Easy }\end{array}$

Ease of adding pictures *Facebook

$\begin{array}{lccccccc} & 0 & 1 & 2 & 3 & 4 & 5 & \\ \text { Not Available } & \mathbb{C} & \mathbb{C} & \mathbb{C} & \mathbb{C} & \mathbb{C} & \mathbb{\square} & \text { Very Easy }\end{array}$

Ease of adding pictures *Clip Marks

\begin{tabular}{lllllll}
0 & 1 & 2 & 3 & 4 & 5 \\
\hline
\end{tabular}

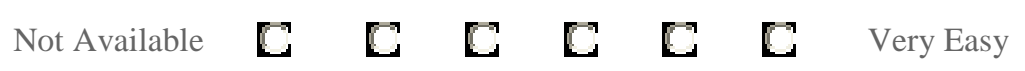

Ease of adding pictures *Friend Lens

$\begin{array}{llllllll} & 0 & 1 & 2 & 3 & 4 & 5 & \\ \text { Not Available } & \mathbb{C} & \mathbb{C} & \mathbb{C} & \mathbb{C} & \mathbb{C} & \boldsymbol{C} & \text { Very Easy }\end{array}$

Ease of adding links to other sites *Facebook

$\begin{array}{llllll}0 & 1 & 2 & 3 & 4 & 5\end{array}$

$\begin{array}{llllllll}\text { Not Available } & \mathbb{C} & \boldsymbol{C} & \boldsymbol{C} & \mathbb{C} & \mathbb{C} & \mathbb{C} & \text { Very Easy }\end{array}$

Ease of adding links to other sites *Clip Marks

$\begin{array}{lllllllll} & 0 & 1 & 2 & 3 & 4 & 5 & \\ \text { Not Available } & \mathbb{C} & \boldsymbol{C} & \boldsymbol{C} & \boldsymbol{C} & \boldsymbol{C} & \boldsymbol{C} & \text { Very Easy }\end{array}$


Ease of adding links to other sites *Friend Lens

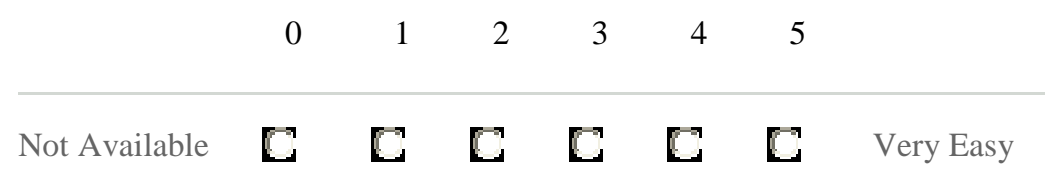

Ability to post content for external sites to your blog/home page. *Facebook

$\begin{array}{rlllllllll} & 0 & 1 & 2 & 3 & 4 & 5 & \\ \begin{array}{r}\text { Cannot include content from } \\ \text { external sites. }\end{array} & \mathbf{C} & \mathbf{C} & \mathbf{C} & \mathbf{C} & \mathbf{C} & \mathbf{C} & \begin{array}{l}100 \% \text { of external content can } \\ \text { be posted }\end{array}\end{array}$

Ability to post content for external sites to your blog/home page. ${ }^{*}$ Clip Marks

$\begin{array}{llllll}0 & 1 & 2 & 3 & 4 & 5\end{array}$
Cannot include content from external sites. $\mathbb{E} \mathbb{G} \boldsymbol{G} \mathbb{G} \quad \begin{aligned} & 100 \% \text { of external content can } \\ & \text { be posted }\end{aligned}$

Ability to post content for external sites to your blog/home page. *Friend Lens

$$
\begin{array}{llllll}
0 & 1 & 2 & 3 & 4 & 5
\end{array}
$$
Cannot include content from external sites.

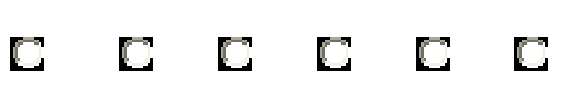
$100 \%$ of external content can be posted

Ability to comment on the posts/pages of other users. *Facebook

$\begin{array}{llllll}0 & 1 & 2 & 3 & 4 & 5\end{array}$

Cannot comment $\mathbb{G} \mathbb{G} \mathbf{C} \mathbb{G}$ Highly complex complex commenting available

Ability to comment on the posts/pages of other users. *Clip Marks 


$\begin{array}{llllllll} & 0 & 1 & 2 & 3 & 4 & 5 & \\ \text { Cannot comment } & \mathbb{C} & \mathbb{C} & \mathbf{C} & \mathbb{C} & \mathbb{C} & \mathbb{C} & \text { Highly complex complex commenting available }\end{array}$

Ability to comment on the posts/pages of other users. *Friend Lens

$\begin{array}{llllll}0 & 1 & 2 & 3 & 4 & 5\end{array}$

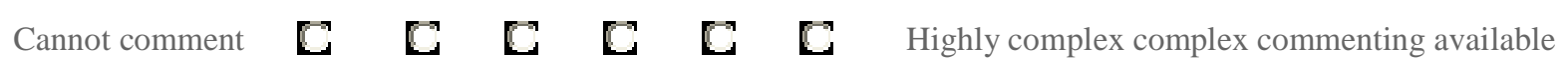

Rank the likelihood of using the application: for the following

The ability of allowing others to edit/comments on material you authored *Facebook

\begin{tabular}{lllll}
1 & 2 & 3 & 4 & 5 \\
\hline
\end{tabular}

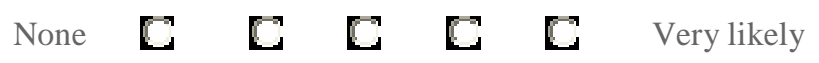

The ability of allowing others to edit/comments on material you authored $*$ Clip Marks

$\begin{array}{lllll}1 & 2 & 3 & 4 & 5\end{array}$

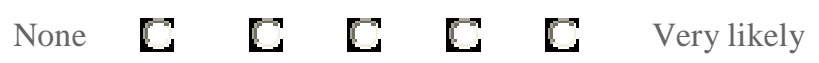

The ability of allowing others to edit/comments on material you authored *Friend Lens

\begin{tabular}{llllll}
1 & 2 & 3 & 4 & 5 \\
\hline
\end{tabular}

$\begin{array}{lllllll}\text { None } & \mathbf{C} & \mathbf{C} & \mathbf{C} & \mathbf{C} & \mathbf{C} & \text { Very likely }\end{array}$

The ability to stay in touch with people you know *Facebook 


$\begin{array}{lllllll} & 1 & 2 & 3 & 4 & 5 & \\ \text { None } & \boldsymbol{\square} & \boldsymbol{C} & \boldsymbol{C} & \boldsymbol{C} & \boldsymbol{C} & \text { Very likely }\end{array}$

The ability to stay in touch with people you know *Clip Marks

\begin{tabular}{lllllll} 
& 1 & 2 & 3 & 4 & 5 & \\
\hline None & $\boldsymbol{C}$ & $\boldsymbol{C}$ & $\boldsymbol{C}$ & $\boldsymbol{C}$ & $\boldsymbol{C}$ & Very likely
\end{tabular}

The ability to stay in touch with people you know *Friend Lens

\begin{tabular}{llllll}
1 & 2 & 3 & 4 & 5 \\
\hline
\end{tabular}

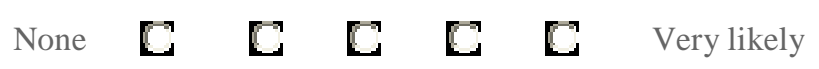

The ability to save content from your favorite web sites *facebook

$\begin{array}{lllllll} & 1 & 2 & 3 & 4 & 5 & \\ \text { None } & \mathbb{C} & \boldsymbol{C} & \boldsymbol{C} & \boldsymbol{C} & \boldsymbol{C} & \text { Very likely }\end{array}$

The ability to save content from your favorite web sites *Clip Marks

$\begin{array}{lllllll} & 1 & 2 & 3 & 4 & 5 & \\ \text { None } & \boldsymbol{C} & \mathbb{C} & \boldsymbol{C} & \boldsymbol{C} & \boldsymbol{C} & \text { Very likely }\end{array}$

The ability to save content from your favorite web sites *Friend Lens

$\begin{array}{lllllll} & 1 & 2 & 3 & 4 & 5 & \\ \text { None } & \boldsymbol{C} & \boldsymbol{C} & \boldsymbol{C} & \boldsymbol{C} & \mathbb{C} & \text { Very likely }\end{array}$


The ability to allow others to see the web sites you visit/enjoy most *Facebook

$\begin{array}{rrrrrrr}1 & 2 & 3 & 4 & 5 & \\ \text { None } & \boldsymbol{E} & \boldsymbol{C} & \boldsymbol{C} & \boldsymbol{C} & \boldsymbol{C} & \text { Very likely }\end{array}$

The ability to allow others to see the web sites you visit/enjoy most *Clip Marks

\begin{tabular}{llllll}
1 & 2 & 3 & 4 & 5 \\
\hline
\end{tabular}

\begin{tabular}{|c|}
\hline \\
\hline \\
\hline \\
\hline \multirow[t]{4}{*}{$\Gamma \Gamma \Gamma \Gamma$} \\
\hline \\
\hline \\
\hline \\
\hline \\
\hline
\end{tabular}

The ability to allow others to see the web sites you visit/enjoy most *Friend Lens

$\begin{array}{rrrrrrr} & 1 & 2 & 3 & 4 & 5 & \\ \text { None } & \mathbb{C} & \mathbb{C} & \boldsymbol{C} & \boldsymbol{C} & \mathbb{C} & \text { Very likely }\end{array}$

Usability for peers to review your work. *Facebook

$\begin{array}{rrrrrrr} & 1 & 2 & 3 & 4 & 5 & \\ \text { None } & \mathbb{C} & \mathbb{C} & \mathbb{C} & \mathbb{C} & \mathbb{C} & \text { Very likely }\end{array}$

Usabilty for peers to review your work. *Clip Marks

$\begin{array}{lrrrrrr} & 1 & 2 & 3 & 4 & 5 & \\ \text { None } & \mathbb{C} & \mathbb{C} & \boldsymbol{C} & \mathbb{C} & \mathbb{C} & \text { Very likely }\end{array}$

Usability for peers to review your work. *Friend Lens 


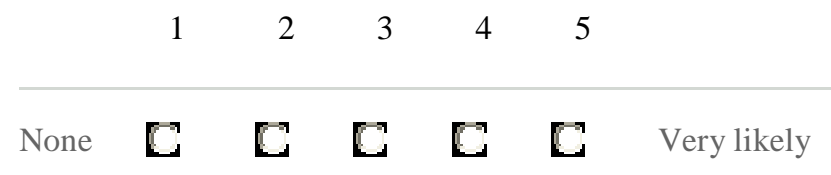

Usability for your profession *Facebook

$\begin{array}{lllllll} & 1 & 2 & 3 & 4 & 5 & \\ \text { None } & \boldsymbol{C} & \mathbb{C} & \mathbb{C} & \mathbb{C} & \mathbb{C} & \text { Very likely }\end{array}$

Usability for your profession *Clip Marks

\begin{tabular}{llllll}
1 & 2 & 3 & 4 & 5 \\
\hline
\end{tabular}

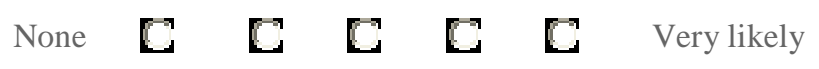

Usability for your profession *Friend Lens

\begin{tabular}{llllll}
1 & 2 & 3 & 4 & 5 \\
\hline
\end{tabular}

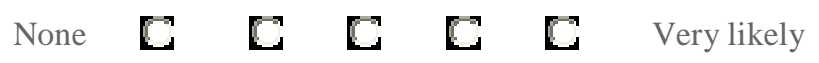

Addition comments for any of the

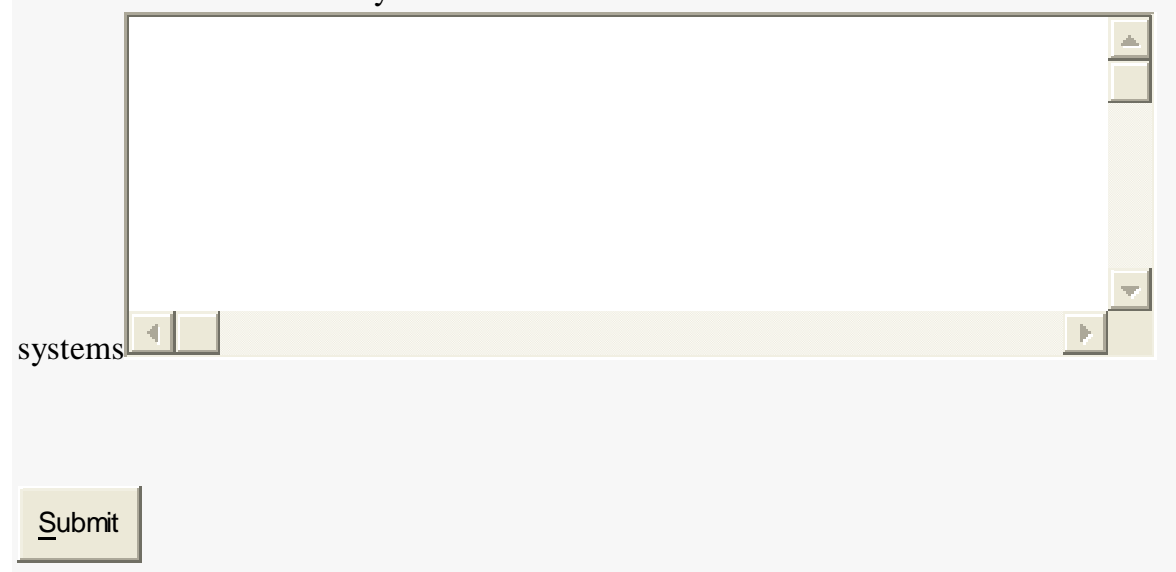

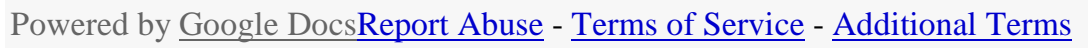




\section{Appendix C) Responses made in the comment section by users}

\section{It should be noted that for professional reasons, expletives were censored.}

\section{Comments from anonymous user}

Need much more webbing to make navigation a lot easier, when updating a page i'd like to see the updated post right after clicking save.

Would like to see options to connect with other users who reference the same sites as me frequently.

Optional HTML code is fine, i'd like to see better/faster ways of posting non-text content besides full web pages

Finding partial web page information like clip marks would be a great boost, actually making me want to use this page immediately, but as it is now, i might as well be just posting links to full web pages.

I'd like to see more options on every page instead of drop-down lists for 5 buttons on top, it takes me 4-5 clicks to get anything done, while facebook/clip marks, takes 2-3

Since facebook is for social networking instead of external sharing, it seems a little out of place next to clip marks and friend lens.

With added development and maybe a browser plug-in, I could see friend lens directly competing with clip marks.

The All User is helpful for seeing everyone on the site, but if the membership continued to grow, then it would become less useful. Some sort of search or filter would help group the users.

I found this to be really user-friendly. It was easy to figure out how to post new blogs and pages. I think the function of being able to post entire webpages and highlighting pertinent (and/or snarky) comments has real potential for lots of goofing around and internet lolz. Additionally, the highlighting capability could be useful both to show your friends what you're referring to when making a comment and for quickening the time that people would have to spend reading the blog if it was exceptionally long; essentially, you could highlight the juicy stuff but still leave the entire text available for those who feel like reading the entire post.

The only potential bug I could find related to the highlighting function. I think it might still have coding problems. Regarding the interface of the highlighting option, I found it a little bit confusing when trying to highlight a picture from a webpage that you posted. It makes sense immediately after you realize that you're supposed to click the "Highlight Selection" after hovering over the image, but the first few times I experimented with it, I had the compulsion to click the image which would then direct me to original website in another tab.

So after I realized that flub I made, I successfully highlighted the image in the Edit Mode. When I clicked "Save Changes," however, it directed me back to the homepage where I could view my blog, yet none of the images I had highlighted showed up as being highlighted (they were just the same as before I had tried to edit them).

This bug only occurred when I tried highlighting images on an external post, but I was successful in highlighting text on a blog post. However, when I tried highlighting in the blog post, everything would be 
going fine: it would take me back to the homepage and say like "there are 0 comment(s) and 1 highlight." I clicked on that link to view the comments and make sure the highlight worked. (The comments all worked fine, bee tea dubs.) But when I selected highlights by erinzingre all that came up was bold text saying like "nulle" "invalid" "code line 58" etc. I told Brien this, so he looked at that blog post to see if he had the same issue with the highlight. At first he did, so he tried adding his own highlight in the Edit Mode. Upon revisiting the blog after adding his highlight both highlights (his and mine) showed up perfectly fine. That might be something to look into. I checked the other fake accounts to see if I had similar problems with the highlights, and it seemed to be kind of hit and miss. Some worked perfectly fine and others would come up with the "nulle" "invalid" bold text like what had happened earlier with mine.

I found it difficult to access my applications in Facebook. Navigation to specific features may be tricky at times. It has a lot of features like the news feed that are not toggle-able. Finding friends was relatively easy, and friend suggestions were useful.

I had trouble selecting some videos using Clip Marks. Also, some of the websites I visited were structured such that I could only clip a small amount at a time. I got a really disconnected feeling from the community when using this service. Clipping most pictures was exceptionally easy however, and big block text was also fast and effective.

Friend Lens community options like 'add friend' should be at the top of the page instead of forcing the user to scroll to the bottom. Also, let's say you highlight some text but notice that you missed something. If you go back to highlight the missing text and accidentally overlap the original highlighted text, nothing gets selected. I also didn't like that I can't return to the previous page after performing highlights and comments. The highlighting and commenting here is the most advanced but also probably the hardest to use. It's intuitive, just rocky at times.

Friend Lens seems a very diverse site that allows users to present complex information, but only if you can create an external post. I do like that it presents a portal for allowing blog-users to connect the multitude of blogging user-selected/interested websites, but still needs a better method for locating specific users without them simply giving you their username. Even having a thumbnail picture of the person placed at the top with a short user-completed description wouid allow people to recognize other users and help users to better mentally organize the content they are viewing by associating it with a face (or other image).

Clipmarks is very user-friendly in posting information and commenting on information, but it gets a nearzero for allowing users to find specific content and especially other users.

Facebook is very visually stimulating, uses a complex engine to allow users to easily operate its features without having to have a lot of web-based knowledge. Hence the draw to massive amounts of idiots like me. Its structure may be limiting, but that is only really a hinderance to GH-esque nerds that make up a muh smaller portion of the population.

In short, facebook markets itself to the population; the other two will need something added to popularize them among more customers than the obvious niche-groups... though that may be the whole point and I just missed it. It could happen.

On friendlens it would be nice if there was a search feature. Currently I can see all the users. But if there were 100 users I would rather search by name than scroll through a listing.

On fiendlens I created my account then had to login. Since I already entered all my information on the create account page, it would be nice if the system would skip the login page after creating an account.

Stephen and I share a gmail account. What I really liked about friendlens was that we could both create an 
account even though we have the same email address. I had a hard time creating an account in clipmarks because of this. Of the three sites friendlens was the fastest and easiest site to create an account.

Survey should have had the ability to declare that the user does not use these sites for this kind of function (e.g. - posting pictures or sharing content).

I dont like that for friendlens, the entire profile of a person is their posts. It would be nice if, like other sites, you could create a profile with info about yourself and a pic. It also wasnt intuitive how to add/follow people. The comments and highlights are nice, but you have to click an additional time to view them, I wish they would just display on the page because few people are going to click all those links to see them.

clipmarks is a cool idea, but $i$ hate that you have to download a plugin to upload anything. i would not use it just because of that. it was also difficult to create an account and had $i$ not been taking the survey, $i$ would have given up and abandoned the site at that point.

facebook i still see as the ultimate social networking because with high school, college and location networks, and use of real names, it is so easy to find people you know or have things in common with.

I try to stay away from these types of things as much as possible. I would probably use facebook the most, just because it is the most popular, and thus used by everyone who I would want to communicate/share with. I find myself increasingly caught up in facebook, although I'm proud to say I don't have anything to do with Mafia wars or build your own vegan lawnmower simulation madness. While I do see the benefits of these types of services, I end up spending more time on them than I want to. And as far as tweets are concerned, I do not care to hear an update from your iphone about the horrendous line at wal-mart. love you!

Facebook:

Primarily used for social networking, it provides features for loading converted video and pictures, but has no support for high resolution or archival media. Extensions to facebook are attempting to capitalize on the money gainable from the venture; but it's only strength is that people use it, and your are likely to find people that also use it since it focused on connecting people originally.

\section{Clipmarks:}

Primarily useless tool; allows you to bookmark sites and display them. Any other service can already do this with links, but this does allow archival of the data on those sites. It appears this is just a 'fad' application thanks to the user base being people who should stick to blogs.

\section{Friendlens:}

The test application; Interfaces need to look and feel good. The internals allow you to make a copy of a page for archival purposes, but does not allow data uploading from video or images. As far as a connection utility it does not provide the functionality facebook has, and therefore will not be use for the networking.

I'm not sure what the purpose here is; but it seems like people want a automated way to post media content to a webserver; as well as tagging it and searching through everyone else's data for friends or similar interests. They also greatly desire security and privacy groups. Blogspot does a good job of most of this, but does not provide for more advanced media uploading (like MP3. movies, high res picture)

-The Comment and Highlighting system is funky.

-No 'stay logged in' feature (Why even have a Logout button?). 
-Full HTML posts are nice, but would likely confuse the interweb novice.

-Highlighting a post alters the page orientation

-At the very least there's no annoying background music, flashing bgs, or Farmville updates, thank you so much for that.

I am less likely to use clip marks or friendlens because I am a private person and don't usually like telling the world or my friends what I am doing and reading online. If I did find something I wanted to share, however, I am most likely to use facebook because 1) I only would want to share with friends, not strangers, and facebook is where $I$ can reach most of my friends at once.

Needs a bit of polish, but over all I like the idea

Friendlens would benefit from the following improvements:

1) Ability to view the comment after you posted it

2) Ability to search for friends

3) As far as I could see, there wasn't a way to post pictures. If there is, it wasn't easily visible.

4) Maybe the entire webpage need not be shown on the main page. Show a small excerpt and let people click on it to see the whole thing if they want to, otherwise it gets a little too cluttered.

Overall, Clipmarks was a mess and took too long to figure out and when I did wasn't worth the effort to filter through all the crap in the feed. There should be more filtering options. As far as communicating with users, its more like a glorified media/link driven message board with a feed. Not that impressive. The design was a clever way to present the feed and view posts without leaving the page. That was smart, but ultimately it was too cluttered and difficult to use.

Friendlens was a simplified Facebook with some of the usability of say a Mixx or Stumbleupon or Digg. Overall it lacked a decent design or layout and the usability suffered. Key navigation such as "add as friend," etc was almost an afterthought at the bottom of the user's page. Also, going to a person's page and have repeated "almost iframes" of their "posts" was confusing at first. Although an interesting idea to actually put the page they're posting about on their profile instead of a list of links, it was confusing at first and created a large page to scroll down. Maybe this was to avoid loading new pages for ease of use...I don't know, but it didn't work as well as maybe planned. I can see this getting really out of hand if a person has more than say 3 or 4 posts and does more like 3 or 4 a day. That could be one hell of a long page.

One this Mixx does really well is have a very user friendly design with actually words to help guide the user through the usability of the site. I feel this is one of the main reasons it has grown in popularity with the "joe schmo" web user that doesn't know a whole lot about the web other than email, Ebay and Facebook or MySpace. Clipmarks and Friendlens could learn a thing or two from the approach Mixx took being that they seem to operate a lot more like a "cousin" of Mixx than of Facebook.

When comparing to Facebook, Facebook's usability is far superior. The design is intuitive for new and experienced users to easily access different parts of the site and interact with not only their friends on the site, but with friends off the site with things such as events, images, videos and more. Not to mention the feed has multiple filtering options that these other sites didn't have.

Ultimately, Clipmarks and Friendlens seem to be slightly different approaches to external content sharing sites such as Digg, Reddit, Mixx, etc moreso that a rethought approach to Facebook. Even so, They offered different features not found on those sites (much like integrating a few small features found in Facebook with, say, a Mixx) which was a nice thought. Altogether, the ideas may be good, but the execution was sub par. I think a more intuitive design, more friendly interface, and an easier "discovery" experience for the user will help these sites find more success. 
I haven't heard of Clipmarks or FriendLens.

clipmarks is $s^{* *} t$. $\mathrm{i}$ was able to view the main page, and even view current posts. everything else had infinite load times. 